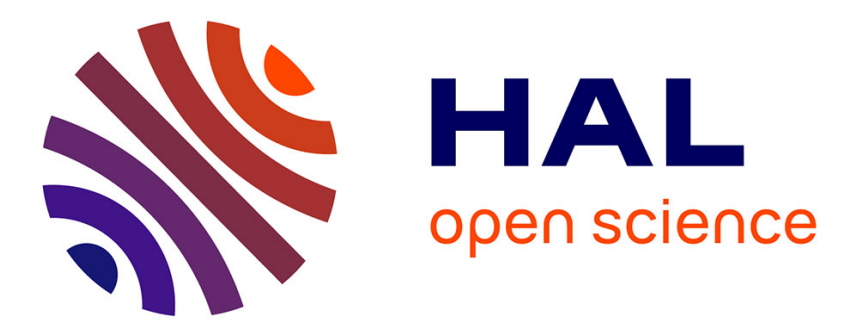

\title{
Pyrolysis modeling, sensitivity analysis, and optimization techniques for combustible materials: A review
}

Tatenda Nyazika, Maude Jimenez, Fabienne Samyn, Serge Bourbigot

\section{- To cite this version:}

Tatenda Nyazika, Maude Jimenez, Fabienne Samyn, Serge Bourbigot. Pyrolysis modeling, sensitivity analysis, and optimization techniques for combustible materials: A review. Journal of Fire Sciences, 2019, Journal of Fire Sciences, 37 (4-6), pp.377-433. 10.1177/0734904119852740 . hal-02359183

\section{HAL Id: hal-02359183 \\ https://hal.univ-lille.fr/hal-02359183}

Submitted on 12 Nov 2019

HAL is a multi-disciplinary open access archive for the deposit and dissemination of scientific research documents, whether they are published or not. The documents may come from teaching and research institutions in France or abroad, or from public or private research centers.
L'archive ouverte pluridisciplinaire HAL, est destinée au dépôt et à la diffusion de documents scientifiques de niveau recherche, publiés ou non, émanant des établissements d'enseignement et de recherche français ou étrangers, des laboratoires publics ou privés. 


\title{
Pyrolysis modeling, sensitivity analysis and optimization techniques for combustible materials: A review
}

\author{
T. Nyazika, M. Jimenez, F, Samyn, S. Bourbigot* \\ Univ. Lille, CNRS, ENSCL, UMR 8207, UMET, Unité Matériaux et Transformations, F59 000 \\ Lille
}

\begin{abstract}
Over the past years, pyrolysis models have moved from thermal models to comprehensive models with great flexibility including multi-step decomposition reactions. However, the downside is the need for a complete set of input data such as the material properties and the parameters related to the decomposition kinetics. Some of the parameters are not directly measurable or are difficult to determine and they carry a certain degree of uncertainty at high temperatures especially for materials that can melt, shrink or swell. One can obtain input parameters by searching through the literature, however, certain materials may have the same nomenclature but the material properties may vary depending on the manufacturer thereby inducing uncertainties in the model. Modelers have resorted to the use of optimization techniques such as gradient-based and direct search methods to estimate input parameters from experimental bench-scale data. As an integral part of the model, a sensitivity study allows to identify the role of each input parameter on the outputs. This work presents an overview of pyrolysis modeling, sensitivity analysis and optimization techniques used to predict the fire behavior of combustible solids when exposed to an external heat flux.
\end{abstract}

Keywords: pyrolysis modeling, sensitivity analysis, optimization, parameter estimation

\section{Contents}

Nomenclature. 2

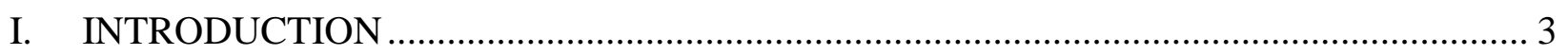

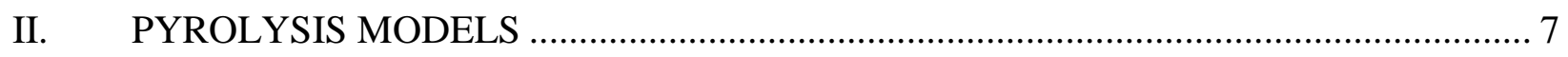

A. Thermal models ..................................................................................................... 7

1. Algebraic and analytical models ................................................................................ 7

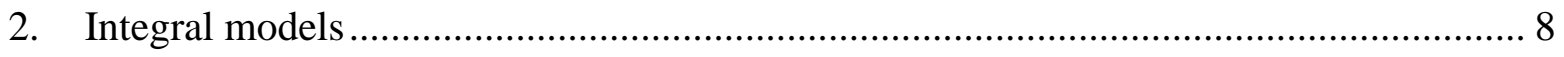

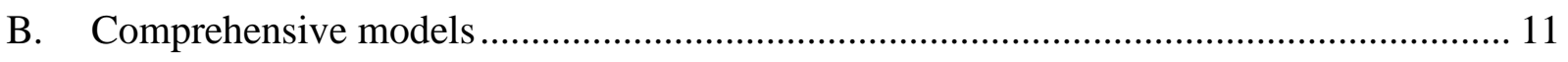

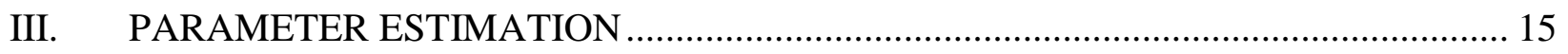

A. Direct measurement by thermal analysis .................................................................... 16

B. Inverse analysis ..................................................................................................... 19

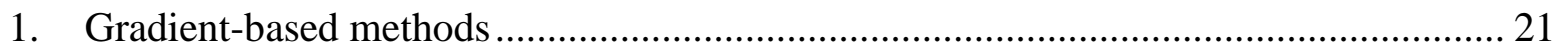


2. Direct search methods

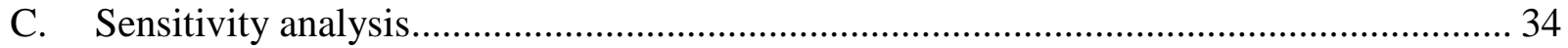

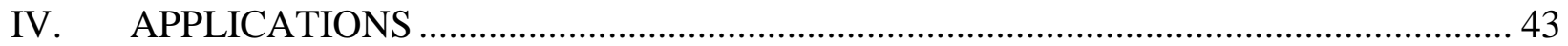

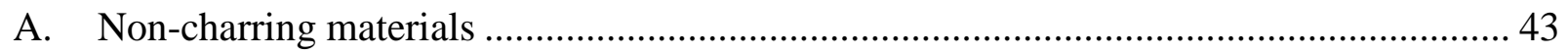

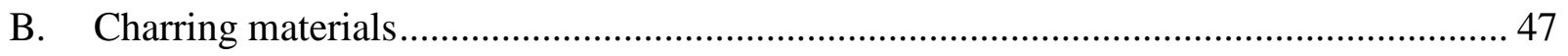

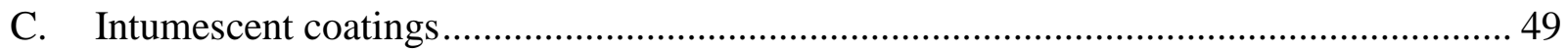

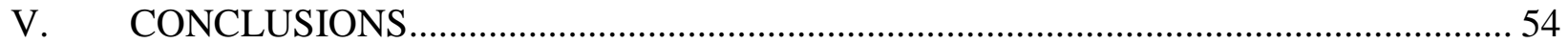

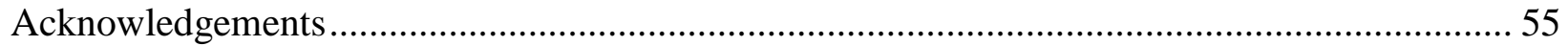

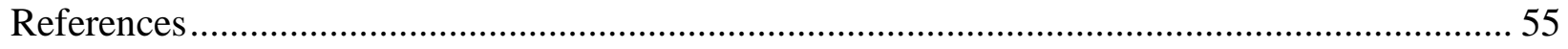

\section{Nomenclature}

$m$ Mass $(\mathrm{kg})$

$Q \quad$ Heat of decomposition $\left(\mathrm{kJkg}^{-1}\right)$

$\dot{m}^{\prime \prime} \quad$ Volatile mass flux $\left(\mathrm{kgm}^{-2} \mathrm{~s}^{-1}\right)$

$\dot{q}_{\text {ext }}^{\prime \prime}$ External radiant heat flux $\left(\mathrm{kWm}^{-2}\right)$

$\dot{q}_{f}^{\prime \prime} \quad$ Flame heat flux $\left(\mathrm{kWm}^{-2}\right)$

$\rho \quad$ Density $\left(\mathrm{kgm}^{-3}\right)$

$c_{p} \quad$ Specific heat capacity $\left(\mathrm{Jkg}^{-1} \mathrm{~K}^{-1}\right)$

$k$ Thermal conductivity $\left(\mathrm{Wm}^{-1} \mathrm{~K}^{-1}\right)$

$T_{r} \quad$ Average cone surface temperature (K)

$T_{a} \quad$ Ambient temperature $(\mathrm{K})$

$h_{c} \quad$ Convective heat transfer coefficient $\left(\mathrm{Wm}^{2}{ }^{2}\right.$ $\mathrm{K}^{-1}$ )

$h_{g} \quad$ Enthalpy of gases $\left(\mathrm{kJkg}^{-1}\right)$

$T_{P} \quad$ Pyrolysis temperature $(\mathrm{K})$

$T \quad$ Temperature (K)

$T_{S} \quad$ Surface temperature $(\mathrm{K})$

$T_{\infty} \quad$ Ambient temperature $(\mathrm{K})$

$L \quad$ Thickness (m)

$t_{p} \quad$ Time when pyrolysis starts

$A$ Pre-exponential factor $\left(\mathrm{s}^{-1}\right)$

E Activation energy $\left(\mathrm{kJmol}^{-1}\right)$

$h_{S} \quad$ Enthalpy of solid $\left(\mathrm{kJkg}^{-1}\right)$

$h_{T} \quad$ Convective heat transfer coefficient $\left(\mathrm{Wm}^{-2}\right.$ $\mathrm{K}^{-1}$ )

M Molecular mass $\left(\mathrm{kgmol}^{-1}\right)$

\section{Greek}

$\varepsilon \quad$ emissivity (-)

$\sigma \quad$ Stefan Boltzmann constant $\left(\mathrm{Wm}^{-2} \mathrm{~K}^{-4}\right)$

$\lambda$ Thermal diffusivity $\left(\mathrm{m}^{2} \mathrm{~s}^{-1}\right)$

$\delta_{c} \quad$ Depth of char layer or pyrolysed material (m)

$\emptyset \quad$ Porosity (-)

$\mu \quad$ Viscosity of volatile gases (Pa.s)

$\kappa \quad$ Permeability $\left(\mathrm{m}^{2}\right)$

$\beta \quad$ Inertial term of the non-linear darcy equation

a Conversion rate

$\gamma \quad$ local concentration ratio of char to unreacted solid

$\delta \quad$ Thermal penetration depth (m)

$\delta_{p} \quad$ Distance of the front surface from the initial position after pyrolysis $(\mathrm{m})$ 


$\begin{array}{cl}n & \text { Reaction order } \\ A_{s} & \text { Surface area }\left(\mathrm{m}^{2}\right) \\ \text { subscripts } \\ v & \text { virgin } \\ c & \text { char } \\ g & \text { gas } \\ s & \text { solid }\end{array}$

\section{INTRODUCTION}

The term pyrolysis often refers to the thermal degradation of the solid-phase caused by external heating under inert atmospheric conditions or in the absence of oxygen [1]. It is a major process contributing to the solid ignition, flame spread and fire growth involving complicated phenomena such as heat transfer through the material, thermal decomposition resulting in the mass transfer that produces combustible or non-combustible gases [2].

The fire behavior of a material can be experimentally investigated at different scales [3, 4]. Thermogravimetric analysis (TGA) [5] and microscale combustion calorimetry (MCC) [6] are often used to study the behavior of the material at matter scale while tests such as the fire propagation apparatus (FPA - ASTM E2058) [7-9], cone calorimeter (CC - ASTM E1354) [10] and radiant panel apparatus [11] are used at bench scale. Moreover, at product scale, medium single burning item and room corner test are commonly used. Fire tests at real-scale can also be conducted for example in an apartment with a single bedroom [12].

To numerically predict the fire behavior of a material, pyrolysis should be modeled. Pyrolysis models allow for example, to understand the fire behavior of a material without having to conduct expensive experimental tests. Once the pyrolysis model is validated against experimental data, a sensitivity study can be performed to identify the material properties governing the phenomenon, thereby helping in the optimization of the material behavior during development. Pyrolysis modeling has become a useful predictive tool in understanding the complex physical and chemical processes. Although the modeling of these processes remains a great challenge, significant advancements have been made in the fire community. Due to the increasing interest in the fire safety of combustible materials used in various applications, significant research work has been reported on pyrolysis models [13-21].

These models vary from thermal to comprehensive models depending on their complexity [22-25]. The modeled materials can be divided into non-charring and charring solids depending on their ability to form char after fire exposure. Some charring materials can expand or intumesce to form a porous carbonaceous char when subjected to external heat flux.

A number of reviews on pyrolysis models for different materials exist in literature. A comprehensive review on pyrolysis models was presented by Di Blasi [17] in 1993. The models took into account both the solid and gas phase combustion processes and they were used to describe the physical and chemical phenomena occurring in charring materials such as wood as well as a non-charring material such as poly(methyl methacrylate). The author also outlined how pyrolysis 
modeling had generally helped in understanding the combustion of solid materials. However, the author concluded that the lack of accurate thermophysical properties and kinetic parameters hindered the accuracy of the model predictions even when a comprehensive model was used. In 1994, Kashiwagi [26] presented a discussion on polymer combustion. At this time, Kashiwagi stated that basic understanding of polymer combustion had progressed for the gas phase thanks to the previous conducted significant research work. However, more research work was required to understand the combustion phenomena in the solid phase. Later in 2000, Di Blasi [19] presented a review on the pyrolysis modeling of charring materials including intumescent materials. The author concluded that comprehensive modeling including complex reaction kinetics for wood had progressively advanced but more work was still needed for charring polymers and intumescent materials.

The same year, Sinha et al. [1] outlined the advances in wood pyrolysis models and focused on issues such as wood composition and morphology. The authors then identified the need for input parameters when dealing with even such complex issues. They recommended that there should be closer interaction between the modeling and experimental efforts. In 2001, Moghtaderi [22] also reviewed the pyrolysis models involving charring materials from over three decades. The improvement of the models in terms of the included physical and chemical processes was presented. They also demonstrated how the input parameters influenced the model outputs and pointed out the difficulty of improving the predicted results without accurate material properties. The same author [23] reviewed in 2006, the numerical models for the thermal decomposition of lignocellulosic materials. The author came up with the similar conclusions as from the previous review in terms of input parameters, except that the complexity of the models was dependent on the modeler making the pyrolysis models non-uniform. In 2005, Lyon and Janssens [27] presented an overview based on the combustion of polymers. Several experimental techniques used in the understanding of the fire behavior of polymers were also presented. From these experimental techniques, several hypotheses were made and mathematical formulations were derived from the properties of the gas and solid phase thereby, providing the experimentalists with information for the design of new materials. Three years later, Laughtenberger and Fernandez-Pello [24] presented pyrolysis models based on non-charring, charring and intumescent materials. Since the conservation equations on which the pyrolysis models were based could be applied universally, they suggested the possibility to formulate a generalized pyrolysis model. The generalized pyrolysis model (Gpyro) was later developed and is presented in [14, 28]. They also provided a database of input parameters of different combustible solids collected from literature. At the same time, Stoliarov and Lyon [13] also developed a generalized pyrolysis model named ThermaKin which was also capable of taking into account a wide range of materials [29].

In 2013, Shi and Chew [30] also presented a review on pyrolysis models based on the same class of materials as those mentioned previously. In their study, the ways in which the physical and chemical phenomena involved in pyrolysis were numerically described were explicitly detailed. They also gathered several input parameters for different materials. They observed that most pyrolysis models focused on wood whereas relatively few models focused on other combustibles as shown in Figure 1. From Figure 1, it can also be noticed which pyrolysis processes have been 
included in models based on literature. However, no information is given by the authors over how many years the statistics were conducted.

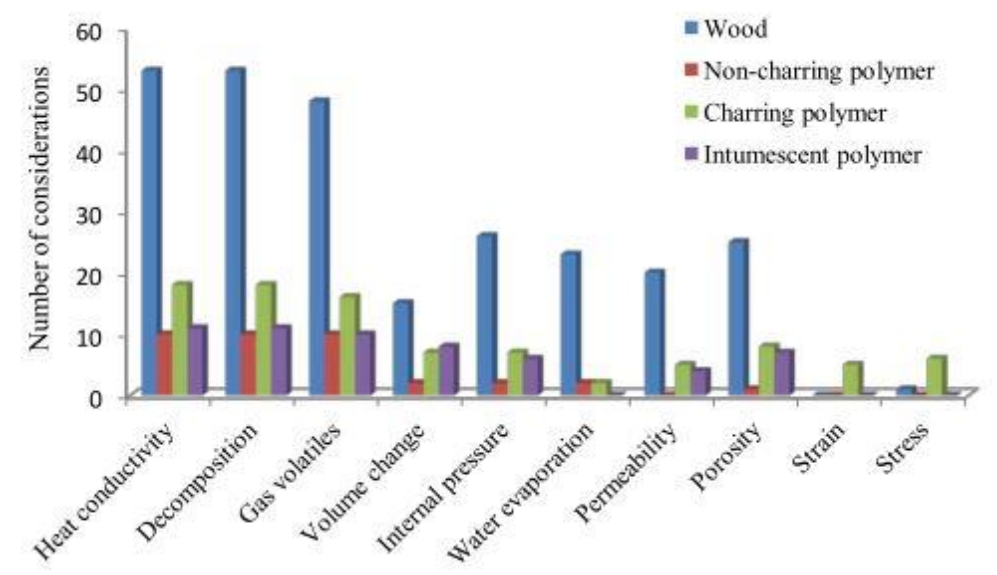

Figure 1. Statistics on 1D models based on different combustible materials [30].

Recently in 2016, Lundström et al. [25] presented a survey of different types of pyrolysis models and focused on their similarities and differences. They also discussed in which cases the models could be applied. They supported the other previous reviews by noting that, when increasing the complexity of the model, more parameters are required. Some of these parameters are difficult to measure and if used as model inputs they may induce uncertainties in the model.

Although this work does not extensively focus on smoldering combustion or composites, noteworthy reviews concerning these topics were presented by Ohlemiller [31] and Mouritz et al. [32]. Ohlemiller [31] extensively reviewed numerical models involving coupled physical and chemical phenomena that take place in self-sustained smoldering combustion. During smoldering, the polymer pyrolysis is involved and was considered to be endothermic and competing with the exothermic oxidative polymer degradation amongst other processes such as char oxidation, thereby making smoldering combustion process complex. As a result, the author concluded that the models that existed at that time were greatly simplified and that more work was needed to approach reality. The reader is referred to more recent review papers on smoldering combustion by Rein [33, 34]. Mouritz et al. [32] reviewed the progress in modeling the fire behavior of polymer composites. At that time, the authors concluded that significant progress had been made, although a number of issues such as experimental validation of models that take into account fire-induced damage (e.g. delamination) still needed to be given attention.

Considering the complexity of these comprehensive models and that most of the model input parameters can carry some degree of uncertainty, a sensitivity analysis is required to understand the role and the influence of the input parameters on the modeling outputs of interest. This step, aiming at simplifying the problem, allows checking whether a small change to an input parameter value has an effect on the modeling results. In general, a sensitivity analysis is useful in identifying the parameters that play a major role in the overall pyrolysis process [35]. Understanding the role of the parameter also helps in reducing the number of parameters that need to be estimated or measured, consequently reducing the calculation time during optimization and the complexity of 
the problem. Several sensitivity analysis techniques have been used in pyrolysis modeling, from local to global sensitivity analyses [36]. The first comprehensive sensitivity analysis using a generalized pyrolysis model was conducted by Stoliarov et al. [37] in the ThermaKin framework.

Comprehensive pyrolysis models have proven to be flexible in describing the pyrolysis of a combustible solid as compared to thermal models by considering the actual thermal degradation processes and transport phenomena taking place. However, these models require a significant number of input parameters [1, 17, 25]. These parameters can be extracted from direct measurement by thermal analysis (e.g. the thermal conductivity from Hot Disk thermal constant analyzer experiments, based on a Transient Plane Source method [15, 38, 39]), searching through the literature or through optimization techniques [40]. Determining parameters this way can be difficult in certain conditions especially at high temperatures, when the material begins to thermally degrade and the same applies to materials that shrink, expand or melt [15]. For example, very few papers deal with the measurement of thermal conductivity of intumescent materials at high temperature $[39,41]$. Errors from each of the measured parameters may result in considerable uncertainty [42]. Moreover, in many cases the measured properties are effective and not intrinsic [40]. Obtaining input parameters by searching through the literature can be inexpensive, however, although certain materials may have the same nomenclature, the material properties may vary depending on the manufacturer and a wide range of values can be observed [37]. The other approach for determining input parameters is to use optimization techniques. In this case, the pyrolysis model is coupled with an optimization technique to solve an inverse problem. Gradientbased and direct search methods such as evolutionary algorithms have been implemented to numerically obtain material pyrolysis properties. For example, Meunders et al. [43] used a gradient-based method to estimate the kinetic and thermophysical parameters of polyurethane foam based on small-scale experiments (TGA and cone calorimeter). Some anomalies were observed, for example some values were equal to the values used as bounds which probably indicated problems in finding the global optimal values. Gradient-based methods have some limitations and recently, direct search methods such as evolutionary algorithms have started to gain attention because of they have been found to perform better in certain cases [44].

From the brief survey of reviews on pyrolysis models, up-to-date, a lot of effort has been made to the modeling of non-charring, charring and, intumescent materials, even though significant work still remains to be accomplished in the field. To our knowledge, none of the reviews on pyrolysis modeling has focused on presenting a review on the set of computational tools from pyrolysis modeling to optimization techniques. Moreover, most of the reviews concluded that without a complete set of input data, even the comprehensive models would perform poorly. This makes sensitivity analysis and optimization interesting topics because of its capabilities and contribution to pyrolysis modeling. This work reports an overview on pyrolysis modeling, sensitivity analysis and optimization techniques used in the prediction of the fire behavior of combustible solids subjected to an external heat flux. The first section presents the classification of pyrolysis models. Given that these models require input parameters, the next section discusses the techniques allowing the estimation of these parameters. These techniques involve direct measurement by thermal analysis as well as solving inverse heat transfer problems using optimization techniques. 
Finally, the applications of these experimental and computational tools on different types of materials i.e. non-charring, charring materials as well as intumescent coatings are discussed and a conclusive section ends this review.

\section{PYROLYSIS MODELS}

A pyrolysis model is a set of governing equations that describes the physical and chemical processes occurring in a combustible solid when subjected to an external heat flux. It can be used as a stand-alone or coupled to a Computational Fluid Dynamics (CFD) model like Fire Dynamics Simulator (FDS) or FireFoam that takes into account the gas-phase phenomena.

Generally, the steps involved in pyrolysis modeling include (i) experimentally testing the material on a small scale test (e.g. cone calorimeter, thermogravimetric analysis (TGA),...) and (ii) describing the experiments using mathematical models. Input model parameters are then determined by direct measurement, searching through the literature or by optimization techniques. The system of equations together with the accompanying boundary conditions is then resolved numerically and the model is validated against experimental data.

There are numerous ways to classify pyrolysis models $[2,24]$ and this review broadly classifies the models into two main categories i.e. thermal and comprehensive models. The distinction between thermal models and comprehensive models is that "thermal models predict the conversion of the virgin material into products based on a critical pyrolysis temperature criterion and an energy balance, while the comprehensive models describe the degradation of the material by a chemical kinetic scheme coupled with the conservation equations for the transport of heat and/or mass [22, 23]." This classification has been adopted from the works of Moghtadheri [22, 23]. The critical pyrolysis temperature criterion is the temperature that determines the onset of pyrolysis [45]. The aim of this section is not to extensively present pyrolysis models since they have already been well documented in previous reviews $[17,22,23]$ but to give the reader a general overview of the progress in their development over the past years.

\section{A. Thermal models}

The easiest approach to pyrolysis modeling is to implement thermal models which do not take into account the reaction kinetics and mass transport. They use few input parameters and due to this, their parameterization requires smaller number of calibration experiments. Moreover, they are also faster computationally [23]. Thermal models can further be divided into algebraic and analytical as well as integral models according to their solution techniques [22]. These different models are described hereafter.

\section{Algebraic and analytical models}

For algebraic and analytical models, an assumption that the gasification rate is proportional to the net absorbed heat flux is made [22, 23, 46]. Equation 1 shows an example of an analytical solution of the energy conservation as a function of the mass loss rate for a thermally thin sample (when Biot number is less or equal to 1) of combustible material when exposed to an external heat flux, assuming that there is no shrinking or expansion during pyrolysis. Moreover, the morphology i.e. 
the structure of the pores as well as the changes in the thermophysical parameters, are also neglected.

$$
\dot{m}=-\frac{\dot{q}_{\text {ext }}^{\prime \prime} A_{s}}{Q}
$$

Equation 1

A more fundamental approach consists of using the integral models [47].

2. Integral models

An integral model is applicable to both charring and non-charring materials depending on the formulation of the equation [45]. In short, for integral models, the original set of partial differential equations describing the problem is reduced to a set of ordinary differential equations, which are easier to solve by considering that the temperature distribution within the solid depends on the space variables. Different temperature profiles have been used in literature such as exponential [48] and in this case a quadratic temperature profile was applied.

The model describes the pyrolysis of a combustible solid when subjected to an external flux. It is basically divided in three stages according to the physical processes occurring in the solid. The first stage is before ignition and heat is transferred into the material by pure conduction (Figure 2(a)). The temperature increases up to the temperature at which pyrolysis is assumed to start. The second stage occurs during pyrolysis and the solid acts in a semi-infinite manner. The difference in behavior between a charring and non-charring material is shown (Figure 2(b)) and (Figure 2(c)). The final stage is when the virgin material has been totally converted.

The 1D model was formulated by describing the materials during the first stage and second stage; The model for the first stage using virgin material properties;

$$
\frac{\partial T_{v}}{\partial t}=\lambda_{v} \frac{\partial^{2} T_{v}}{\partial x^{2}}
$$

Equation 2

The net heat flux on the surface $\left(\dot{q}_{\text {net }}\right)$

$$
\dot{q}_{\text {net }}^{\prime \prime}=\dot{q}_{\text {ext }}^{\prime \prime}-h\left(T_{s}-T_{\infty}\right)-\sigma \varepsilon\left(T_{s}^{4}-T_{\infty}^{4}\right)
$$

Equation 3

And the boundary condition at $x=L$,

$$
\frac{\partial T_{v}}{\partial x}(x=L)=0(\text { insulated })
$$

Equation 4 


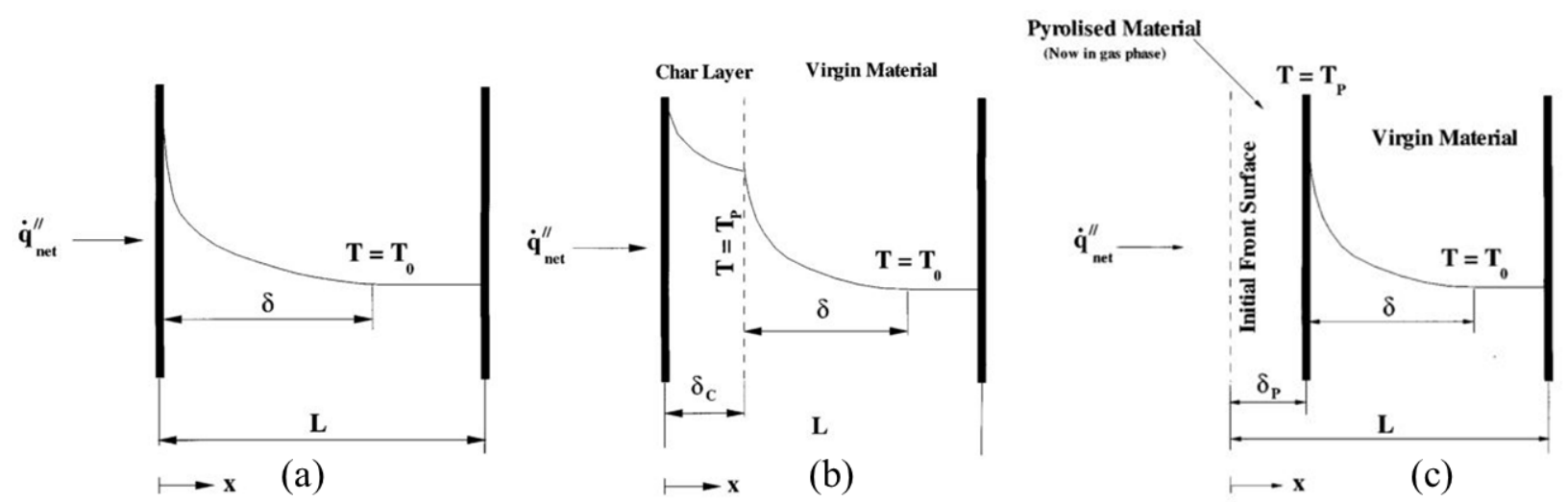

Figure 2 (a) First stage, (b) second stage for a charring solid, (c) second stage for a noncharring solid [45].

Considering the scenario of a solid which undergoes charring, heat is transferred by pure conduction in the char layer as well and the governing equation is given by:

$$
\frac{\partial T_{c}}{\partial t}=\lambda_{c} \frac{\partial^{2} T_{c}}{\partial x^{2}}
$$

Equation 5

and it is subject to the initial condition $T_{c}\left(0, t_{p}\right)=T_{P}$, with the applied boundary conditions as:

$$
\begin{gathered}
-k_{c} \frac{\partial T_{c}}{\partial x}(x=0)=\dot{q}_{n e t}^{\prime \prime}=\dot{q}_{\text {ext }}^{\prime \prime}+\dot{q}_{f}^{\prime \prime}-h_{c}\left(T_{s}-T_{\infty}\right)-\sigma \varepsilon\left(T_{s}^{4}-T_{\infty}^{4}\right) \\
T_{c}\left(x=\delta_{c}\right)=T_{p}
\end{gathered}
$$

Equation 6

Equation 7

with $T_{c}$ the temperature distribution corresponding to the char layer, $T_{p}$ the pyrolysis temperature, $\dot{q}_{f}^{\prime \prime}$ the heat flux due to the flame. $\lambda_{c}$ and $k_{c}$ the thermal diffusivity and thermal conductivity of the char, respectively.

The coupling of the heat transfer between the char and virgin layer is described by the Stefan condition at the pyrolysis front:

$$
k_{v} \frac{\partial T_{v}}{\partial x}\left(x=\delta_{c}\right)-k_{c} \frac{\partial T_{c}}{\partial x}\left(x=\delta_{c}\right)=\dot{m}^{\prime \prime} Q
$$

Equation 8

Where $\mathrm{Q}$ is the heat of pyrolysis and $\dot{m}$ "is expressed in terms of the pyrolysis front as:

$$
\dot{m}^{\prime \prime}=\left(\rho_{v}-\rho_{c}\right) \frac{d \delta_{c}}{d t}
$$

Equation 9

$\rho_{v}$ and $\rho_{c}$ being the densities of the virgin and char materials respectively. 
The results from the model presented above were confronted with experimental data and they provided a reasonable level of accuracy and captured the peak of mass flux. To understand the influence of the heat of pyrolysis (Q) on the mass flux, a sensitivity study was conducted as shown in Figure 3. As observed, the value of the peak of mass flux increases as Q decreases. This is because, as reported by reported by Weng and Fan [49], when Q exhibits a low value, the amount of energy required to decompose the material into volatiles and char is low; as a result the pyrolysis temperature $\left(\mathrm{T}_{\mathrm{p}}\right)$ is reached very quickly.

In Figure 3, the curve of the mass flux against time increases up to a maximum followed by a gradual decrease. The heat of pyrolysis has an influence on the maximum value and the gradual decrease is mainly caused by the char formation which acts as a thermal barrier.

An interesting study using a thermal model from Rhodes and Quintiere [50] was conducted by Hopkins and Quintiere [51]. They extracted the thermophysical properties of the material using the experimental results from a cone calorimeter. Thermal models are also computationally cheap enough to couple with CFD models. Moghtaderi et al. [52] successfully incorporated an integral model into a CFD fire code.

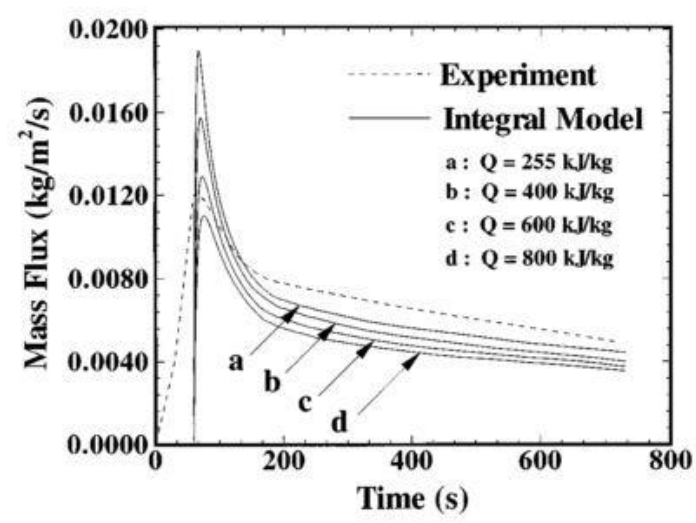

Figure 3. Integral model results confronted with experimental data for white pine under an inert environment [45].

The reader is recommended to consult the following papers [45, 46, 48, 52-56] for more detailed mathematical formulations. A summary of some thermal models is shown in Table 1.

Table 1. Examples of thermal models

\begin{tabular}{|l|l|l|l|}
\hline Author & $\begin{array}{l}\text { Type of } \\
\text { model }\end{array}$ & Material & $\begin{array}{l}\text { Comments on sensitivity/ } \\
\text { parameters }\end{array}$ \\
\hline Moghtaderi et al. [45] & Integral & PMMA & $\begin{array}{l}\text {-The effect of the heat of the } \\
\text { pyrolysis on the mass flux was } \\
\text { studied. The mass flux as well as } \\
\text { the peak on the mass flux curve } \\
\text { were influenced by the heat of } \\
\text { pyrolysis. }\end{array}$ \\
\hline $\begin{array}{l}\text { Quintiere and Iqbal } \\
\text { [55] }\end{array}$ & Integral & PMMA & $\begin{array}{l}\text {-Input parameters were taken from } \\
\text { literature. }\end{array}$ \\
\hline
\end{tabular}




\begin{tabular}{|l|l|l|l|}
\hline Steckler et al. [57] & Analytical & PMMA & $\begin{array}{l}\text {-Heat of reaction was measured } \\
\text { and the other temperature- } \\
\text { dependent thermal properties were } \\
\text { approximated. }\end{array}$ \\
\hline $\begin{array}{l}\text { Hopkins and } \\
\text { Quintiere [51] }\end{array}$ & Integral & $\begin{array}{l}\text { PMMA, Nylon, } \\
\text { PE, PP }\end{array}$ & $\begin{array}{l}\text {-Utilized experimental results } \\
\text { fom the cone calorimeter to } \\
\text { obtain the input thermophysical } \\
\text { parameters for the prediction of } \\
\text { the time of ignition and the } \\
\text { burning rates. }\end{array}$ \\
\hline $\begin{array}{l}\text { Spearpoint and } \\
\text { Quintere [56] }\end{array}$ & Integral & $\begin{array}{l}\text { - The ignition temperature, the } \\
\text { thermal conductivity, and specific } \\
\text { heat capacity were mathematically } \\
\text { obtained from ignition data whilst } \\
\text { the heat of gasification and flame } \\
\text { heat flux were obtained by } \\
\text { optimization. }\end{array}$ \\
\hline Weng and Fan [49] & Integral & White pine & $\begin{array}{l}\text { The influence of input } \\
\text { parameters such as the emissivity } \\
\text { of the char surface on the mass } \\
\text { loss rate were studied. }\end{array}$ \\
\hline
\end{tabular}

(PMMA - poly(methylmethacrylate), PE- Polyethylene, PP- Polypropylene)

The main disadvantage of thermal models is that they are too simplified by the hypothesis of the pyrolysis temperature and they do not properly describe the major processes occurring during pyrolysis. For a complete understanding of the phenomena, comprehensive pyrolysis models, which are more representative, have gained more attention from researchers due the development of better computational resources.

\section{B. Comprehensive models}

Comprehensive models consider the actual thermal degradation processes and transport phenomena taking place within the solid material. These include coupled physical and chemical phenomena such as heat transfer, morphological changes, expansion, shrinkage, char formation, chemical reactions, in-depth radiation etc. [58]. These phenomena are normally represented as submodels. Comprehensive pyrolysis modeling has improved progressively. The earliest possible model was presented by Bamford et al. [59] in 1946. It was based on 1D pyrolysis model applied to wood that was exposed to an external heat flux. The model consisted of a heat and mass conservation equation and assumed a first order single step reaction (the boundary conditions are not presented here):

$$
\frac{\partial}{\partial t}\left(\rho C_{p} T\right)=\frac{\partial}{\partial x}\left(k \frac{\partial T}{\partial x}\right)-Q \frac{\partial m}{\partial t}
$$

Equation 10 


$$
\frac{\partial m}{\partial t}=-A \cdot \exp \left(-\frac{E}{R T}\right) \cdot m
$$

Equation 11

The left hand side (LHS) of the Equation 10 represents the rate of change of energy. The right hand side (RHS) represent the heat transferred by conduction and the heat released by thermal decomposition. Equation 1 is the Arrhenius equation representing the rate of decomposition, where $m$ is the mass of the solid. Even if the model was relatively simple, the predicted temperature at the center of the considered wood slab fitted with the experimental data although there were deviations when applying the model to a thicker slab. The authors further investigated the release of gases when the wood degrades. Many of the pyrolysis models available for combustible solids in the literature are either extensions or modifications of the model developed by Bamford et al. [59]. The same model was implemented in various other works afterwards, such as the work of Roberts and Clough [60]. Other authors went on to improve it by including more physical phenomena.

Tinney [61] improved the model by using a kinetic scheme comprising two consecutive reactions. Matsumoto et al. [62] applied the model to plastics and incorporated a temperature-dependent thermal conductivity obtained from the linearization of experimental data from Wilson [63] using the least squares method and included the char removal phenomena. Kung [64] then later developed a wood pyrolysis model including physical processes such as internal gas convection and the author particularly implemented variable thermophysical input parameters mainly obtained from linear approximation between the virgin and char material. The main disadvantage of the model was that it was not confronted with bench-scale data, however, the author was able to investigate, on a theoretical basis, the influence of parameters such as thermal conductivity of char and thickness of the material on the rate of pyrolysis.

In 1977, a more complete model was developed by Kansa et al. [65]. The model was applied to wood, which was considered as a porous media. Figure 4 shows the various heat transfer phenomena taken into account in the model, namely, 1) incident heat flux $\left(\dot{Q}_{i}\right)$, 2) the heat transferred by convection on the surface and in the material $\left.\left(\dot{Q}_{c o n v}\right), 3\right)$ heat lost by radiation $\left(\dot{Q}_{e}\right)$, 4) heat transferred by conduction in the material $\left(\dot{Q}_{c o n d}\right)$ and 5) wood pyrolysis $\left(\dot{Q}_{x}\right)$.

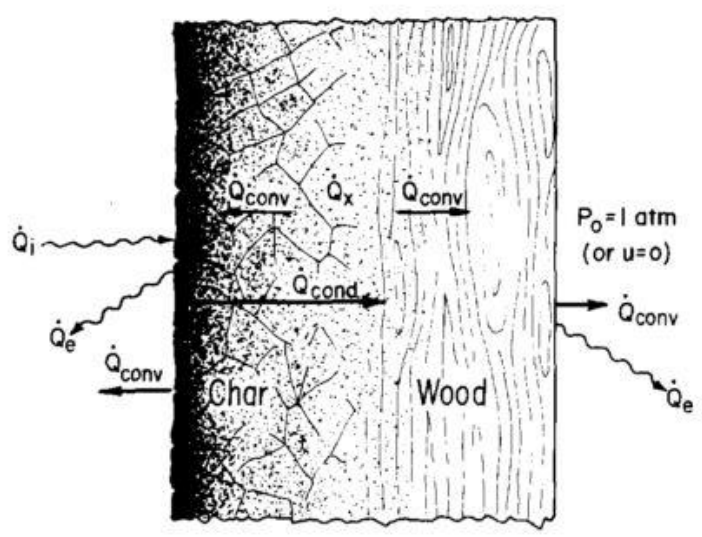

Figure 4. Various heat transfer phenomena taken into account in the model [65]. 
The complete mathematical description of the model is given below considering that the gas and solid matrices were in non-local thermal equilibrium.

Mass conservation equation of gas in the porous material:

$$
\frac{\partial\left(\varnothing \rho_{g}\right)}{\partial t}+\nabla \cdot\left(\rho_{g} u\right)=\dot{R}_{g} ; \dot{R}_{g}=-\dot{R}_{s}
$$

Momentum conservation equation of gas flow in a porous matrix (Darcy's law):

$$
\left(\frac{\mu}{\kappa}\right) u+\beta \rho|u| u+\nabla p=0
$$

Energy conservation equation of gas:

$$
\begin{gathered}
\frac{\partial\left(\varnothing \rho_{g} h_{g}\right)}{\partial t}+\nabla \cdot\left(\rho_{g} u h_{g}\right)+\left(\frac{h_{T}}{\emptyset}\right)\left(T_{s}-T_{g}\right)-\frac{\partial(\varnothing p)}{\partial t}-\nabla \cdot\left(k_{g} \nabla T_{g}\right)+q_{g}^{\prime} \quad \text { Equation } 14 \\
=0
\end{gathered}
$$

Energy conservation of the solid phase:

$$
\frac{\partial\left[(1-\emptyset) \rho_{s} h_{s}\right]}{\partial t}-\nabla \cdot\left[(1-\emptyset) k_{s} \nabla T_{s}\right]+\frac{h_{T}\left(T_{s}-T_{g}\right)}{1-\emptyset}+q_{s}^{\prime}=0
$$

Rate of decomposition of the solid expressed in Arrhenius form:

$$
\dot{R}_{s}=\frac{\partial(1-\emptyset) \rho_{s}}{\partial t}=-A \exp \left(-\frac{E}{R T_{s}}\right) *\left[\rho_{s}-\rho_{c}\right]^{n}=0
$$

Equation of state of an ideal gas:

$$
p=\left(\frac{R}{M}\right) \rho_{g} T_{g}
$$

Where $\mathrm{u}$ is considered as the superficial gas velocity, $\mathrm{p}$ is the pressure, $\mathrm{R}$ is the gas constant and $\mathrm{n}=1$.

To complete the model, the initial and boundary conditions for the above system of equations are shown in [65]. Most of the material properties such as the specific heat capacity were linearly approximated from $f(\gamma)=\gamma f_{\text {virgin }}+(1-\gamma) f_{\text {char }}$, where $f(\gamma)$ stood for the considered material property whereas $\gamma$ represented the overall extent-of-reaction or degree of decomposition related to the densities/masses in the fully virgin and fully charred conditions, with $\gamma=1$ representing the fully virgin condition and $\gamma=0$ representing the fully charred condition. Initially, they used input parameters from literature, then they were optimized using temperature profiles from experimental results. Generally, the numerical and experimental results corresponded with each other at low heat fluxes as compared to high heat fluxes. This was attributed to the noninclusion of phenomena such as shrinkage, radiation exchange inside the pores as well as an improved kinetic mechanism to fully take into account the physical processes at high fluxes. The 
comprehensive pyrolysis model formulation presented here shows how these models require more input parameters as compared to semi-empirical formulations.

During this period, considerable work was conducted on modeling the pyrolysis of composites. In 1985, Henderson et al. [66] developed a pyrolysis model for composites which was different from the previous models in the way that decomposition was taken into account using $\mathrm{n}^{\text {th }}$ order Arrhenius equations and the diffusion of the gases released from the decomposition reactions through the char. Moreover, the work used input properties that were both temperature and mass dependent. The following year, Henderson and Wiecek [67], on the basis of the previous model [66], included thermochemical expansion as well as the storage of decomposition gases. The inclusion of these phenomena improved the capability of the model to predict the fire behavior of composites, and in particular the prediction of pressure profiles in the composite.

In 1987, Vovelle et al. [68] developed a model for the prediction of the mass loss rate of PMMA exposed to a radiant heat flux. The model was also similar to Bamford's model in that it was a combination of the heat transfer equation and the Arrhenius equation assuming a first order reaction. Moreover, they introduced the Landau transformation to take into account surface regression.

Since it is difficult to fully integrate all the complex phenomena in the model, certain assumptions are considered. Basically in the comprehensive pyrolysis approach, the heat transfer, the thermal decomposition represented by a chemical kinetic scheme and mass transport are solved using conservation equations.

In the 2000s, several comprehensive models have since been developed as numerical codes including Gypro/Gypro3D [14, 28, 69], ThermaKin/ThermaKin2D [13, 16], Pyropolis [20, 70] and FiresCone [71]. Furthermore, Computer Fluid Dynamics software such as NIST Fire Dynamics Simulator (FDS) [72] and FM Global's FireFOAM [73, 74] also include a pyrolysis model. An example of the Pyropolis overall model structure is shown in Figure 5.

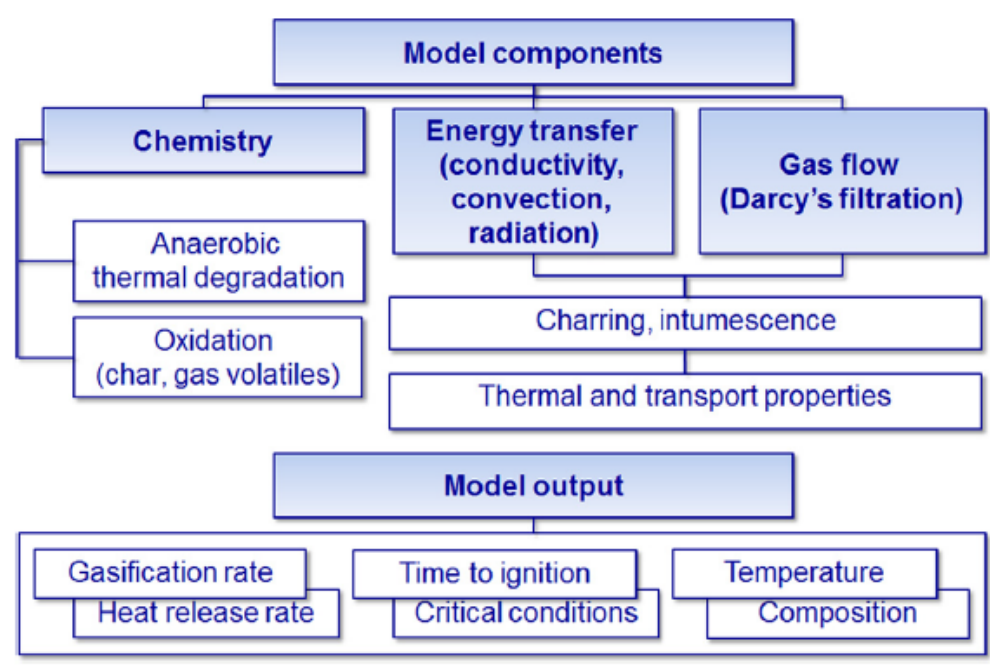

Figure 5. Structure and output of the Pyropolis model [20] 
Most of these numerical codes are formulated in a generalized way to take into account all the types of materials. Laughtenberger and Fernando-Pello [14] validated Gypro using a variety of combustible materials which behave differently when subjected to an external flux. The combustible materials used were a non-charring solid (poly(methylmethacrylate)), a charring solid (white pine), an intumescent coating and polyurethane foam (for the study of smoldering combustion). Given the complicated fire behavior of the studied materials, Gypro performed reasonably well.

COMSOL Multiphysics has also successfully been used to model pyrolysis [38, 75-77]. For example, Girardin et al. [38] predicted the gasification experiments of ethylene-vinyl acetate containing aluminum tri-hydroxide using COMSOL Multiphysics. Agreement between experimental and numerical results of temperature and mass loss was good. Moreover, the model also allowed conducting a sensitivity study on different scenarios of diffusion by tuning the coefficient of mass transfer.

These codes are developed using the same theoretical basis of coupling momentum, mass and energy conservation equations, although they have different mathematical and numerical formulations. Gpyro uses the Finite Difference Method, Comsol and ThermaKin uses the Finite Element Method and FiresCone uses Finite Volume Method. The Finite Difference Method relies on the differential form of the governing equations while the Finite Volume and Finite Element methods are based on the weak formulation or integral form. Furthermore, radiative heat transfer are not treated in the same manner in FDS and ThermaKin [78]. The effect of this difference was observed in the work of Linteris [79] applied to poly(methylmethacrylate) where the results of mass loss rate (MLR) for both programs corresponded well, apart from the case where there was high in-depth radiation absorption. Linteris et al. [42] also implemented FDS and Thermakin to thermoplastics such as polyamide 6,6 , polyoxymethylene and the same conclusions were reported. Kempel et al. [78] used ThermaKin and FDS for predicting the MLR of poly (butylene terephthalate) (PBT) and PBT reinforced with glass fibres (PBT-GF). They reported that given precise input properties, the choice between the two numerical tools was not significant and the characteristic model output (e.g. the peak of mass loss rate (PMLR)) obtained using the two models was within $\pm 4 \%$.

A study to compare ThermaKin, Comsol and FDS was conducted by Witkowski et al. [80] using a 1D pyrolysis models applied to cable sheathing materials. They concluded that the choice of model between the three computer programs, using the same input parameters, is not important given the similar nature of the applied governing equations to describe the physical phenomena.

Comprehensive pyrolysis models have the capability to predict the pyrolysis of different combustible materials. However, to implement them, they require input material properties as well as boundary conditions for the experiment being modeled. The next section discusses how model input parameters can be determined.

\section{PARAMETER ESTIMATION}

As previously mentioned, to implement the pyrolysis models and predict the fire behavior of combustible materials, the input material properties are required. This section thus discusses how 
model input parameters can be determined. The first part of this section discusses the determination of model input parameters using experimental techniques and the uncertainties in the measurements. The second part discusses the estimation of parameters considering inverse analysis combined with optimization methods and the chapter concludes with a discussion on the sensitivity analysis techniques.

\section{A. Direct measurement by thermal analysis}

Material properties such as thermal conductivity and specific heat capacity can be 'directly measured by thermal analysis', using for example, the Hot Disk thermal constant analyzer which is based on a Transient Plane Source (TPS) method and Differential Scanning Calorimetry (ASTM E1269-11) respectively [38, 76, 81]. In addition, the emissivity can be determined from the hemispherical directional reflectometer and the thermal diffusivity from the Laser Flash Apparatus (ASTM E1461) [82]. Most of these tests are standardized ASTM test methods and a comprehensive presentation of these tests were discussed by Kim and Dembsey [2]. Some of the tests are presented briefly below.

The TPS method was developed by Gustafsson in 1991 [83]. The method is based on a sensor that acts as a heat source and generates the heating power using Joule heating. The sensor is inserted in between an infinite medium and the heat diffuses into the material. The mean sensor temperature rises with time and the temperature function i.e. the shape of the rise is dependent on the type of sensor (e.g. its radius). In an ideal scenario, from the temperature function measurement, the thermal conductivity and diffusivity of the material can be determined from one single experiment from a parameter estimation process. However, in reality they are different factors (such as the material not being infinite) that influence the measurement and different improvements have been proposed by different research groups [83-85]. A typical example is that of Bohac et al. [84] who introduced an improvement in the method by calculating an optimal time window for measurement using the difference analysis together with the analysis of the sensitivity coefficients.

The Laser Flash Analysis (LFA) is also a measurement technique principally used to estimate the thermal diffusivity of a material, in addition, the specific heat capacity and the thermal conductivity can also be deduced. It should be noted that the LFA is based on the flash method developed by Parker et al. [86] in 1961. In general, it is a non-contact method based on heating a sample on one side using a xenon lamp as a heat source. The temperature rise is then captured on the other side of the sample using an infrared detector. The temperature profile that is obtained is then analyzed using an appropriate mathematical model and optimization methods. Finally, the thermal diffusivity is obtained. The mathematical model is generally chosen to find the best fit from the temperature profile. Different such as models exist in literature such as the Adiabatic model [86], Cowan model [87], Cape-Lehman model [88], Radiation model [89] etc.

The thermal decomposition of a material can be studied using TGA, DSC as well as the Simultaneous Thermal Analysis (STA) [90]. The heats of reactions can be extracted from DSC or STA measurements. More precisely, for example, TGA measures mass loss and the mass loss rate of a sample under well-defined heating conditions i.e. heating rate, atmosphere etc. The Arrhenius parameters are then extracted from numerical optimization using TG curves as discussed later in this section $[90,91]$. 
It is noteworthy that even though this technique is often referred to as 'direct measurement by thermal analysis', generally, an inverse analysis (using some mathematical model coupled with an optimization method that can either be manual or automated iterative) of the experimental results from the measuring tool is required to extract the relevant thermophysical parameters from the data set as explained above. The definition of the mathematical models, the equations to be resolved and the parameters to be optimized (i.e. what acceptance criteria) are equally important.

Stoliarov et al. [92] investigated the pyrolysis of poly(methyl methacrylate) (PMMA), high-density polyethylene (HDPE) and high-impact polystyrene (HIPS) using the cone calorimeter and gasification experiments. The densities of the materials at room temperature were derived from measuring the mass and the dimensions of the samples. The temperature dependent densities were extracted from literature. The heat capacities as a function of temperature as well as the decomposition thermodynamics i.e. the heats of melting and decomposition were determined using differential scanning calorimetry (DSC) and the method is described in [81]. The thermal conductivity was determined based on the transient line source method. For the measurement of melting polymers, the method is described in [93]. The optical properties, the reflectivity and absorption coefficient were obtained from literature [94, 95]. The Arrhenius parameters were obtained by fitting the reaction rate constants to the first order Arrhenius equation. The uncertainties associated with the property measurements were given as, $\pm 15 \%$ for the thermal conductivity, heat capacities and decomposition thermodynamics, $\pm 5 \%$ for densities, $\pm 3 \%$ for heats of combustion and energies of activation, $\pm 50 \%$ for Arrhenius pre-exponential factors and respectively $\pm 20 \%$ and $\pm 50 \%$ for reflectivity and absorption coefficient.

Linteris et al. [42] measured input parameters for their models in FDS and Thermakin. Uncertainties were taken into account, some are presented here and their effects were explored by conducting a sensitivity analysis. Figure $\mathbf{6}$ shows the results for the thermal conductivities using different methods (transient plane and line source methods). The relative uncertainties in the thermal conductivity were estimated to be $6 \%-8 \%$ for polypropylene (PP), polyamide 6,6 (PA66), and polyethylene terephthalate (PET) and the uncertainty for polyoxymethylene (POM) was $20 \%$. For properties such as heat capacities and heats of reaction, the error was $16 \%$ according to Stoliarov et al. [81] and 3\% for reflectance. 

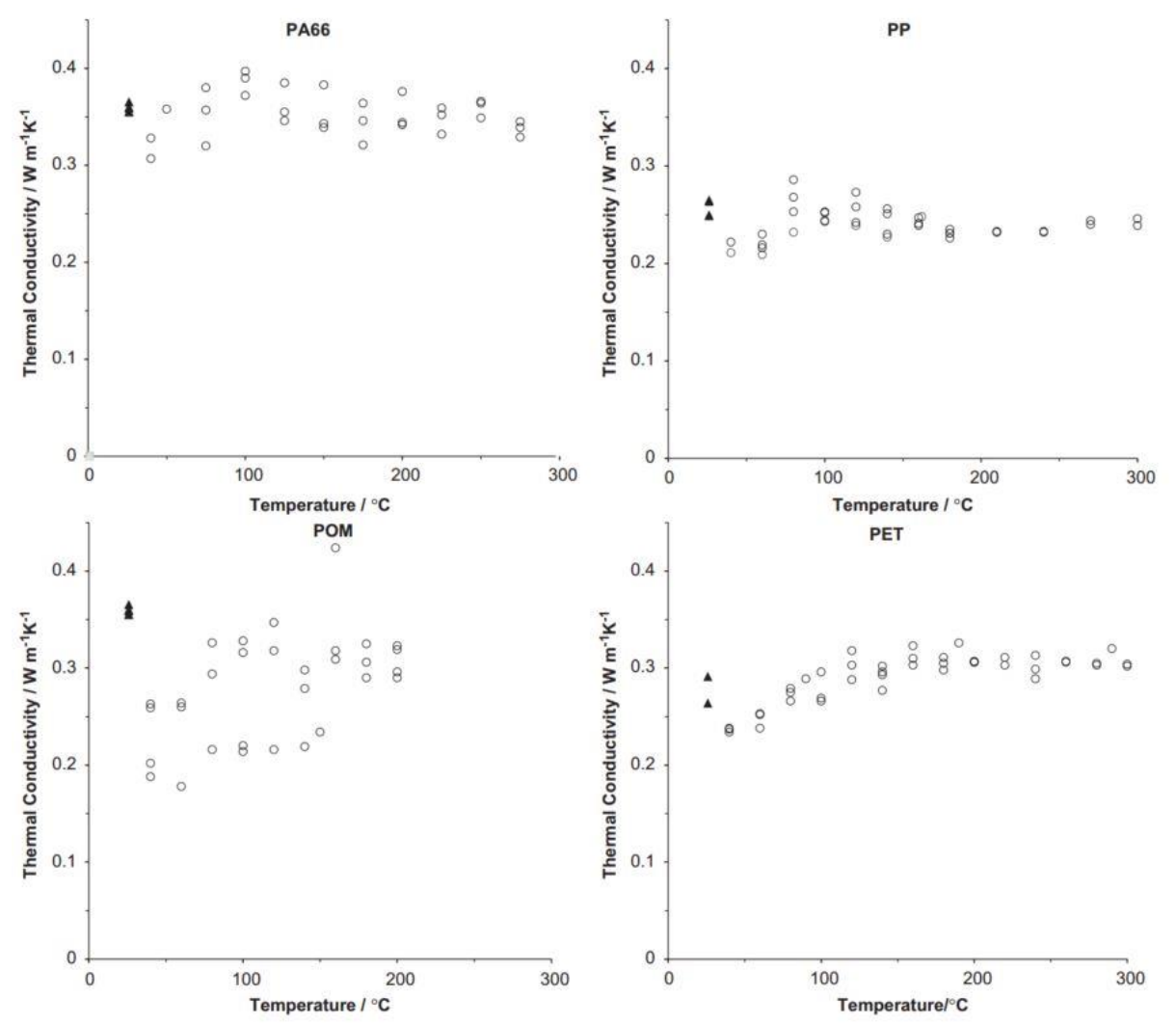

Figure 6. Thermal conductivity measurements of different polymers (PP, PA66, POM, and PET) using the methods : transient plane $(\Delta)$ and line $(O)$ [42].

Girardin et al. [38, 76] directly characterized the thermophysical properties of ethylene-vinyl acetate copolymer/ aluminum tri-hydroxide/nanoclays (EVA/ATH/NC). They also used DSC and transient plane source methods. Moreover, for the optical properties, transmittance and reflectance spectra were measured using spectrophotometers equipped with an integrating sphere. The uncertainty in the measurements was $\pm 3 \%$ and the method for the determination of absorption coefficients and emissivity is described in [80]. The heat capacity of decomposition gases was also determined by identifying the gaseous products using a controlled-atmosphere mass loss calorimeter connected to a Fourier Transform Infra-Red (FTIR) spectrometer. The procedure is described in [38].

For charring materials, numerical models often require the properties of the formed char. The char is often fragile and non-uniform, making direct measurements difficult [15]. However, Gardelle et al. [39] measured the thermal conductivity of a silicone-based intumescent coating from ambient temperature to $500^{\circ} \mathrm{C}$ using a hot disk apparatus. They observed that the thermal conductivity decreased from $0.5 \pm 0.02 \mathrm{Wm}^{-1} \mathrm{~K}^{-1}$ to $0.21 \pm 0.02 \mathrm{Wm}^{-1} \mathrm{~K}^{-1}$ at $400^{\circ} \mathrm{C}$ owing to the formed carbonaceous char structure and then rises to $500^{\circ} \mathrm{C}$ due to radiation in the porous structure. Muller [96] also used the same technique to measure the thermal conductivity of intumescent polyurethanes. 
Stoliarov et al. [15] used the same experimental techniques as above for determining heat of decomposition and heat capacities of charring polymers and extracted other parameters from literature as well as approximations when no other solution could be found.

Tranchard et al. [97] characterized the thermophysical properties of a carbon epoxy composite exposed to fire. The experimental techniques included TGA, STA, Laser Flash Analysis (LFA) as well as Fourier Transform Infrared (FTIR). These techniques were used to determine the specific heats, anisotropic thermal conductivity, decomposition kinetics and thermodynamics. The application of inverse analysis to parameter estimation of input material parameters for pyrolysis models is presented in the next section.

\section{B. Inverse analysis}

A parameter estimation problem can be formulated as an inverse heat transfer problem involving optimization with an objective function which minimizes the error between experimental and model data. This approach involves obtaining input model parameters from e.g. bench scale tests used for temperature measurements or mass loss rates determination. It has been widely used in the fire community $[9,44,98]$. The most noticeable early work on the parameterization of comprehensive pyrolysis models from experiments include that of Stoliarov and Lyon [15, 92]. Lautenberger et al. [44] also worked on parametrization but used an evolutionary algorithm which was later improved by Chaos et al. [9]. These research works are further discussed later in this section.

When conducting optimization, the idea is to compare numerical results from the pyrolysis model and the results from the experiment and a stopping criterion like the relative tolerance on the objective function is normally defined. Calabrese et al. [99] defined the relative tolerance to be lower than $10^{-4}$ in their study. Comprehensive pyrolysis models are then coupled with numerical optimization methods. A detailed study and guide on parameter estimation applied to comprehensive pyrolysis models was conducted by Kim [2, 40, 100]. As shown on the work flow of their methodology presented on Figure 7, they categorized the process of parameter estimation in three blocks containing 1) the main parts of the pyrolysis model i.e. initial input values of the material properties, numerical optimization method etc., 2) the block containing the numerical results which are confronted with the experimental results, errors etc. i.e. the validation phase and 3 ) the block which allows to comment or discuss information on the results of the optimization study etc. 


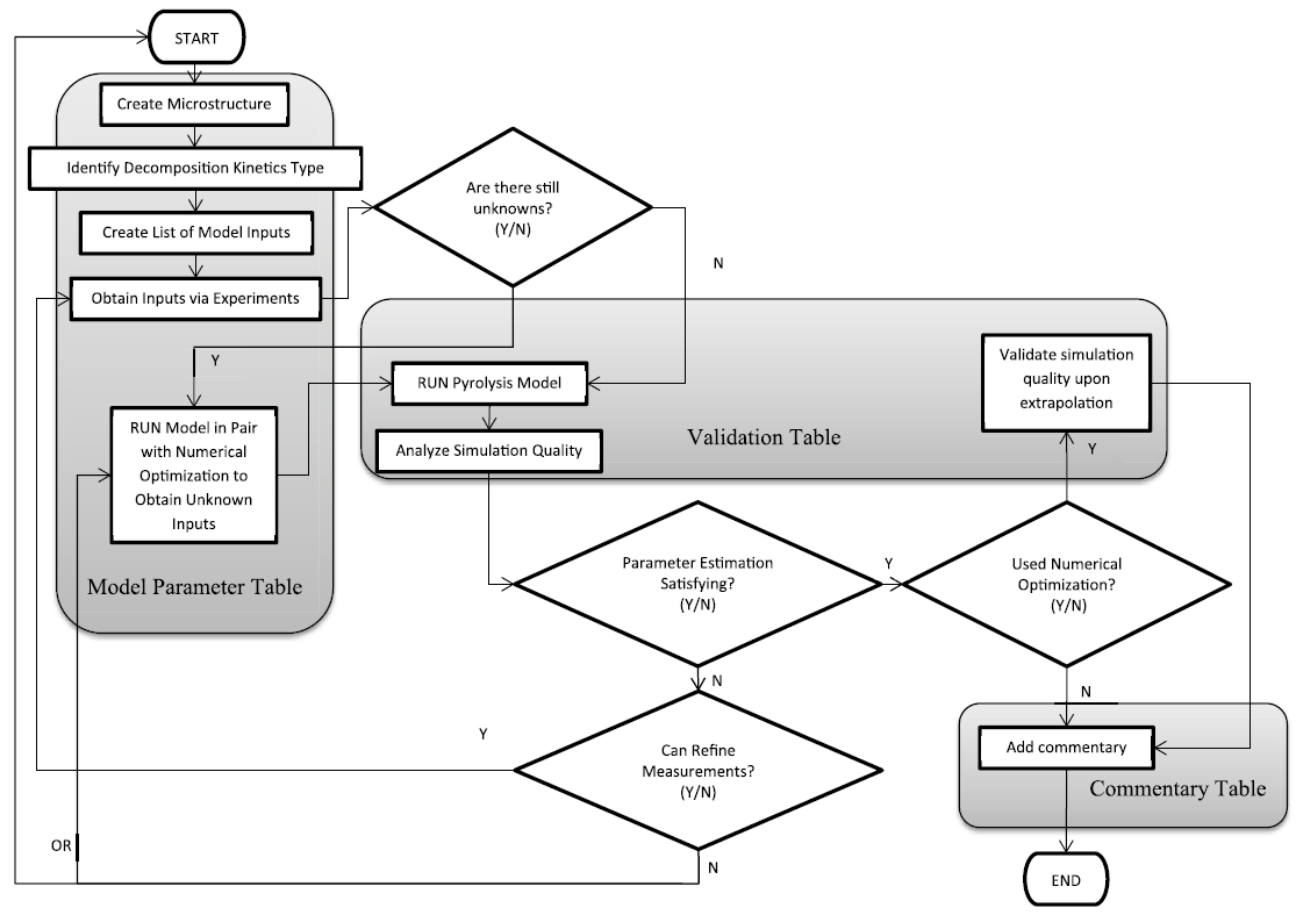

Figure 7. Workflow on how to conduct a parameter estimation study [2, 40].

A number of curve-fitting algorithms have been developed and used over the past years and they have been successfully applied to pyrolysis models. Optimization plays an essential role in the estimation of material properties to be used as inputs for pyrolysis models and it is crucial to identify which optimization technique is best suited for a particular problem in terms of how it converges and overall performance. Besides the selected optimization technique, experiments for which they are applied and the final model validation are highly important. The conducted experiments should be relatively accurate otherwise an incorrect data set can be obtained. For the validation step, the predictions should be compared to the experimental results and an agreement should be observed preferably over a wide range of conditions e.g. different external heat fluxes. If the agreement is not achieved, it means that there was a phenomenon not included in the model or that an incorrect parameter or boundary condition was used. In this case the pyrolysis model should be improved [101].

To solve the inverse heat transfer problem, different types of optimization methods are used. Several optimization methods exist in literature such as manual optimization and automated search techniques [99]. These methods are generally classified by the optimization community as gradient-based versus direct search methods. Using this classification, evolutionary algorithms fall under direct search methods.

In this review, we present gradient-based and direct search methods which are often applied to pyrolysis of combustible materials. Additional class of approaches for finding model parameters from data are Bayesian methods such as Markov Chain Monte Carlo (MCMC). These methods are interesting as they characterize the model parameters from a probability distribution rather than as 
a single value. Bruns [102] used MCMC to find kinetic parameters from TGA data for HIPS, PC and PVC.

1. Gradient-based methods

Several gradient-based methods such as Simplex method, Gradient method, Newton, LevenbergMarquardt, Sequential quadratic programming (SQP) etc. exist in literature. The gradient-based method often implemented for non-linear problems is the Levenberg-Marquardt method [103109].

Gradient-based methods have often been applied to estimate material thermophysical properties of materials as well as kinetic parameters. Calabrese et al. $[99,110]$ proposed a methodology to estimate the effective thermal conductivity applied to a material that intumesces. COMSOL coupled with the Nelder-Mead algorithm coded in Matlab was used to solve the problem. Experimental data for the optimization target were gathered from temperature measurements from thermocouples that were placed at two different heights inside the intumescent layer. The results demonstrated how the thermal conductivity varies with temperature and the possibility to estimate the thermal conductivity using inverse heat transfer. Bozozoli [111] also applied the same methodology. Since in their case they were only estimating one material property, there was no information on the performance of the algorithm. Theuns et al. [46] determined the material properties of charring combustible solids by implementing an automatic optimization technique called downhill Simplex in multidimensions (which is also known as the Nelder-Mead simplex method) using experimental mass release curves. They set their relative tolerance as $10^{-4}$. In their optimization procedure, they also chose bounds to allow for realistic values. Some of the optimized parameters resembled those found in literature while others did not, probably because of differences in the source of the materials. Scott and Beck [112] estimated the thermophysical properties of a composite using a Gauss minimization procedure and temperature measurements at different locations. The obtained parameters corresponded very well with the synthetic values that were used to produce temperature values.

Meunders et al. [43] investigated an optimization method for estimating kinetic and thermophysical parameters of polyurethane (PU) foam. Experimental information was collected from bench-scale tests such as Thermo-Gravimetric Analysis (TGA) and cone calorimeter. TGA and heat release rate (HRR) results were used as optimization targets for the kinetic parameters and thermophysical properties respectively. In this study, the heats of reaction were taken from literature [113] and the Arrhenius equation was manually adjusted to obtain a good fit against the experimental data from the TGA to estimate the Arrhenius parameters. The obtained set of Arrhenius parameters was then used to determine the thermophysical properties and FDS 6.0.1 was coupled to an optimization algorithm which was based on the gradient method. The comparison between the predicted and experimental HRR was considered consistent for the overall burning time and average HRR. However, the model could not capture the two-stage fire behavior probably because the kinetic scheme was not capable of taking this behavior into account. The bounds prescribed on the material properties for the optimization technique were very large and consequently the estimated parameters would be based on the used pyrolysis model and boundary conditions. Even though the bounds prescribed on the parameters were large, two of the estimated 
parameters were equal to the upper boundary indicating that there were issues with the modeling approach (Table 2). It makes sense as the pyrolysis model chosen could not predict the two-step burning of PU at high fluxes.

Table 2. Bounds prescribed and estimated values [43].

\begin{tabular}{|c|c|c|c|c|}
\hline & Units & $\begin{array}{l}\text { Lower } \\
\text { bound }\end{array}$ & Upper bound & $\begin{array}{c}\text { Estimated } \\
\text { Values }\end{array}$ \\
\hline Mass fraction $(\mathrm{C} 1)$ & - & - & & 0.22 \\
\hline Mass fraction $(\mathrm{C} 2)$ & - & - & & 0.67 \\
\hline Activation Energy, E (C1) & $\mathrm{kJ} / \mathrm{kmol}$ & - & & $1.50 \times 10^{5}$ \\
\hline Activation energy, E (C2) & $\mathrm{kJ} / \mathrm{kmol}$ & - & & $1.85 \times 10^{5}$ \\
\hline $\begin{array}{l}\text { Pre-exponential factor, A } \\
\text { (C1) }\end{array}$ & $1 / \mathrm{s}$ & - & & $1.07 \times 10^{12}$ \\
\hline $\begin{array}{l}\text { Pre-exponential factor, A } \\
\text { (C2) }\end{array}$ & $1 / \mathrm{s}$ & - & & $5.90 \times 10^{12}$ \\
\hline Emissivity, $\varepsilon$ (C 1) & - & 0.70 & 1.00 & 0.70 \\
\hline Emissivity, $\varepsilon$ (C 2) & - & 0.70 & 1.00 & 0.78 \\
\hline Specific heat, $c_{p}(C 1)$ & $\mathrm{kJ} /(\mathrm{kg} \cdot \mathrm{K})$ & 1.50 & 4.00 & 3.17 \\
\hline Specific heat, $c_{p}(C 2)$ & $\mathrm{kJ} /(\mathrm{kg} \cdot \mathrm{K})$ & 1.50 & 3.00 & 3.00 \\
\hline $\begin{array}{l}\text { Thermal conductivity, } \mathrm{k}(\mathrm{C} \\
\text { 1) }\end{array}$ & $\mathrm{W} /(\mathrm{m} \cdot \mathrm{K})$ & 0.01 & 0.15 & 0.01 \\
\hline $\begin{array}{l}\text { Thermal conductivity, } \mathrm{k}(\mathrm{C} \\
\text { 2) }\end{array}$ & $\mathrm{W} /(\mathrm{m} \cdot \mathrm{K})$ & 0.15 & 0.23 & 0.23 \\
\hline
\end{tabular}


Optimization techniques have also been widely used for determining the kinetic parameters using kinetic models. Different kinetic models have been implemented to model the thermal degradation of combustible solids. These kinetics models can be simple one-step or multi-step complex reaction schemes [17]. To understand how the level of complexity of the kinetic model plays a role on pyrolysis modeling, a typical study was conducted by Marquis et al. [114] on polyisocyanurate foam (PIR). They evidenced that simple kinetic models were acceptable to represent thermal decomposition of PIR. Ritchter et al. [115] studied the influence of kinetics of several wood species on their charring behavior. They then concluded that the kinetic model for one wood species can be applied to other wood species and that modelers should pay more attention to their thermophysical properties. For non-charring materials, issues concerning model complexity have been discussed by Bal and Rein [116-118], and Ghorbani et al. [58]. Bal and Rein [117] conducted a brief comparison of three models (implemented in different codes) used for predicting the same experimental results, which revealed that some degree of complexity in mechanisms was unnecessary. They then proved that using complicated kinetic schemes was not necessary once heat transfer processes were simplified. However, for scenarios such as smoldering combustion in polyurethane foam the heterogeneous chemistry has been fully described. Rein et al. [119] implemented a 5-step mechanism to take into account the smoldering combustion of polyurethane foam which was an improvement to the most used 3-step mechanism proposed by Ohlemiller [120]. The model was capable of reproducing the smoldering characteristics such as the thermal and species structure of the reaction-front propagation rate etc. and described both opposed and forward propagation despite inaccuracies.

Many solid-state decomposition kinetic models have been developed over the past years and upto-date the Arrhenius law is still being used to model the solid decomposition. Equation 18 describes the reaction rate of a solid-phase reaction and gives the relationship between reaction rate and temperature,

$$
\frac{d \alpha}{d t}=k(T) f(\alpha)
$$

Equation 18

The rate constant $k(T)$ is expressed in terms of the Arrhenius equation (Equation 19);

$$
k(T)=A e^{-\left(E_{a} / R T\right)}
$$

Equation 19

where, $\mathrm{A}$ is the pre-exponential factor $(1 / \mathrm{s}), \mathrm{E}_{\mathrm{a}}$ is the activation energy $(\mathrm{kJ} / \mathrm{mol}), \mathrm{T}$ is the absolute temperature, $\mathrm{R}$ is the gas constant, $\mathrm{f}(\alpha)$ is the reaction model related to the solid reaction mechanism (some kinetic models are listed in Table. 5) and $\alpha$ is the conversion degree defined by Equation 20:

$$
\alpha=\frac{m_{0}-m_{t}}{m_{0}-m_{f}}
$$

Equation 20

Where, $\mathrm{m}_{0}$ is the intial weight, $\mathrm{m}_{\mathrm{t}}$ is the instantaneous weight, and $\mathrm{m}_{\mathrm{f}}$ is the final weight. 
There are several ways to determine the Arrhenius parameters. They can be extracted from isothermal kinetic data by applying Equation 18 . Equation 18 is then adapted into a non-isothermal rate expression (Equation 21) leaving the reaction rate as a function of temperature at a constant heating rate,

where $\beta$ is the heating rate.

$$
\frac{d \alpha}{d T}=\frac{A}{\beta} e^{-\left(\frac{E_{a}}{R T}\right)} f(\alpha)
$$

This transformation is based on the assumption that changing the experimental conditions from isothermal to non-isothermal has no effect on the reaction kinetics, which is quite reasonable when dealing with simple single-step process but may have serious implications for multi-step reactions kinetics as discussed by Vyazovkin and Wight [121]. Reaction kinetics is commonly studied by using thermogravimetric analysis (TGA) and derivative thermogravimetric (DTG) curves but can also be studied using Differential scanning calorimetry (DSC) curves [122, 123].

Isothermal or non-isothermal kinetic analysis can be performed by using model-based or modelfree methods (Figure 8). Model free methods such as Friedmann, Kissinger, Flynn-Wall-Ozawa, Kissinger-Akahira-Sunose method [124, 125] have the ability to calculate the activation energy without the assumption of reaction models but they however have some disadvantages, hence, a model to describe the reactions is often applied for the solid thermal degradation.

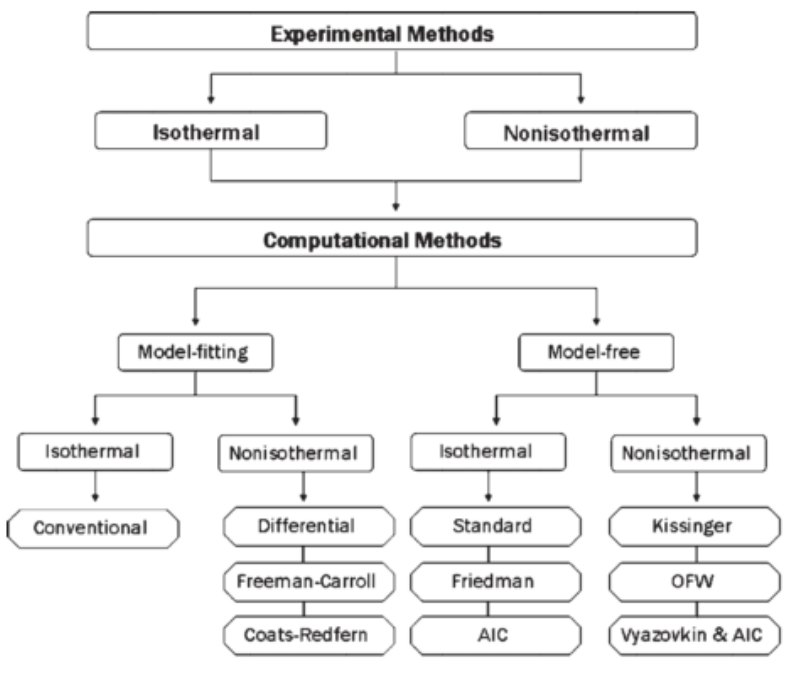

Figure 8. Typical kinetic analysis methods [126].

For a comprehensive understanding on these methods the reader is referred to papers $[124,126-$ 132]. A model-based method is one that fits different reaction models $f(\alpha)$ or $g(\alpha)$ (Table 3 ) into the general kinetic equation (Equation 18) and the activation energy and pre-exponential factor are often calculated by non-linear regression analysis (least square optimization) [131]. A number of optimization methods exist for the extraction of the kinetic parameters e.g. gradient-based [106], simulated annealing [133], genetic algorithm (GA) [134, 135], particle swarm algorithm (PSO) [136-138] etc. These algorithms are explained later in this section. 
Table 3. Examples of reaction models [139].

\begin{tabular}{lcc}
\hline model & differential form & \multicolumn{1}{c}{$\begin{array}{c}\text { integral form } \\
g(\alpha)=k t\end{array}$} \\
\hline & $f(\alpha)=1 / k$ d $\alpha / \mathrm{d} t$ & $\alpha^{1 / 2}$ \\
power law (P2) & nucleation models & $\alpha^{1 / 3}$ \\
power law (P3) & $2 \alpha^{1 / 2}$ & $\alpha^{1 / 4}$ \\
power law (P4) & $3 \alpha^{2 / 3}$ & {$[-\ln (1-\alpha)]^{1 / 2}$} \\
Avrami-Erofeyev (A2) & $4 \alpha^{3 / 4}$ & {$[-\ln (1-\alpha)]^{1 / 3}$} \\
Avrami-Erofeyev (A3) & $2(1-\alpha)[-\ln (1-\alpha)]^{1 / 2}$ & {$[-\ln (1-\alpha)]^{1 / 4}$} \\
Avrami-Erofeyev (A4) & $3(1-\alpha)[-\ln (1-\alpha)]^{2 / 3}$ & $\ln [\alpha /(1-\alpha)]+c^{\alpha}$ \\
Prout-Tompkins (B1) & $4(1-\alpha)[-\ln (1-\alpha)]^{3 / 4}$ & $1-(1-\alpha)^{1 / 2}$ \\
& $\alpha(1-\alpha)$ & $1-(1-\alpha)^{1 / 3}$ \\
contracting area (R2) & geometrical contraction models & \\
contracting volume (R3) & $2(1-\alpha)^{1 / 2}$ & $\alpha^{2}$ \\
& $3(1-\alpha)^{2 / 3}$ & $((1-\alpha) \ln (1-\alpha))+\alpha$ \\
1-D diffusion (D1) & diffusion models & $\left(1-(1-\alpha)^{1 / 3}\right)^{2}$ \\
2-D diffusion (D2) & $1 /(2 \alpha)$ & $1-(2 / 3) \alpha-(1-\alpha)^{2 / 3}$ \\
3-D diffusion-Jander (D3) & $-[1 / \ln (1-\alpha)]$ & $\alpha$ \\
Ginstling-Brounshtein (D4) & {$\left[3(1-\alpha)^{2 / 3} /\left[2\left(1-(1-\alpha)^{1 / 3}\right)\right]\right.$} & $-\ln (1-\alpha)$ \\
& $3 /\left[2\left((1-\alpha)^{-1 / 3}-1\right)\right]$ & {$[1 /(1-\alpha)]-1$} \\
zero-order (F0/R1) & reaction-order models & $(1 / 2)\left[(1-\alpha)^{-2}-1\right]$ \\
first-order (F1) & 1 &
\end{tabular}

Since a large number of kinetic models exist, Burnham and Braun [140] reviewed some of these models, they outlined how they work and gave recommendations on the selection of an appropriate model.

Significant effort has been made in the development of numerical methods for the determination of the kinetics of decomposition, however, most studies reported in literature do not explain the physical significance of the obtained parameters and reaction schemes. Development of experimental techniques is required to physically understand the extracted kinetic parameters. An interesting study was conducted by Tranchard et al. [141] relating the obtained kinetic parameters of a composite material to a physical sense. Based on the determination of the degradation pathway of the material, they proposed a multi-step reactions model composed of two main competitive reactions, an auto-catalytic reaction and $\mathrm{a}^{\text {th }}$ order reaction. In a similar way, Bourbigot et al. [142] determined the kinetic degradation scheme of a polystyrene-montmorillonite nanocomposite. Results from the kinetic analysis were justified by using the heat release curve from the cone calorimeter. A concise paper on the challenges of modeling the thermal decomposition of solid fuels is presented by Rogaume [143].

Currently, different numerical codes exist to calculate the kinetic triplet such as TA-KIN, NETZSCH thermokinetics software, KINETICS... [127]. For example, NETZSCH thermokinetics software determines the parameters of the model-free and model based approach following the methodology by Opfermann [144]. Anderson et al.[145] investigated three different computer programs (RATE, KINETICS MK and TA-KIN) to determine activation parameters using nonlinear evaluation methods. TA-KIN implements the the Levenberg-Marquardt algorithm, RATE implements Simplex algorithm while the KINETICS MK uses the modified Gauss-Newton algorithm. TA-KIN performed very well because it was flexible.

Bruns et al. [146] extracted Arrhenius parameters of thermoplastic materials by using the algorithm based on sequential quadratic programming. TGA curves obtained from several heating rates were used in the study and their pyrolysis model was based on a population balance approach. Generally, 
the population-based model performed well for the prediction of TG curves and the same was reported by Staggs [6]. However, there were typical issues with the parameter estimation study and there was no conclusion on the extracted parameters because the global minimum could not be reached due to the kinetic compensation effect.

The kinetic compensation effect is a major issue when it comes to finding optimum kinetic parameters $[146,147]$. Generally, it is possible to generate the same TG curve by simultaneously varying the values of the activation energy (E) and the pre-exponential factor (A). Ceamanos et al. [147] reported that for polyethylene, the activation energy can vary between 175 and $325 \mathrm{~kJ} / \mathrm{mol}$ while the pre-exponential factor varied between $10^{10}$ and $10^{22} \mathrm{~s}^{-1}$. Koga [148] presented a comprehensive review on this topic. A visualization of kinetic compensation is shown in Figure 9 where the objective function (sum of squared errors (SSE)) is plotted for the activation energy against the pre-exponential factor [146] for a "critical molecule size of a monomer unit" using the random scission model. There are two major observations: the first one is the valley for which the experimental data is predicted by the model which highlights the kinetic compensation effect. At $\mathrm{A}=5.49510^{9} \mathrm{~s}^{-1}$ and $\mathrm{E}=130 \mathrm{~kJ} / \mathrm{mol}$ a unique shallow minimum was found even though the SSE was relatively flat along the kinetic compensation line. The second observation is the noticeable flat region for large values of $\mathrm{A}$ and small values of $\mathrm{E}$ which is a consequence of the considered limited range of temperatures for the data points of the experiments.

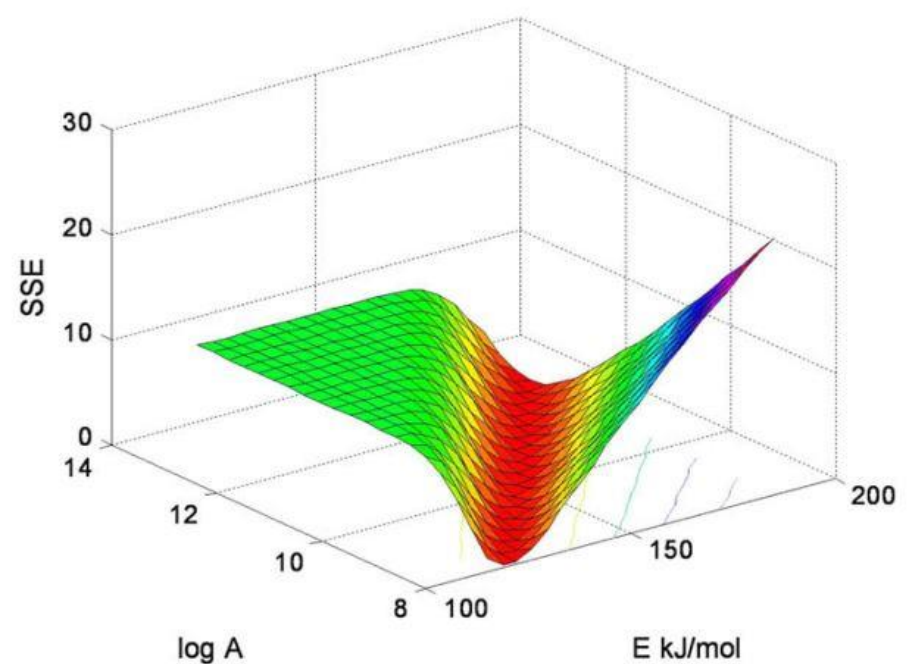

Figure 9. 3D Visual representation of the kinetic compensation for PMMA with random scission model for a "critical molecule size of a monomer unit"[146].

Loulou et al. [109] aimed at applying optimization techniques to obtain the Arrhenius parameters from a proposed kinetic model for the pyrolysis of a cardboard material. Mass loss information from thermogravimetric measurements was used. The Levenberg-Marquardt algorithm was implemented and it was robust in fitting with the experimental data. Constraints were also imposed on the estimated values e.g. to keep the parameters always positive. The comparison between the experimental and simulated data was acceptable given that there were small differences on the 
curvature of the total mass loss. However, the methodology was affected by the values used initially and this was attributed to the kinetic models being non-linear and consequently they proposed the use of genetic algorithms for better initial guesses. Mamleev and Bourbigot [106] used a method involving modulated thermogravimetry to estimate the Arrhenius parameters. The methodology was the same as the Levenberg-Marquardt method and it sped up the numerical processing time.

For intumescent modeling, Griffin [107] applied the Levenberg-Marquardt method for the estimation of the kinetic parameters of an intumescent coating. Independent first order parallel reactions were assumed. They obtained a correlation coefficient that was higher than $99.5 \%$, however they observed poor fits at inflexion points and at the end of the weight loss curves. An example of the fit between predicted and measured results is shown in Figure $\mathbf{1 0 .}$

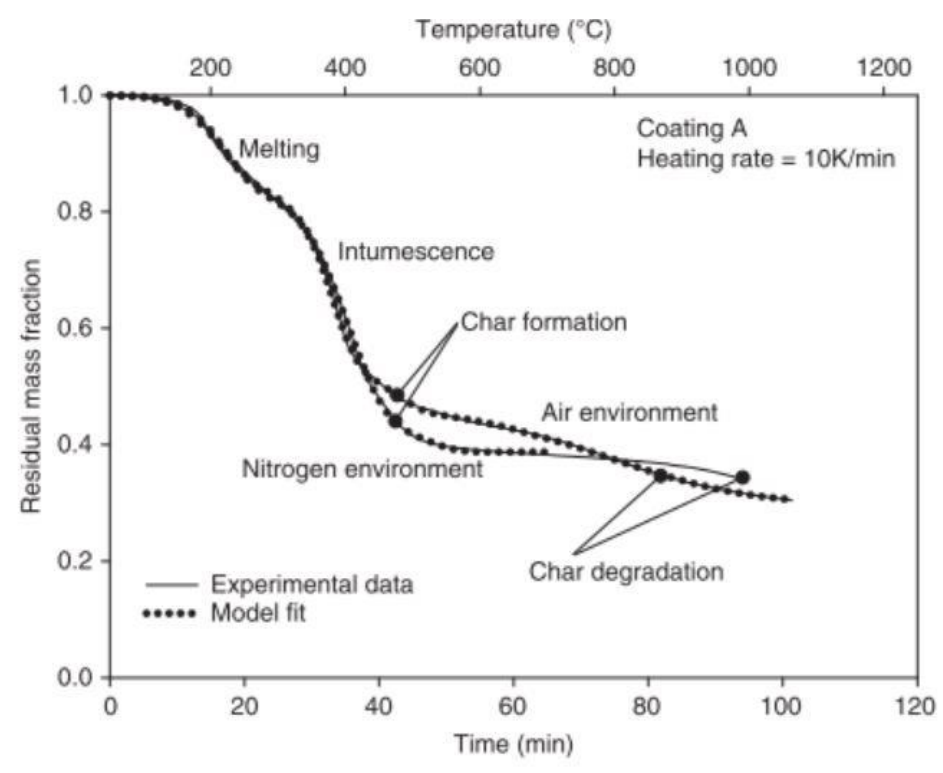

Figure 10. Weight loss and predicted curves [107].

Di Blasi and Branca [149] proposed that an intumescent coating made of three ingredients degrades following independent finite-rate reactions. Thermogravimetric data (TGA) were used for estimating Arrhenius parameters using a direct method. The estimated parameters corresponded to those which were found in a previous study. Reverte et al. [108] also used TGA data and contributed to the research on parameter estimation. A gradient-based method, which was a version of Levenberg-Marquardt method, was implemented. Other numerical methods for the estimation of kinetic parameters were presented.

Rozyki [150] compared the Arrhenius parameters that were estimated from different methods such as the linear method etc. Generally, he concluded that the values of the calculated parameters depended on the estimation method. The use of the non-linear least squares methods was recommended because it allowed calculating statistical weights and it did not bring into play transformations involving algorithms. 
A different approach was presented by Lyon [151] to determine the kinetic parameters from TGA data. These data were obtained from different heating rates i.e. 1,5 and $20 \mathrm{~K} / \mathrm{min}$. The methodology was based on using nonisothermal, single step thermal degradation kinetics to express the heat release kinetics combining material properties as well as thermal stability parameters. Using a simplified kinetic model to describe the thermal decomposition for polymers, they managed to predict a good fit between the model and experimental data except for temperatures higher that $700{ }^{\circ} \mathrm{C}$ because secondary reactions were not taken into account in the model. For determining the kinetic parameters from TGA data, the Stoliarov's group [152] has used this method as a basis in ThermaKin as well as other studies in FDS [43].

Li and Stoliarov [90, 91] developed a systematic approach for the determination of kinetics and thermodynamics of the thermal decomposition of non-charring and charring polymers based on the simultaneous thermal analysis (STA) using ThermaKin. The ThermaKin model was fitted to the experimental TGA curves to obtain the kinetics of decomposition and then used for the analysis of the heat flow curves from the DSC to determine the parameters related to the thermodynamics of decomposition (sensible, melting and decomposition reaction heats). The parameters obtained from this methodology were capable of reproducing both the experimental TGA and DSC curves. Li et al. [29, 153] used the same procedure as above to determine the Arrhenius parameters, heats of decomposition and the heat capacities. Moreover, other parameters such as the emissivities and the absorption coefficients were determined from independent experiments. Finally, the thermal conductivities were the only unknowns and their values were computed by fitting the gasification sample back surface temperature evolution. In their model development, the optimization problem is well poised and the gasification experiment MLR were not used as fitting targets but were instead utilized in the model validation. This is a critical feature of the Li et al.'s approach [29] $[153]$ that differentiates it from the majority of other pyrolysis parameterization studies $[15,77$, $78,92,154]$. In most similar studies, MLR was used as an optimization target and thus the model's ability to capture MLR was not viewed as an independent indicator of the model's validity. The same technique was used by McKinnon et al. [155] applied to corrugated cardboard. The authors also used TGA and DSC to determine the reaction mechanism, the enthalpy of decomposition reactions as well as the apparent heat capacities related to the species. Moreover, the heat of combustion of evolved gases for the respective reactions were determined from the pyrolysiscombustion flow calorimetry. This approach has an advantage because it results in a pyrolysis model that is physically representable [156]. A detailed study on this approach is presented by Stoliarov [101].

Another approach consists in fitting all or almost all material properties into a set of cone calorimeter or FPA experiments. By doing so, the problem is both highly complex (multidimensional parameter space) and ill-posed (multiple solutions exist representing local minima in the multi-dimensional parameter space). Finding solutions to these problems require sophisticated optimization methods. In this case, direct search methods such as evolutionary algorithm are useful and they are presented in the next section. 


\section{Direct search methods}

The objective of this section is not to describe the evolutionary algorithms but to give an overview of their application in pyrolysis models. Detailed descriptions of these algorithms can be found elsewhere [82, 157-159]. These optimization methods are inspired by the theory of evolution and are often referred to as Evolutionary Algorithms. Gradient-based optimization techniques optimize a single individual whilst evolutionary algorithms are focused on optimizing a population. These algorithms do not identify the global minimum but they do combine traditional mathematical optimization with random exploration of the parameter space, which makes them effective in identifying multiple local minima, the best of which is subsequently selected. In pyrolysis modeling, up-to date, evolutionary algorithms have been successfully implemented.

Genetic algorithms have been applied in other fields such as turbulent reacting flows for the optimization of reaction rate coefficients and they were found to be numerically robust and efficient as well as being flexible and easy to use [68]. In 2001, Şahin et al. used genetic algorithms (GA) to determine the kinetic parameters from thermogravimetric analysis of ammonium pentaborate. They compared the results between the GA method and Coats-Redfern methods and the former presented better results. In 2006, Rein et al. [44, 134], started implementing GA for the estimation of thermophysical and kinetic parameters from cone calorimeter and TGA experiments. Rein et al. [134] obtained the Arrhenius parameters of the pyrolysis and oxidation of flexible polyurethane (PU) foam by applying a GA together with TGA data. Before applying the GA to PU they applied the methodology to a case which has been extensively studied, that is the pyrolysis of cellulose [160]. In this preliminary work, the GA methodology was used to estimate the Arrhenius parameters of cellulose (activation energy - $E_{p}$, pre-exponential factor $-A_{p}$, ) as well as the stoichiometric coefficient $\left(\vartheta_{c, p}\right)$. Figure 11(a) shows the performance of the GA at simulating the TGA experiments; the simulated results perfectly correspond with the experimental data for the duration of the experiment. Figure 11(b) illustrates how the GA performs during search of optimized parameters. It shows how initial individuals perform poorly and how the GA progresses up to convergence. Figure 11(c) shows the fitness vs generations. The figure shows how the fitness evolves from the start i.e. in a quick manner, then slowing down toward the end of the search.

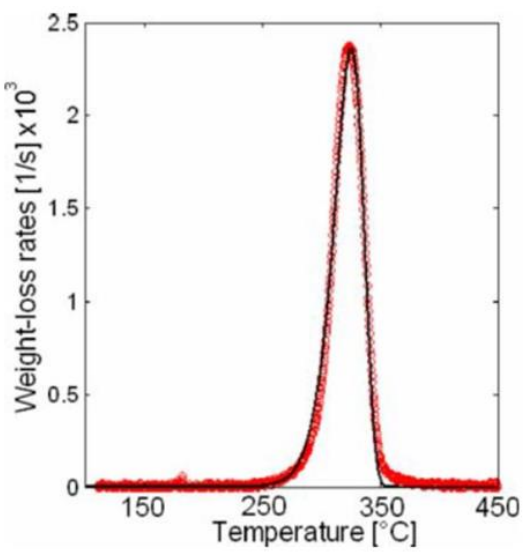

(a)

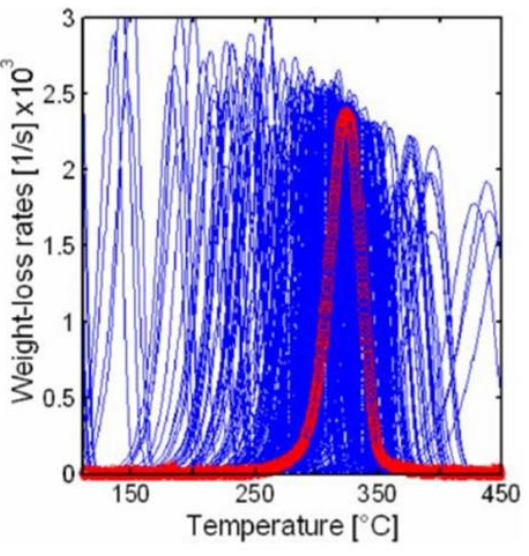

(b)

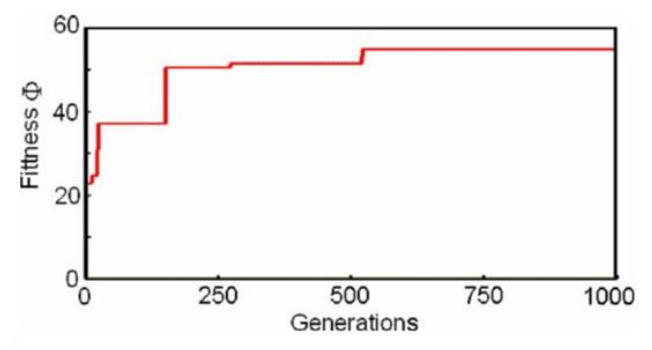

(c) 
Figure 11. (a) Comparison of experimental (red) and numerical (black) results of cellulose massloss rate curves in nitrogen at $5^{\circ} \mathrm{C} / \mathrm{min}$ [160], (b) GA (blue) performance during the search of optimized parameters (in red is the experimental curve), (c) Fitness evolution during GA optimization [134].

The optimized kinetic parameters from the GA are shown in Table 4. The parameters agree very well with the parameters obtained from a gradient-based method. Significant scatter (TG scatter) was reported among measured TGA data from several laboratories because of errors in the data which consequently caused differences in the estimated parameters (Table 4).

Table 4. Comparison of estimated parameters [134].

\begin{tabular}{cccccc}
\hline Parameter & GA & $\begin{array}{c}\text { TG } \\
\text { benchmark }\end{array}$ & TG scatter & $\begin{array}{c}\text { GA-TG } \\
\text { difference }\end{array}$ & Units \\
\hline $\mathrm{E}_{\mathrm{p}}$ & 236 & 241 & $12 \%$ & $2 \%$ & $\mathrm{~kJ} / \mathrm{mol}$ \\
$\log _{10}\left(\mathrm{~A}_{\mathrm{p}}\right)$ & 18,4 & 18.8 & $17 \%$ & $2 \%$ & $\mathrm{Log} 10(1 / \mathrm{s})$ \\
$\vartheta_{c, p}$ & 0.050 & 0.052 & $90 \%$ & $4 \%$ & - \\
\hline
\end{tabular}

The study suggested that the differences between results from the GA and benchmark were lower than that from the benchmark and experimental data because of the errors observed. For the PU foam, Arrhenius laws were implemented using a 5 step reactional scheme. The GA performed very well and the estimated parameters well predicted the experimental TGA data at different conditions as well as some physical characteristics associated with smoldering combustion.

Other works involving the use of GA for determining the Arrhenius parameters are included here; Matala et al. [161] applied the methodology which was developed by Lautenberger et al. [44] and Rein et al. [134] involving the use of GA for the estimation of the Arrhenius parameters of several combustible materials from TGA measurements in FDS. The methodology worked very well and further confirmed the use of evolutionary algorithms in estimating input parameters in the field of fire safety. More work was also done on applying the GA, for example the work of Rogaume et al. [162]. They used the GA to calculate the kinetic parameters of five-step kinetic scheme describing the thermal decomposition of polyether polyurethane foam. The experimental and predicted mass loss rate data were consistent.

Lautenberger et al. [44] demonstrated applicability of the previous methodology using cone calorimeter data instead of TGA data applied to redwood and red oak as well as polypropylene. Their optimization targets were the surface temperature and the MLR. In their study, the comparison between calculated and experimental results was acceptable given that the estimated parameters were model dependent (boundary conditions, assumptions), a sensitivity study would be necessary. The GA was also able to estimate the material properties within $\sim 10 \%$ of those found in the literature. However, the advantage of the approach was the possibility to apply it to any pyrolysis model using experimental data from small-scale tests.

In a similar way, Chaos et al. [9] used evolutionary optimization methodologies. Their objective was to study the ability of the SCE and GE "to converge to a global optimum using the least amount of data". In this study, the MLR from the Fire Propagation Apparatus (FPA) was used to 
generate synthetic data by adjusting the input parameters to get the best fit. This synthetic data was then used to investigate the performance of the SCE and GA algorithms. This exercise showed the ability of SCE to return almost the exact same data as the initial synthetic data. Moreover, it was accurate, efficient and robust. The MLR was used as a target at different heat fluxes i.e. $25 \mathrm{~kW} / \mathrm{m}^{2}$, $62.5 \mathrm{~kW} / \mathrm{m}^{2}$ and $100 \mathrm{~kW} / \mathrm{m}^{2}$ and the SCE further provided excellent agreement as well as residual that was as low as $10^{-7}$ as shown in Figure 12. The authors chose the MLR as an optimization target because it was assumed to be measured accurately as compared to the temperature data. This was because the measured temperature data had uncertainties. However, they reiterated that the modeler should use several target data and not limit it when available and accurate. Moreover, additional target data provides confidence in the data set obtained from optimization.
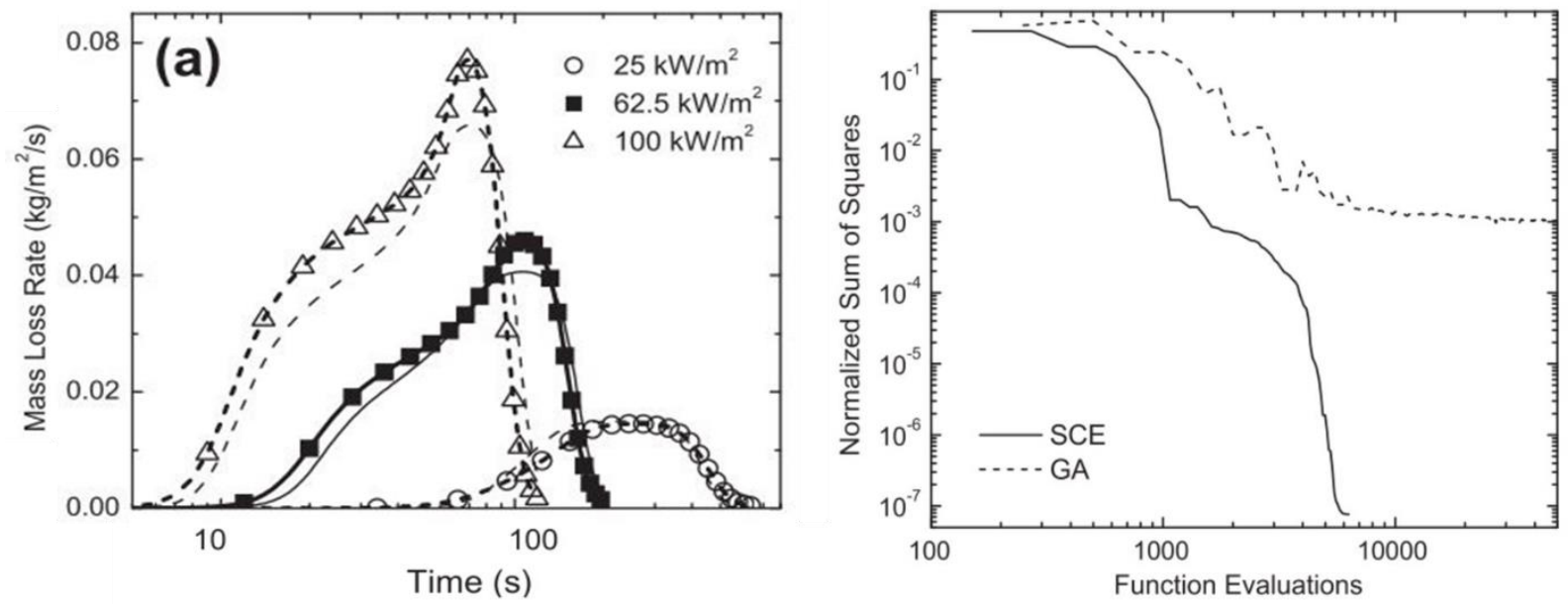

Figure 13. (a) MLR from optimized parameters ( SCE - bold lines, GA - thin lines) vs synthetic data (symbols) for a non-charring material (b) Residuals of the SCE and GA during optimization [9].

The SCE was further recommended by Lautenberger and Fernandez-Pello [163] for general use in the estimation of material properties because of its balance between efficiency and accuracy. They presented a comprehensive review on the application of four different optimization techniques with Gpyro (namely vanilla GA, hybrid GA/simulated annealing, SHC and SCE). They also evaluated the different experimental techniques that can be used when conducting a parameter estimation study.

The same methodology used by Chaos et al. [9] (described above) was successfully used by the same author [164] with application to hardwood pyrolysis. In their study they however decoupled the boundary conditions from the optimization problem by measuring the spectral properties of the material surface. Ding et al. [165] used the FireFoam pyrolysis model to study the pyrolysis of wet wood using the optimized parameters obtained by Chaos [164]. Chaos et al.[166]. also investigated the flame spread and fire response of corrugated cardboard using the CFD program FireFoam. This study was conducted on vertically orientated panels and exposed to an external propane sand burner. For this particular test, the heat release rate and the smoke generation were evaluated. In addition, surface temperatures and heat flux were determined so as to add to the validation data set. Using the pyrolysis model in FireFoam, input material properties were 
obtained using optimization against experimental data from the FPA. These properties were then used for the CFD simulations and the model results overpredicted the peak of HRR. Moreover, a sharp decay was observed towards the end of the combustion process and this was probably due to the char oxidation which was not taken into account in the model. In addition, the same methodology [9] was also applied by Zeinali et al. [74] for the determination of input model parameters to examine the pyrolysis and flame spread on medium density fiberboard (MDF) using FireFoam.

Interesting work was presented by Ghorbani et al. $[58,167]$ who also studied the two algorithms GA and SHC using six different models to describe the pyrolysis of polyvinyl chloride. The authors further presented the limitations of the optimization technique that was implemented. The models differed in their thereby affecting the number of unknown properties as well as the algorithm used. The optimization targets were experimental data obtained from the cone calorimeter i.e. MLR and temperature at the back surface. Some of the properties, such as the char density estimated by the GA, were too low and without any physical sense. This was attributed to the typical parameter estimation problem of the non-existence of a unique solution. Both the algorithms were capable of globally capturing the MLR curves. Precisely, they successfully predicted the time to ignition and the predictions for the time of the first peak, magnitude of the first peak, total burn out time, time for the second peak, magnitude of the second peak, total burn out time and total mass loss were within $20 \%, 10 \%, 30 \%, 15 \%, 10 \%$ and $5 \%$ respectively. For the temperature curves, the predictions were capable of capturing the early moments up to around 100 ${ }^{\circ} \mathrm{C}$ and experimental values beyond this temperature were not taken into account because they were considered unreliable. The authors reported that these models were only valid for the set of conditions used during model calibration after applying them to a scenario involving flame spread. To overcome this problem, in addition to the cone calorimeter or FPA, DSC, DSC and/or STA could be used for calibrating the models as well as improving the bench-scale tests and measurements. Capote et al. [168] presented a methodology combining the cone calorimeter and STA to estimate thermophysical properties and the kinetic parameters respectively. The methodology was similar to that of Stoliarov and Li [101] in that it separated the individual pyrolysis processes during optimization i.e. the STA results were used to obtain the kinetic parameters and then the cone calorimeter data (MLR) as the optimization target for the thermophysical properties. The cone calorimeter tests were conducted at external hea fluxes of $25 \mathrm{~kW} / \mathrm{m}^{2}, 40 \mathrm{~kW} / \mathrm{m}^{2}, 50 \mathrm{~kW} / \mathrm{m}^{2}$ and $75 \mathrm{~kW} / \mathrm{m}^{2}$. The methodology was applied on polyethylene and optimization was conducted by implementing evolutionary algorithms in Gpyro. The initial values were obtained both from measurements and from literature. The methodology was able to provide with a reasonable set of properties. However, the following relative errors were observed; $0 \%$ at $75 \mathrm{~kW} / \mathrm{m}^{2}$ and $27 \%$ at $50 \mathrm{~kW} / \mathrm{m}^{2}$ for the ignition times, $135 \%$ at $25 \mathrm{~kW} / \mathrm{m}^{2}, 45 \%$ at $40 \mathrm{~kW} / \mathrm{m}^{2}, 4 \%$ at $50 \mathrm{~kW} / \mathrm{m}^{2}$ and $32 \%$ at $75 \mathrm{~kW} / \mathrm{m}^{2}$ for the peak MLR and $21 \%$ at $25 \mathrm{~kW} / \mathrm{m}^{2}, 35 \%$ at $40 \mathrm{~kW} / \mathrm{m}^{2}, 3 \%$ at $50 \mathrm{~kW} / \mathrm{m}^{2}$, and $4 \%$ at $75 \mathrm{~kW} / \mathrm{m}^{2}$ for the time to peak. In general, the optimization performed well at $50 \mathrm{~kW} / \mathrm{m}^{2}$ and the ignition times for the other heat fluxes were acceptable. Moreover, errors for the peak MLR were higher than those of the ignition times.

Generally, the major drawback associated to parameter estimation problems especially with gradient based algorithms is the non-existence of a unique solution because the complicated 
pyrolysis phenomenon is numerically described using simplified models. In this case, methods based on evolutionary algorithms are necessary [169, 170]. Marquis et al. [169] worked on proving that a unique solution existed which satisfied the initial conditions for a given model. Kinetic parameters were obtained using the GA and mass loss rates under air and nitrogen atmospheres were used as optimization targets. They implemented the Picard-Lindelöf based on a model for the pyrolysis of polyether-polyurethane foam. They managed to prove that a unique solution actually existed which satisfied the initial conditions for a given model in certain conditions.

Several papers in literature have been reported to evaluate the performance of the different types of evolutionary algorithms. Webster and co-workers [58, 157, 167] examined the use of an algorithm called stochastic hill-climber for the estimation of material properties from mass loss rates from bench scale data. The results were compared to results obtained using genetic algorithms. The stochastic hill-climber (SHC) algorithm performed much better for pyrolysis parameter optimization. Lauer et al. [171] compared the performance of different optimization algorithms i.e. the Fitness Scaled Chaotic Artificial Bee Colony algorithm (FSCABC), Artificial Bee Colony algorithm (ABC) and SCE. In terms of accuracy as well as efficiency, both the FSCABC and the SCE performed very well. Ira, Hasalova et Jahoda [172] also dealt with both the GA and SCE for estimating wood thermophysical properties from TGA experiments. In their study, in overall, SCE performed slightly better than the GA.

More advanced optimization techniques are also found in literature. Saha et al. [173] studied the pyrolysis of several thermoplastics and focused on searching for the optimized kinetic model as well as the kinetic parameters. Instead of using the model-fitting methods because of their drawbacks, they applied a hybrid GA (HGA) on 15 different kinetic schemes using TGA data. The HGA reduced the calculation time because it was based on the general GA but used a different method for the search of parameters thereby increasing convergence. The kinetic models that performed very well were the nucleation and growth models together with the $\mathrm{n} t h$ order. Other research work was done by $\mathrm{Li}$ et al. [135] to reach the same objective as mentioned previously. In their work, they implemented the GA coupled with the Kissinger's Method (K-K method). As compared to the regular GA, the K-K method was highly efficient because the Kissinger's Method is first used to search for the possible initial parameters and then these parameters are fed into the GA. Park et Yoon [138] used the repulsive particle swarm optimization (RPSO) algorithm to numerically determine the material pyrolysis parameters. The RPSO algorithm was an improved particle swarm algorithm. Ritcher et al. [115] implemented the Multialgorithm Genetically Adaptive method which used several optimization algorithms to estimate the kinetic parameters of wood. The several combined optimization algorithms used were GA, PSO, Adaptive Metropolis Search as well as the Differential Evolution. This algorithm was both accurate and less time consuming compared to others.

In a similar way, a very interesting study was conducted by Raudensky [160]. The authors focused on the notion of artificial intelligence in parameter estimation for materials. They compared a genetic algorithm as well as an algorithm based on neural networks. Neural network algorithms emanate from how the brain of a human works. Both algorithms performed well although they all had advantages and limitations. Genetic algorithms were stated to take time during simulation 
whereas neural networks required acceptable initial values. They proposed that a combination of both algorithms would improve the results. Najafi and Woodbury [174] used neural networks to estimate the heat flux at the surface of a material using temperature information, then they also discussed their limitations and benefits.

In summary, within the framework of pyrolysis modeling, optimization can broadly be used to solve two main categories of problems. The first category is where most of the model input parameters are determined from independent experiments [29, 153]. Then the few remaining parameters are optimized using, for example, the gasification sample back surface temperature evolution. In this case, optimizations are not time consuming and can be carried out by manually method adjusting parameter values or by the gradient-based methods until satisfactory agreement is achieved. The second category of optimization problems involves fitting all or almost all material properties into a set of Cone or FPA experiments. These problems have been discussed and include the use of evolutionary algorithms [9, 163, 167, 175]. These algorithms are not guaranteed to find the global minimum (no algorithm is capable of that) but they generally combine traditional mathematical optimization with random exploration of the parameter space, which makes them effective in identifying multiple local minima, the best of which is subsequently selected based on physical consideration. However, Ghorbani [58] stated that the estimated values from this approach, when using one set of target data, sometimes do not provide reliable predictions outside the range of conditions in which the calibration was realized. Several research works have focused on trying to overcome this problem. These works involve a systematic approach of combining cone calorimeter or FPA data with TGA, DSC and/or STA data. In this way, it is possible to separate the individual phenomena involve in pyrolysis [101, 153]. Moreover, improved measuring techniques and controlled bench-scale tests have been implemented [29].

In all the cases described above, it is essential to have the knowledge on how the estimated parameters influence the model outputs of interest. The next part highlights the use of sensitivity studies in the fire community.

\section{Sensitivity analysis}

In general, a sensitivity analysis permits the quantification of the role of parameters in the model predictions. The application of sensitivity analysis to chemical problems dates back to as early as 1981. Rabitz [176, 177] presented an overview of sensitivity theory for the application to chemical problems. In 1994, a comprehensive review presenting more than a dozen sensitivity analysis methods intended for those not familiar with the techniques was presented by Hamby [178]. Some of the techniques applied in the fire-related field are presented here.

Generally, when the most influential parameters are determined, it allows the elimination of the less important parameters and the modeler concentrates on the experimental or numerical determination of the most sensitive parameters in order to increase model accuracy. Sensitivity analysis (SA) methods can generally be classified into three classes i.e. 1) screening, 2) local, 3) global [179, 180].

Screening is a qualitative method that only involves the ranking of input parameters according to their sensitivity. They are advantageous for complex problems as compared to other SA methods 
because they are computationally economic. Gillet [181] conducted a sensitivity analysis using the screening method on a one dimensional intumescent coating model.

On the other hand, the local sensitivity methods are quantitative and are carried out by changing each input parameter at a time and maintaining the other parameters constant. This method provides the gradient of the model output with respect to a nominal set of input parameters. Chaos [35] performed a sensitivity analysis on a given pyrolysis model that was a simplification of Gpyro [14] applied on both a charring and non-charring combustible solid. In their study, instead of varying the parameters by an arbitrary uncertainty value such as in [36], they used a complex-step differentiation approach to compute the normalized first-order local sensitivity coefficients. The outputs of the model were the temperature of the surface and the MLR. Figure 14 shows some of the results of the sensitivity of the surface temperature at different heat fluxes with respect to the input parameters in the case of a non-charring combustible solid. Note that the kinetic parameters were grouped because of the compensation effect. From the first row in Figure 14, an increase in the heat flux (from $25 \mathrm{kWm}^{-2}$ to $100 \mathrm{kWm}^{-2}$ ) caused the sample surface to reach a higher temperature in the steady state. Near the end, the temperature decreases slightly in both cases. This was explained to be the effect from the mass loss of the material which reduced the thickness consequently reducing the absorbed in-depth radiation and heating rate. The parameters were divided into material properties i.e. thermal conductivity $\left(k_{v}\right)$, heat capacity $\left(C_{p, v}\right)$, density $(\rho)$ then optical parameters (emissivity $\left(\varepsilon_{v}\right)$, absorptivity $\left(\alpha_{v}\right)$, absorption coefficient $(\kappa)$ and parameters related to reaction kinetics $(\mathrm{Ea} / \mathrm{lnZ}$, reaction order $(\mathrm{n})$, heat of pyrolysis $(\Delta \mathrm{Hp}))$.

Regarding the surface temperature sensitivity coefficients, they generally exhibit an initial unsteady stage during the first moments and then remain relatively steady except for the parameters related to reaction kinetics. This observation shows the effect of varying the input parameters. The materials properties lower the heating rate because of the dynamic thermophysical properties. The heat flux reaching the surface is dependent on the optical properties and absorptivity is the most sensitive to the increase in temperature. The parameters related to the reaction kinetics hardly have an influence at this stage because conduction controls the heat transfer phenomena. When the material starts to decompose, Ea/LnZ becomes the most influential parameter. $\Delta \mathrm{Hp}$ lowers the temperature of the surface and the effect is demonstrated by its sensitivity coefficient curve. Moreover, from Figure 14, it can be observed that some of the sensitivity coefficients change from a negative value to a positive value with time. This demonstrates how values obtained by optimization could be affected due to compensation effects between the parameters i.e. a variation in some parameters during optimization gives rise to a change in other parameters. Bal [116] extensively studied these effects. 

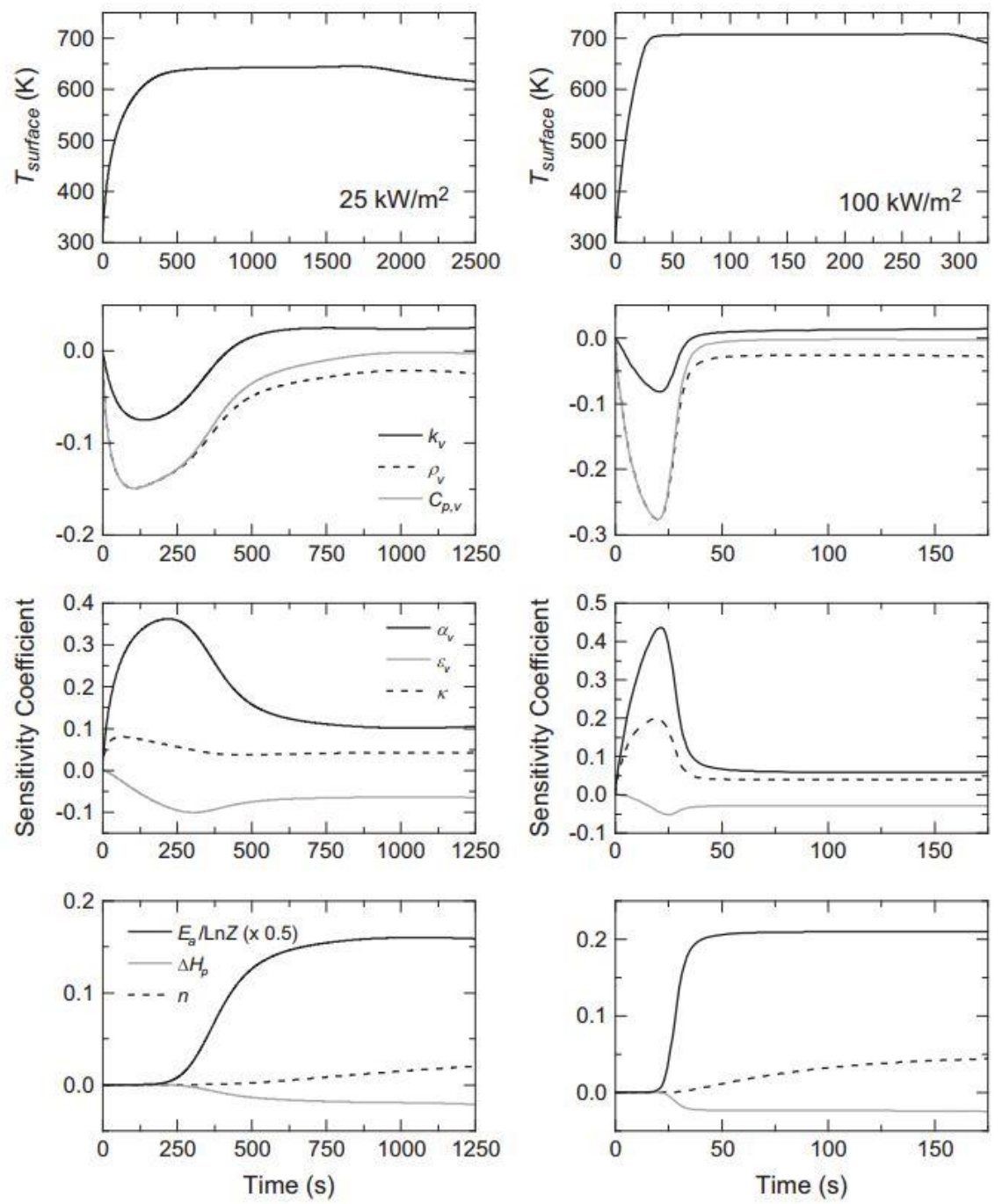

Figure 14. Sensitivity of the temperatures of the surface at different heat fluxes $25 \mathrm{kWm}^{-2}$ (left column) and $100 \mathrm{kWm}^{-2}$ (right column). with respect to the input parameters in the case of a noncharring combustible solid [35].

Their targets were the MLR and surface temperature and most of the parameters qualitatively exhibited relatively the same sensitivity curves. The most sensitive parameters were $\alpha_{\mathrm{v}}$ and Ea/LnZ. Chaos [35] also conducted a sensitivity study on the time to ignition, average MLR, and peak MLR. For charring material, the thermophysical properties for both the virgin and char state except for the heat capacity of the char had an influence on the time to ignition, average MLR, and peak MLR, in particular at low heat fluxes. Moreover, Ea/LnZ significantly influenced the average and peak of MLR. Figure 15 shows the results for the non-charring material. The ignition was not influenced by $\Delta \mathrm{Hp}$ but it was significantly influenced by Ea/LnZ as well as by $\alpha_{v} \cdot \mathrm{k}_{\mathrm{v}}, \mathrm{C}_{\mathrm{p}, \mathrm{v}}$ and $\rho$ also affected the ignition time given that these properties play a role during the initial heating phase of the material (Figure 14). As for the average and the peak MLR, Ea/LnZ, $\Delta H p, \alpha_{v}$ and $\varepsilon_{v}$ were the most influential parameters. 
a

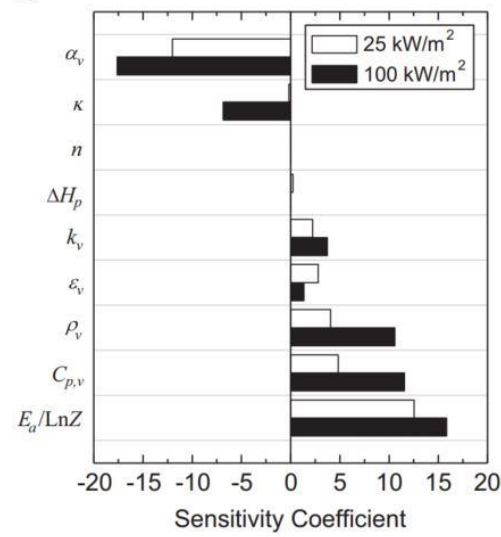

b

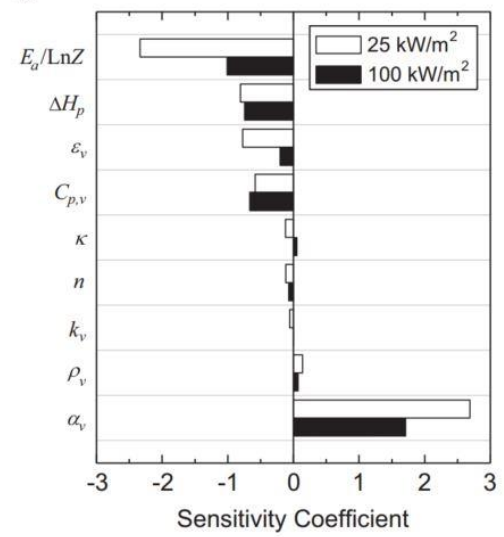

C

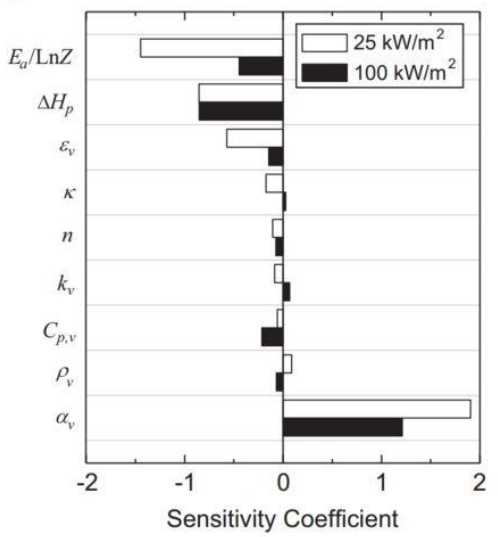

Figure 15. Global sensitivity analysis for non-charring material (a) time to ignition, (b) average MLR, (c) peak MLR [35].

The results observed by Chaos [35] were consistent with those from Stoliarov [37] and Linteris [79] in that the thermophysical properties as well as $\kappa$ had an impact on the time to ignition. Moreover, the average MLR was also noticed to be sensitive to $\Delta \mathrm{Hp}$ and $C_{p, v}$. However, when considering the impact on the peak of MLR, the results were only consistent with those of Stoliarov [37].

Global sensitivity methods are also quantitative and they focus on how all the parameters influence the outputs of the numerical model. They vary all the inputs at the same time as well as providing information concerning statistical distributions which is necessary for a deeper understanding of the role of the parameters. These methods are useful when a significant number of parameters is involved [36].

Ramroth et al. [36] used a finite-element pyrolysis model to simulate the fire behavior of a composite and then conducted both a local and global sensitivity study. All the parameters were varied by an uncertainty of $1 \%$. As a preliminary step, the sensitivity of the temperature on the cold surface to material properties were calculated in terms of the local sensitivity coefficients. Statistical information related to uncertainty was then obtained by using the Monte Carlo method. Figure 16. shows results concerning the local sensitivity coefficients. Figure 16(a) shows the change in the value of every property with time. The change in colors from left to right represents the change of the parameter with time. The values above zero demonstrate that if the material property is increased, the temperature value which is the output is also increased and vice-versa for the values below zero. Figure 16(b) ranks the material properties with the evolution of time. The higher the position at any given instant shows that the parameter is the most influential and vice-versa. However, varying the parameters by $1 \%$ did not significantly affect the results. 


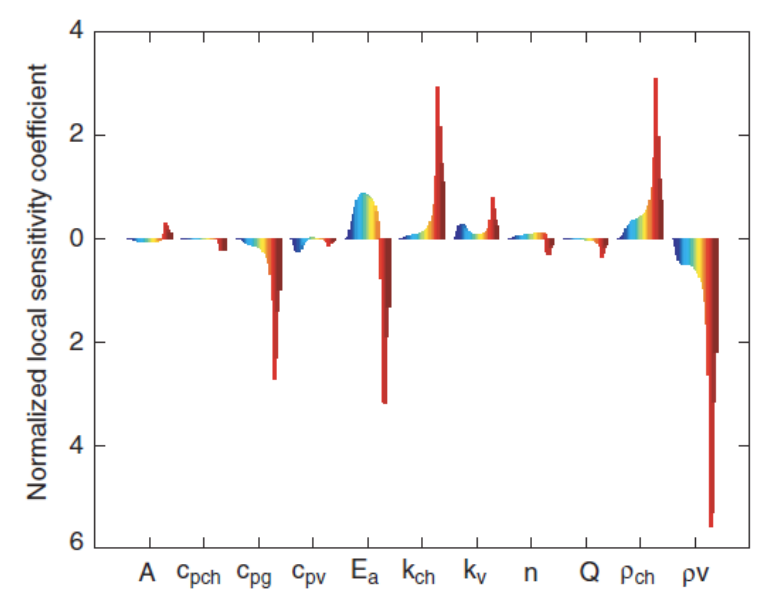

(a)

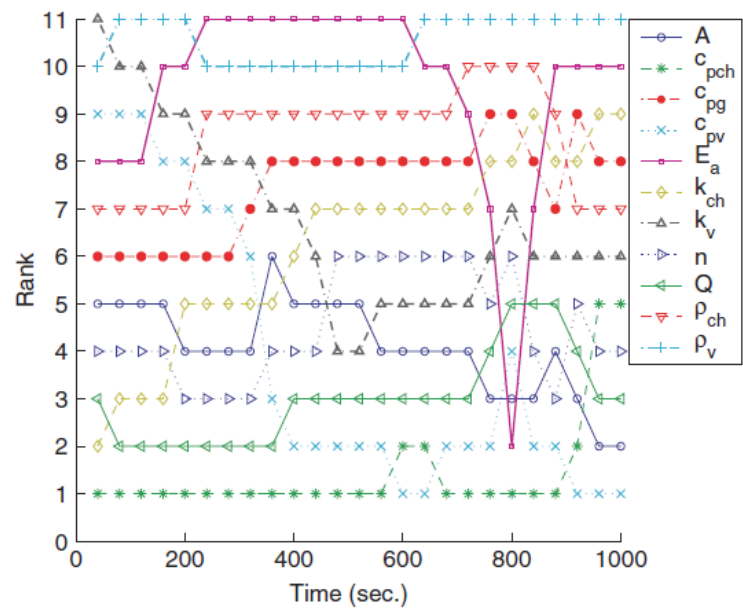

(b)

pre-exponential factor - $A\left[s^{-1}\right]$, specific heat of the char $-c_{p c h}\left[\mathrm{Jkg}^{-1} \mathrm{~K}^{-1}\right]$, specific heat of the product gases $-c_{p g},\left[\mathrm{Jkg}^{-1} \mathrm{~K}^{-1}\right]$, specific heat of the virgin composite $-c_{p v}\left[\mathrm{Jkg}^{-1} \mathrm{~K}^{-1}\right]$, activation energy $-E_{a}\left[\mathrm{Jkmol}^{-1}\right]$, conductivity of char $-k_{c h}\left[\mathrm{Wm}^{-1} \mathrm{~K}^{-1}\right]$, conductivity of the virgin composite - $k_{v}\left[\mathrm{Wm}^{-1} \mathrm{~K}^{-1}\right]$ Reaction order $-n$, heat of decomposition $-Q\left[\mathrm{Jkg}^{-1}\right]$, density of char $-\rho_{c h}\left[\mathrm{kgm}^{-}\right.$ $\left.{ }^{3}\right]$, density of the virgin composite $-\rho_{v}\left[\mathrm{kgm}^{-3}\right]$

Figure 16. (a) Normalized local sensitivity coefficients (b) Ranking of the material properties as a function of time [36].

Moreover, they conducted a comparison of the results from the local and global sensitivity study results. The results agreed in many ways, however, there was contrast in a few instances. At early times of the calculation, the most sensitive parameters in both methods were obviously $c_{p v}, k_{v}$ and $\rho_{v}$ because heat transfer is controlled by pure conduction until degradation starts and the importance of $E_{a}$ comes into play. During the simulation, which is the degradation phase, both methods showed $c_{p g}, E_{a}, k_{c h}$ and $\rho_{v}$ to be of significance. However, the local sensitivity method, showed $\rho_{c h}$ as significant, whilst the global sensitivity method indicated $A$ as important. Finally, near the end of the calculation, $c_{p g}, \rho_{c h}, k_{c h}$ and $\rho_{v}$ were more influential as per both methods. However, according to the local sensitivity method, $E_{a}$ and $k_{v}$ were more significant at this time, while they were not for the global sensitivity method. Both methods demonstrated that $c_{p c h}, n$ and $Q$ were not of significance. The discrepancies between these two analyses were solely attributed to the nature of the methods.

Stoliarov et al. [37] conducted a study on the pyrolysis of polymeric materials as well as a sensitivity study using ThermaKin. The sensitivity analysis was carried out based on the predicted MLR curves. The motivation of their study was to investigate which properties could be guessed with reasonable accuracy based on existing property data and which properties must be measured for each material to provide reasonable predictions. In this analysis, each property was varied within the range representing the majority of synthetic polymers. This range was different for each property. Figure 17 shows the mean and maximum variations. Regarding the maximum variations, 
the signs shows how the peak or average mass loss rate responds to an increase of the input parameter. Their conclusion was that the parameters related to kinetics (E/A ) and decomposition ( $h_{\text {dec }}$, char yield) were of great influence to the peak and average mass loss rates as shown in Figure 17. Moreover, the average mass loss rate was sensitive to $\alpha$ (Figure 17(b)).

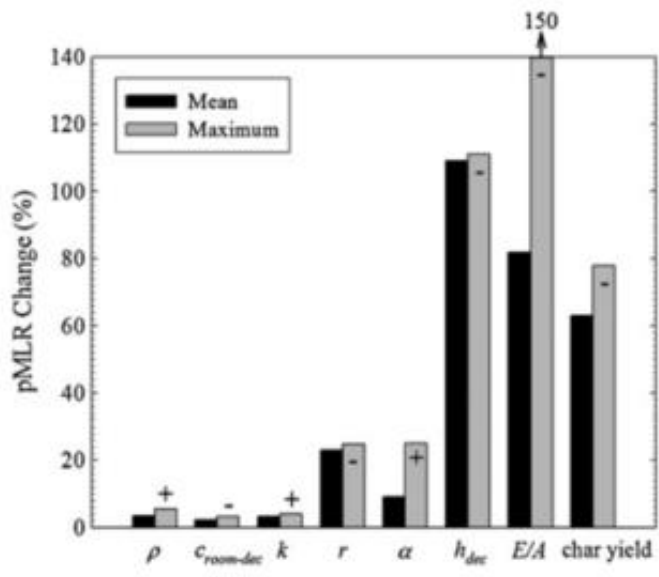

(a)

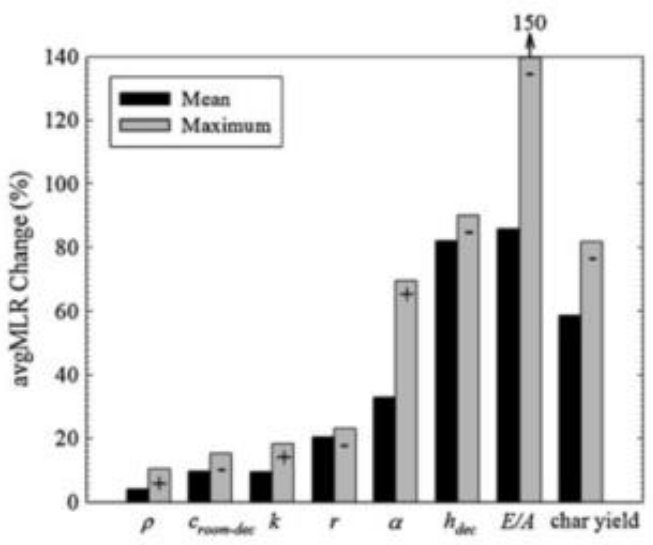

(b)

density - $\rho$, heat capacity describing $c_{\text {room-dec }}$ temperature range, thermal conductivity - $k$, reflectivity $-r$, absorption coefficient $-\alpha$ heat of decomposition $-h_{d e c}$, activation energy $-E$, pre-exponential factor - $A$

Figure 17 (a) Peak mass loss rate sensitivity to material properties (b) Average mass loss rate sensitivity to material properties [37].

Linteris [79] further conducted numerical simulations on PMMA exposed to radiant fluxes to understand the effect of property variations using FDS and ThermaKin. Both programs were used to calculate the mass loss rate and to evaluate its sensitivity to material properties. The nominal property values that were used were taken from [50]. The values were varied by a factor of 2-2.5 around the nominal values. As reported, these variations were greater than those applied by Stoliarov et al. [37] for typical polymers. This was done so as to take into account new materials with a wide range of properties. In their study, they reported that the heat of reaction was the most sensitive and the activation energy the least sensitive parameter. The result suggested that for the prediction of the mass loss rate, the heat of reaction needed to be measured with accuracy. It is a key property defining the fire response of a non-charring combustible solid as it contributes to the energy needed to transform a unit mass of solid to materials to volatiles [81]. According to Linteris [79], for the conditions assumed, activation energy was the least important parameter which was in contrast with results from Stoliarov [37]. This was attributed to the different ranges in which $\mathrm{E}$ and A were varied in the two works revealing how the sensitivity of the parameters are model dependent.

As discussed earlier, material properties that are directly measured by thermal analysis have a certain degree of uncertainty that can induce errors in the numerical predictions. In this case, a 
sensitivity analysis helps in in understanding how much percentage uncertainty can be accepted so as to obtain minimum error in the predictions. Stoliarov et al. [182] noted that one of the potential sources of discrepancy between their numerical model and experimental results was the uncertainties in the material properties. In this case, a sensitivity analysis brings additional insights on the uncertainty quantification. Girardin et al. [76] modeled the pyrolysis of EVA/ATH/NC. The particularity of their work was the measurement of temperature-dependent thermophysical parameters. The numerical and experimental results were in reasonable agreement, however, to fit the final mass loss curves with accuracy, the mass transfer need to be adjusted. In their work, a sensitivity study was conducted on the kinetic parameters and the mass transfer coefficient. They concluded that the later was the only parameter to help fit the model and they reported that the diffusion of the gases did not have a significant effect on the temperature but rather on the mass loss curves. However, they did not conduct a sensitivity analysis to quantify the uncertainty from each of the property measurements which could have further explained differences between the numerical and experimental results.

Linteris et al. [42] measured inputs parameters for their models in FDS and Thermakin as described in the direct measurement by thermal analysis section. Figure 18 shows sensitivity of the mass loss rates to changes in the materials properties. Different percentage variations were used in the sensitivity study for the properties. The basis of the variations for the thermal conductivity was on the standard deviation in the mean of the measured properties (Figure 6) for each material. The variations were given as $\pm 7 \%$ for the thermal conductivity for all polymers except for POM which was $\pm 20 \%$. $\pm 16 \%$ was taken for the heat of reaction and specific heat based on the uncertainty in the measurements that was reported in [81]. The Arrhenius parameters, activation energy and preexponential factor, were varied by $\pm 50 \%$ and $\pm 3 \%$ based on uncertainties give in literature [92]. The uncertainty values for the absorption coefficient were chosen based on its dependency on thickness of the material [183]. The variations are extensively explained in Linteris et al. [42] to try and understand the source of differences between the calculated and experiment mass loss rates at some points mainly for PA66. The left column in Figure 18 shows the influences of $\mathrm{H}$ (heat of reaction), A (pre-exponential factor) and $\mathrm{E}$ (activation energy) while the right column shows the influences of a (absorption coefficient), $\mathrm{C}$ (heat capacity) and all (All) properties at once. The signs + and - indicate the value bounds corresponding to each property. $\mathrm{E}_{\mathrm{cr}}$ denoted that $\mathrm{E}$ was simultaneously varied with A in a way to alter the temperature on the surface. In general, the thermal conductivity did not have an influence on mass loss rate but affected the ignition time. The parameter that exhibited the largest effect on the mass loss rate results, depending on the conditions of simulation, was the heat of gasification and the least was the coefficient of absorption. It appeared that the uncertainties that were observed in the properties that were experimentally determined were not the reason for the differences between the calculated and experiment mass loss rates for PA66. They therefore attributed the discrepancies to other physical burning features which needed to be understood and included in the model. 

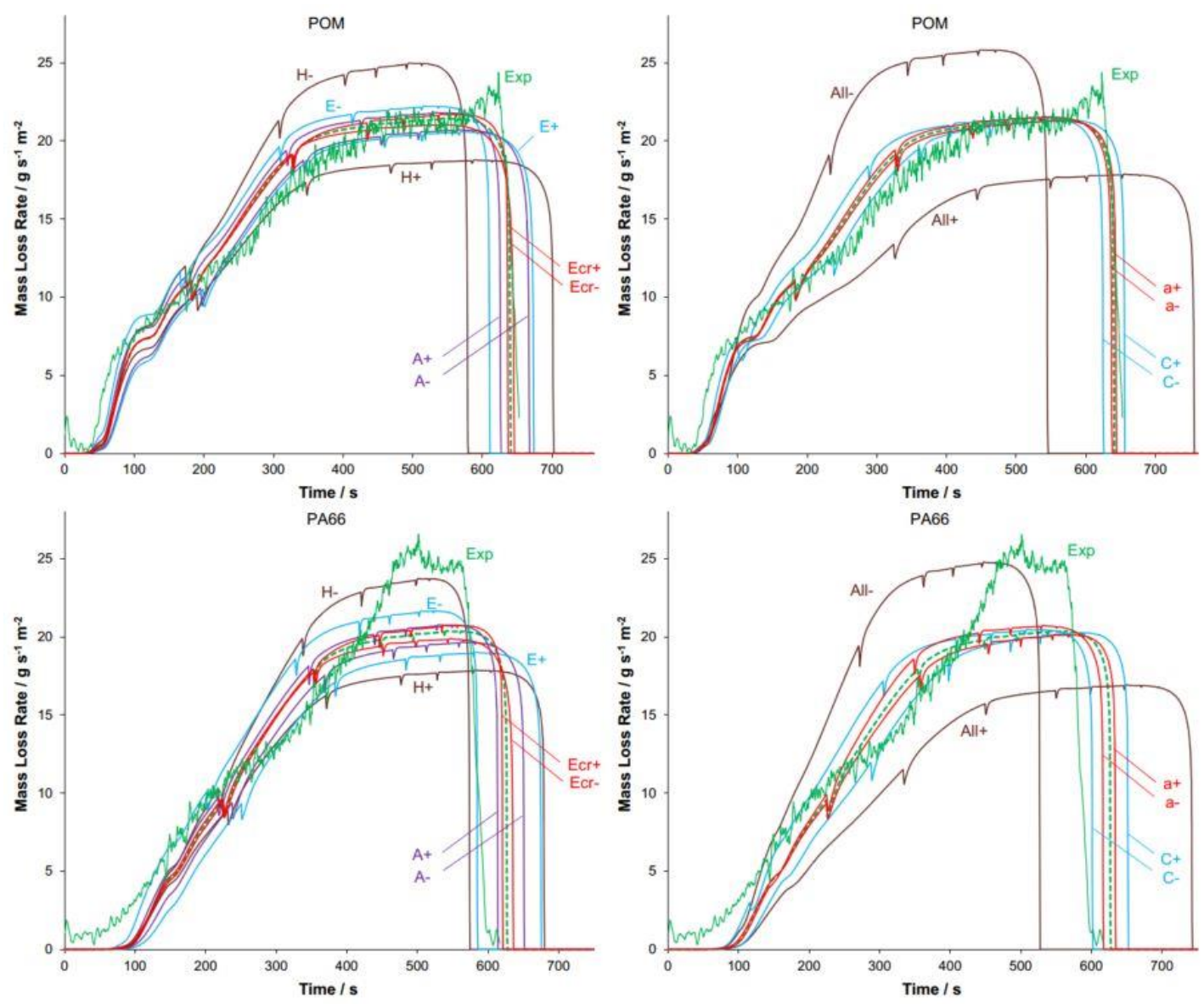

activation energy - E, pre-exponential factor, A - pre-exponential factor, heat of reaction - H, absorption coefficient - a, heat capacity $-\mathrm{C}$, all the parameters combined - All

Figure 18. The sensitivity of calculated mass loss rates to E, A, and H (left column) and a, C, and all parameters (All) (right column) for POM and PA66 [42].

Kempel et al. [78] used FDS and ThermaKin to calculate the mass loss rate of two polymers namely poly (butylene terephthalate) (PBT) and PBT reinforced with glass fibres (PBT-GF). The former burns to leave no residue while the later does. Three different sets of material properties were used i.e. data from the material supplier, properties determined at room temperature and temperature dependent properties. Temperature dependent properties gave better correspondence between model and experiment demonstrating the importance of the precision of the input properties on the performance of the model. Of interest in this section was the sensitivity analysis. The material properties were varied by $\pm 20 \%$ and for both materials, the time to mass loss (tML) was sensitive to changes in $\mathrm{Cp}$ and $\mathrm{k}$. The rest of the materials properties hardly had an influence on the tML. The peak of mass loss rate (pMLR) corresponding to PBT was influenced by variations in Hdec while the pMLR corresponding to PBT-GF was influenced by the variations in $\mathrm{k}$, Hdec and $\mathrm{Cp}$.

Bal and Rein [117] presented a different methodology as compared to the other sensitivity methods focused on input parameters. Their methodology focused on the effect of adding the heat, mass 
and chemical processes during the development of model on the model output. They concluded that generally once the heat transfer processes were simplified in the model, the model was not sensitive to complicated kinetic schemes and simple ones would be acceptable.

When applied to decomposition kinetics, a sensitivity study helps to understand how the change in the Arrhenius parameters affects the results of the kinetic model both in a qualitative and quantitative way [180]. Batiot et al. [179] applied a method using the local and global SA to study a kinetic model using a one-step mechanism. The Sobol's technique was applied as global sensitivity method. The work demonstrated how the mass loss rate is influenced by the Arrhenius parameters and also highlighted issues concerning the compensation effect of these parameters. A local sensitivity method was implemented by Dong et al. [184] on kinetic models applied to the pyrolysis of cellulose i.e. the 1 st and nth order. The models were much more influenced by the activation energy and the logarithmic pre-exponential factor. They concluded that for optimization purposes, it was advisable to use the logarithmic pre-exponential factor rather than the preexponential factor because it was hardly sensitive.

In summary, it should be mentioned that the outcome of sensitivity studies strongly depends on the specific question being answered as seen above. Often, researchers seek to understand the sensitivity of key model predictions (mean HRR, time to ignition, surface temperature, etc.) to the uncertainties in the measured properties by varying the properties within a certain percentage of uncertainty. This percentage is not always the same for all the researchers and is not applied uniformly to all properties e.g. Kempel et al. [78] varied all the properties by $\pm 20 \%$ while Linteris [42] varied the properties with different percentages. On the other hand, Stoliarov et al. [37] and Linteris [79] varied the properties within a certain range of values representing the studied polymers. It should be noted that the chosen range was different between the two authors. Moreover, the outcome of the sensitivity studies also depends on their targets. However, collectively, these studies show that the thermophysical properties of the material together with the absorption coefficient have a significant influence on the ignition time and that the heat pyrolysis affects the average MLR. Moreover, both Stoliarov et al. [37] and Chaos [35] found that the heat of pyrolysis and the reaction rate were the most influential on the peak MLR. Kempel [78] also found that the heat of pyrolysis was influential on the peak MLR. The difference between the results from Stoliarov et al. [37] and Linteris [79] is mainly on how the Arrhenius parameters influence the ignition time and the average MLR; Linteris observed that Ea/LnZ was the less influencing parameter which was contrary to Stoliarov et al. [37] and Chaos [35]. This difference can be attributed to the considered range of variations in the parameters by Linteris [79] which were not consistent and different from Stoliarov [37].

Non-charring, charring and intumescent materials behave differently when exposed to a fire scenario. The next sections describe the applications of the computational tools that have been presented above for comprehensive pyrolysis models for each of these materials. 


\section{APPLICATIONS}

A. Non-charring materials

When non-charring materials are exposed to an external thermal constraint, they either burn completely or leave some residue as well as melt or drip. Zeng et al. [185] presented a review focused on thermal decomposition of a typical non-charring polymer (poly(methyl methacrylate)). They reported that the fire behavior of poly(methyl methacrylate) could be explained in three stages. The first stage involves the production of the monomer methyl methacrylate (MMA) followed by the decomposition of MMA to form "small gaseous molecules" and lastly the combustion of these "small gaseous molecules" leading to the release of final products that include $\mathrm{CO} 2, \mathrm{H} 2 \mathrm{O}$ and some toxic gases as well as heat.

Stoliarov et al. [92] implemented the ThermaKin model for non-charring polymers such as poly(methyl methacrylate) (PMMA), high-density polyethylene (HDPE) and high-impact polystyrene (HIPS). The key physics that was modeled included heat transfer by conduction inside the material, the kinetics and the thermodynamics of the decomposition reaction as well as the indepth radiation absorption. Some of the input parameters for the model were experimentally determined and other parameters were extracted from previous research work. The agreement between experimental and numerical data for gasification experiments was considered excellent for PMMA and HIPS given the uncertainties observed in the model input parameters and that no model calibration was conducted. However, less agreement was observed for HPDE because of the expansion of the material that was observed during the tests. The peak MLR and average MLR, for PMMA were 3\% and 13\% lower than the experimental data respectively. For HIPS, the predicted peak and average MLR were $6 \%$ and $2 \%$ lower while for HDPE, the simulation results for the peak ad average MLR were 27\% and 17\%. They observed that besides the precision of the material properties, the fire behavior of the material influenced the response of the model, for example the time-to-ignition which depended on the conditions of the experiment.

Later, Li et al. [153] also used ThermaKin to study PMMA and HIPS as well as poly(oxymethylene) (POM). This study provided more accurate pyrolysis models for these materials as compared to the study by Stoliarov et al. [92] because they used better controlled gasification experiments in the parameterization process. The controlled gasification experiments involved mainly conducting the experiments in a controlled atmosphere as well as non-contact temperature and improved radiation absorption measurements. Moreover, they obtained the model inputs using a systematic approach that was described in the optimization section $([90,91])$. The difference between simulated burning rates and the experimental results were averaged to fall within $10 \%$.

Shi et al. [71] used FiresCone to study the pyrolysis of PMMA. The experiments were conducted using a standard cone calorimeter. Different sample thicknesses $(10 \mathrm{~mm}$ and $20 \mathrm{~mm})$ and heat fluxes $\left(25 \mathrm{~kW} / \mathrm{m}^{2}-75 \mathrm{~kW} / \mathrm{m}^{2}\right)$ were considered. By dividing the computational domain into two, the FiresCone framework was set to consider the gas phase as 2D and the solid phase as 1D as an assumption. The assumption was justified by experimental observation. They modeled the gas 
phase physics by solving the 2D Navier-Stokes equations coupled with the conservation equations of continuity, energy and species which were adapted for the gas phase.

Figure 19 shows some of the model results when confronted with experimental data. The three stages in terms of the MLR are; the first stage represents the increase of MLR that is observed just after ignition, the second stage as the temperature rises, PMMA begins to melt and the MLR slightly increases followed by complete transformation of the solid PMMA into a liquid and the apparition of the MLR peak due to the heat feedback from the insulation block. Alternatively, the three stages can be explained by considering the heat transfer in the problem. There is an initial steep ramp rate, followed by a flattening of the curve as a near equilibrium surface boundary condition is reached, and finally a sharp peak associated with rapid heating of the thin slab of remaining material. These stages in PMMA combustion are clearly captured by the model as well as the peak of mass loss rate that is observed at the final stages which is attributed to the heat feedback from the insulation block.

In general, all of the mass loss rate (MLR) results from the model agreed well with experiments except for the scenario where a $20 \mathrm{~mm}$ thick sample was exposed to an external heat flux of $25 \mathrm{~kW} / \mathrm{m}^{2}$ (Figure 6(a)). The modeling results showed higher MLR than the experiment and it was explained as follows. During the experiment, the $20 \mathrm{~mm}$ thick sample only melted and it did not produce any flame during burning. This might also show that the critical heat flux of PMMA is higher than $25 \mathrm{~kW} / \mathrm{m}^{2}$ in the auto-ignition regime.
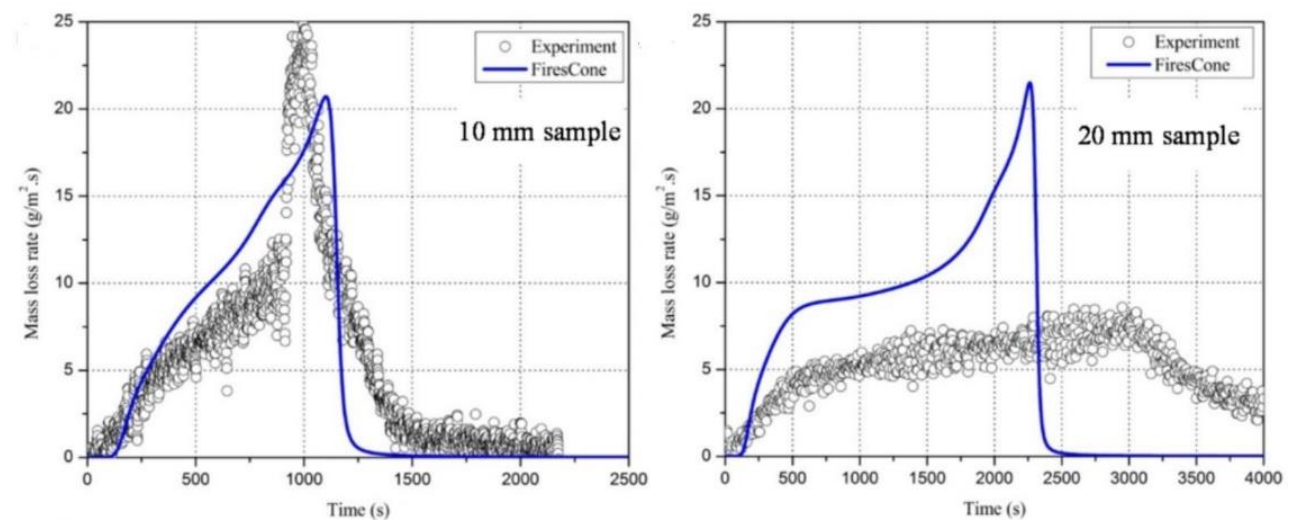

(a)
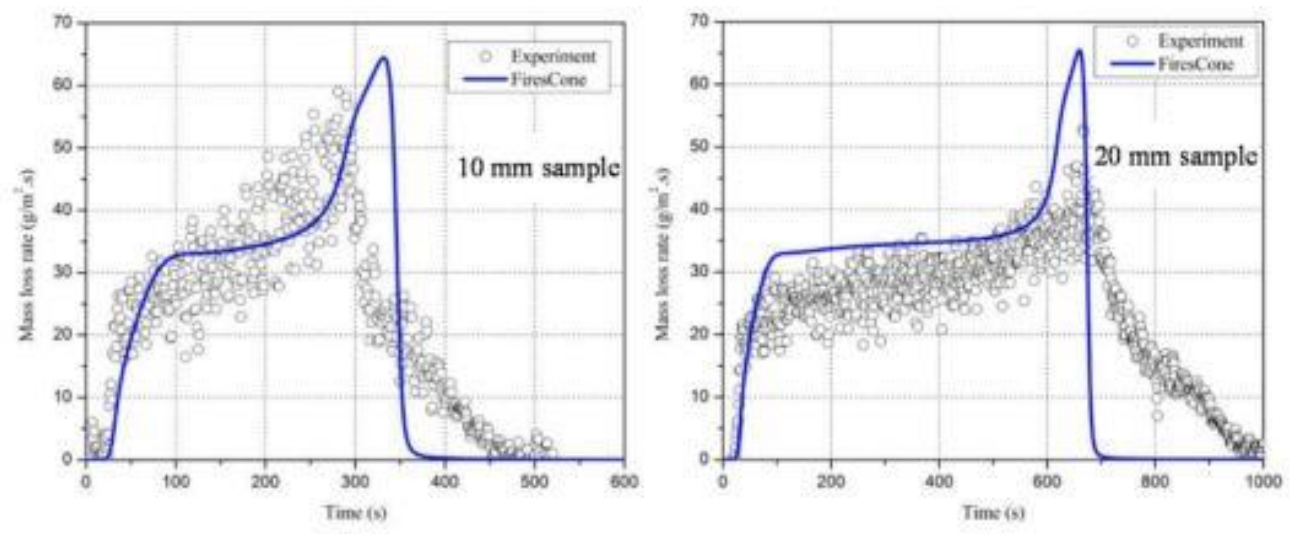
(b)

Figure 19. Modeling results when confronted with experimental data under different heat fluxes (a) under $25 \mathrm{~kW} / \mathrm{m}^{2}$ and (b) under $75 \mathrm{~kW} / \mathrm{m}^{2}$ [71].

Di Blasi et al. [186] investigated the ignition of PMMA exposed to a radiative heat flux using a 1D model. The model took into account different phenomena that was occurring in both the solid material and the flame. The phenomena taken into account in the condensed phase were heat transfer by conduction, pyrolysis, in-depth radiation absorption as well as the regression of the sample surface. In the gas phase, combustion, transport phenomena and radiation absorption was taken into account. The model was able to qualitatively simulate the time-to-ignition as compared to experimental data at different heat fluxes when acceptable absorption coefficients in the gas phase were applied. When low values of the absorption coefficients in the gas phase were in the range 0.01-0.06 atm $\mathrm{am}^{-1}$, a strong dependence between the time-to-ignition and the intensity of the radiative heat flux was observed. It was the opposite for higher values suggesting that the times to ignition were associated to the heating of the material. The values taken for the gas phase absorption coefficient were indicative to those found in literature. The sensitivity of the ignition phenomenon to parameters related to absorption of radiation and kinetics were also investigated. Ignition was greatly influenced by the kinetics implemented for the flame and material pyrolysis. The influence was strong at low values of radiation absorption as compared to higher values. They concluded that a 2D model would provide improved results since the 1D model did not take into account effects caused by convection.

Esfahani et Kashani [187] also modeled the combustion of PMMA using a 1D model and considered the solid and gas phases. The input parameters used were not temperature dependent. The influence of the concentration of oxygen and the radiative heat flux was then investigated. Oxygen had an influence only on the temperature distribution in the gas phase and the radiative heat flux had an influence on both phases. Since the model was simplistic, they concluded that a more complex model taking into account mechanisms such as surface regression would improve the model. Bal and Rein [117] focused mainly on the effect of physical and chemical processes on modeling the pyrolysis of PMMA. They observed that the kinetic scheme was sensitive to MLR and not the temperature on the surface of the sample whereas heat transfer processes had significant effect on both parameters. Zong et al. [188] investigated the pyrolysis of acrylonitrile butadiene styrene (ABS) under various experimental conditions of heat flux and pressure deficient atmosphere. A 1D pyrolysis model was used to simulate the experiment. The model agreed well with experimental results at greater values of heat flux because in this case the temperature profiles and MLR were hardly affected by the pressure as compared to low values of heat flux. Linteris et al. [42] worked on modeling four different thermoplastic materials using FDS and Thermakin. These polymers were chosen because of their complex fire behavior. The input material properties were experimentally determined. Uncertainties were observed and their effects explored by sensitivity analyses, the results were discussed in the 'sensitivity analysis' section. The results from both programs were confronted with experimental data. In general, for PET, the results agreed only in the first instance up to around 150s because of its fire behavior. For POM, the results only agreed by fitting them using the heat of reaction while for the case of PA66 and PP, the results 
corresponded well for the greater part of the duration of the computation. A summary of some of the models is illustrated in Table 5.

Table 5. Summary of comprehensive pyrolysis models for non-charring materials

\begin{tabular}{|c|c|c|c|c|}
\hline Author & $\begin{array}{l}\text { Numerical } \\
\text { code/ } \\
\text { Method }\end{array}$ & $\begin{array}{l}\text { Kinetic } \\
\text { scheme/m } \\
\text { ethod }\end{array}$ & Material & Comments on sensitivity/ parameters \\
\hline $\begin{array}{l}\text { Stoliarov et al. } \\
{[92]}\end{array}$ & Thermakin & $\begin{array}{l}\text { Multi- } \\
\text { step, First } \\
\text { order } \\
\text { reactions }\end{array}$ & $\begin{array}{l}\text { PMMA } \\
\text { HIPS } \\
\text { HDPE }\end{array}$ & $\begin{array}{l}\text {-Potential sources of discrepancies } \\
\text { between model and experiments included } \\
\text { uncertainties in material properties, } \\
\text { sensitivity of experimental conditions (e.g. } \\
\text { time to ignition). }\end{array}$ \\
\hline Shi et al. [71] & FiresCone & Multi-step & PMMA & $\begin{array}{l}\text {-The grid spacing }<0.1 \mathrm{~mm} \text { did not have } \\
\text { effect on the output parameters on the solid } \\
\text { phase i.e. } \\
\text { temperature of the surface and MLR. }\end{array}$ \\
\hline $\begin{array}{l}\text { Di Blasi et al. } \\
{[186]}\end{array}$ & $\begin{array}{l}\text { Finite } \\
\text { Difference }\end{array}$ & First order & PMMA & $\begin{array}{l}\text {-Sensitivity of kinetic and radiation } \\
\text { absorption parameters with respect to } \\
\text { ignition was conducted. }\end{array}$ \\
\hline $\begin{array}{l}\text { Esfahani and } \\
\text { Kashani [187] }\end{array}$ & $\begin{array}{l}\text { Finite } \\
\text { Volume }\end{array}$ & $\begin{array}{l}\text { One-step } \\
\text { global, } \\
\text { first order }\end{array}$ & PMMA & $\begin{array}{l}\text {-The influence of the concentration of } \\
\text { oxygen and the radiative heat flux was then } \\
\text { investigated. Oxygen had an influence only } \\
\text { on the temperature distribution in the gas } \\
\text { phase and the radiative heat flux had an } \\
\text { influence on both phases. }\end{array}$ \\
\hline $\begin{array}{l}\text { Girardin et al. } \\
{[38,76]}\end{array}$ & COMSOL & $\begin{array}{l}\text { Multi- } \\
\text { step, nth } \\
\text { order }\end{array}$ & $\begin{array}{l}\text { EVA/AT } \\
\mathrm{H} / \mathrm{NC}\end{array}$ & $\begin{array}{l}\text {-Parameters were experimentally } \\
\text { determined and were validated against } \\
\text { temperature on the backside of the material } \\
\text { as well as the MLR. } \\
\text {-The diffusion of the gases did not have a } \\
\text { significant effect on the temperature but } \\
\text { rather on the mass loss curves. } \\
\text {-It was observed that the assumption of } \\
\text { slow diffusion of pyrolyzates is required to } \\
\text { model the gasification of EVA/ATH. }\end{array}$ \\
\hline $\begin{array}{l}\text { Bal and Rein } \\
\text { [117] }\end{array}$ & Gpyro & Multi-step & PMMA & $\begin{array}{l}\text {-A range of models for the decomposition } \\
\text { of PMMA were compared with the } \\
\text { objective investigating their sensitivity to } \\
\text { heat, mass and chemical processes. }\end{array}$ \\
\hline $\begin{array}{l}\text { Linteris et al. } \\
{[42]}\end{array}$ & $\begin{array}{l}\text { FDS/ } \\
\text { Thermakin }\end{array}$ & First order & $\begin{array}{l}\text { PET } \\
\text { PP } \\
\text { PA } \\
\text { POM }\end{array}$ & $\begin{array}{l}\text {-Material properties were measured by } \\
\text { independent laboratory tests and } \\
\text { uncertainties were observed and the effects } \\
\text { of the uncertainties were explored through } \\
\text { sensitivity analyses. }\end{array}$ \\
\hline
\end{tabular}

(PMMA - poly(methylmethacrylate), HIPS - high-impact polystyrene, HDPE - high-density polyethylene, EVA/ATH/NC - ethylene vinyl acetate copolymer/aluminum tri- 
hydroxide/nanoclay, PET - polyethylene terephthalate, POM - polyoxymethylene, PP polypropylene, PA - polyamide 6,6 )

The melting phenomenon has been thermodynamically included in several pyrolysis models. For example, Li et al. [153] represented the melting of POM by including a first order reaction which occurs at $455 \mathrm{~K}$ as well as the associated heat of reaction. Similarly, Shi et al. [71] used the Arrhenius model to incorporate the melting of PMMA. Melt flow has generally not been included in the cone calorimetry or gasification experiments for horizontally oriented samples because it is not significant. However, in vertically oriented samples, samples experience flame spread and melt flow can be significant and this is what affects the burning behavior of a material [189]. Therefore, for such experiments it has been taken into account in the pyrolysis models $[190,191]$.

\section{B. Charring materials}

Modeling charring materials is complicated because of the char formation. This is because the physical and chemical processes in charring involve complex kinetic mechanisms that may include "many separate intermediate steps" such as multi-step primary and secondary reactions [19, 21]. Moreover, charring materials may also evolve dynamically thereby causing changes in morphology (e.g. shrinkage and cracking). The changes in morphology have an effect on pyrolysis modeling and it should be recommended to take them into account so as to improve the accuracy of pyrolysis models $[192,193]$. Processes such as cracking are not included in Gpyro, Thermakin and FDS but maybe taken into account by using submodels [14, 70, 72]. Shen at al. [194] derived formulas for cracking of wood from an experimental study which can be readily implemented into pyrolysis model. Li et al. [195] studied the char cracking of medium density fiberboard and used FDS to model pyrolysis and modeled the mechanical process separately. Some charring materials such as polyurethane foam undergo smoldering combustion which further complicates the modeling process because the chemical kinetics needs to be explicitly described. An insight on this phenomena is presented by Rein [33].

Polycarbonate (PC) and poly-vinyl chloride (PVC) are considered here as charring even though they expand to form a carbonaceous structure. Shi et al. [71] studied the fire behavior of polycarbonate using FiresCone under a cone calorimeter. Experimentally, the polymer swelled irregularly resulting in poor repeatability (also observed by Stoliarov et al. [15]). Even though, the numerical results reasonably corresponded with experimental results. The experimental curves were unstable what was not the case for the predicted data because the model did not take into account the phenomena (e.g. irregular expansion) involved when the polymer was dynamically evolving. Stoliarov et al. [15] investigated the pyrolysis of PC and PVC using Thermakin. Figure 20 shows the numerical vs the experimental results and Figure 21 shows the samples after being heat at $75 \mathrm{~kW} / \mathrm{m}^{2}$ for $200 \mathrm{~s}$. Considering the errors observed during the experiments, the model performed reasonably well. They proposed that in order to improve the numerical predictions, 3D effects should be taken into account in modeling the fire behavior of the materials. 

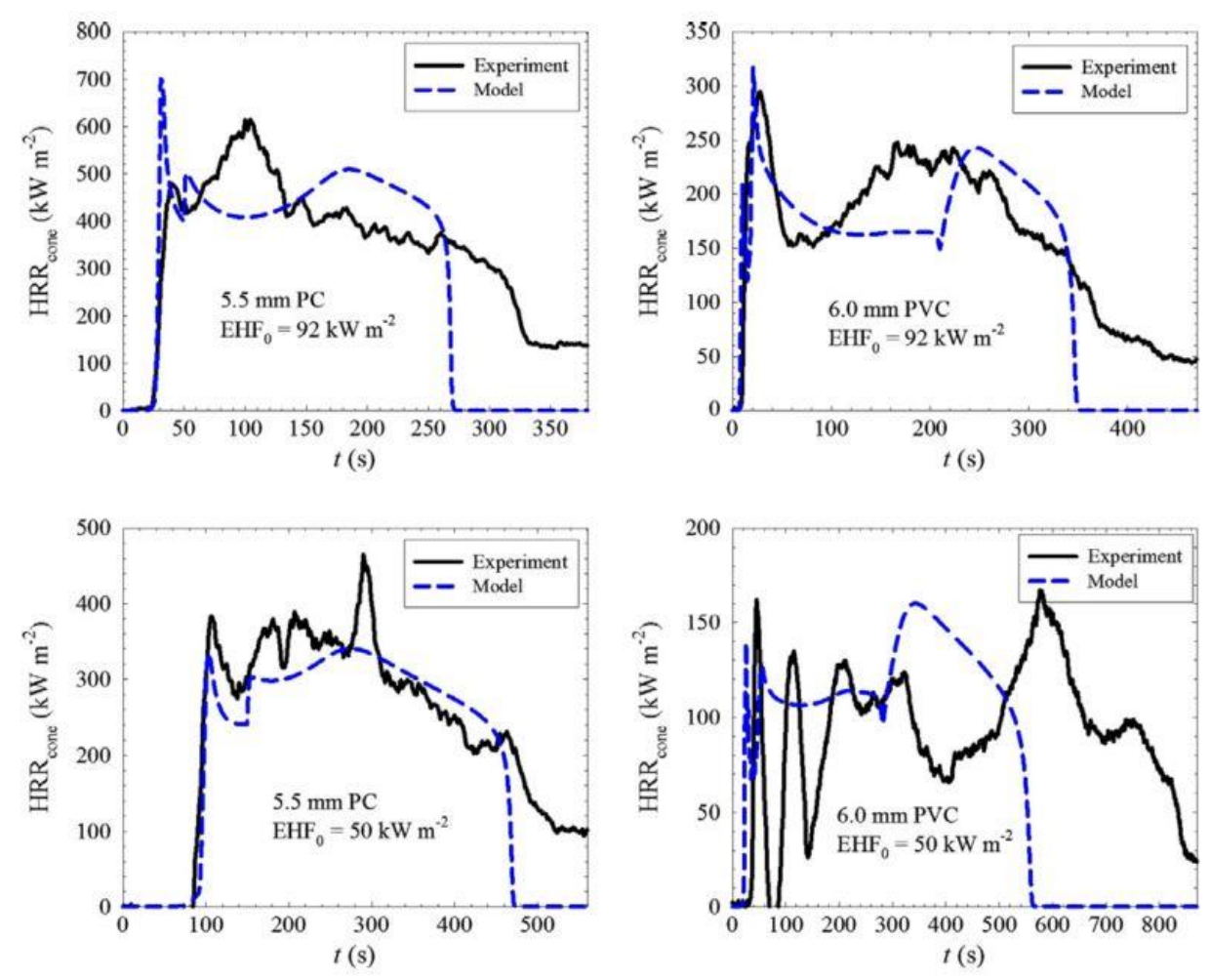

Figure 20. Numerical vs experimental results HRR at external heat flux $=50$ and $92 \mathrm{~kW} / \mathrm{m}^{2}$ on 5.5 and $6 \mathrm{~mm}$ thick samples [15].
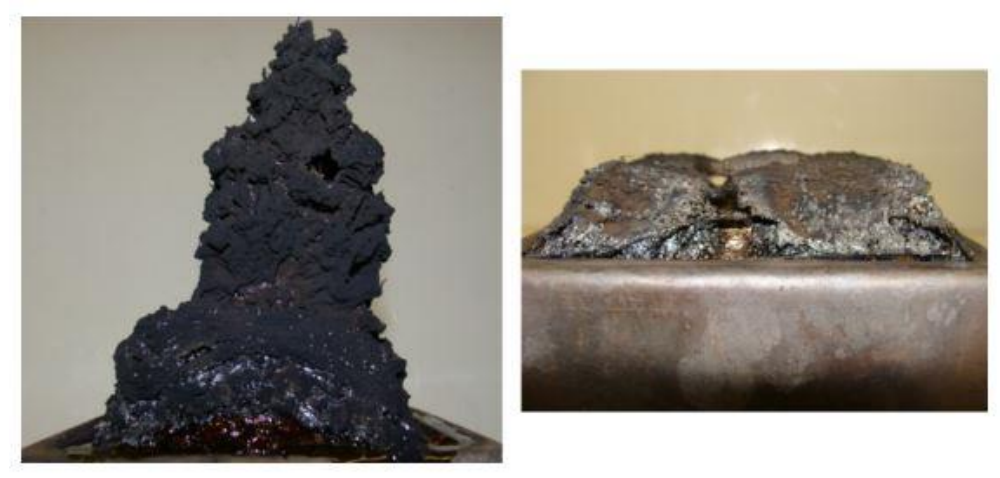

Figure 21. PC (left) and PVC (right) after exposure to a heat flux of $75 \mathrm{~kW} / \mathrm{m}^{2}$ for 200 s (initial thickness of samples was $6 \mathrm{~mm}[15]$.

Salvador et al. [156] developed a pyrolysis model for the combustion of a porous medium (cardboard and polyethylene). The standard cone calorimeter was used to provide the sample of the materials with an external heat flux of $50 \mathrm{~kW} / \mathrm{m}^{2}$ [196]. A sensitivity analysis was conducted to understand the influence of the parameters related to the exposed surface boundary condition i.e. the emissivity, heat transfer coefficient, view factor, ambient temperature and cone temperature on the solution. The authors stated that all these parameters had an impact on the solution (i.e. the mass loss rate and temperature evolution at different in-depth locations). Nevertheless, the cone temperature was the most influencing parameter. Unfortunately, although no quantifiable data was 
provided, it can be concluded that the study showed that the boundary conditions needed to be well understood to improve the accuracy of the model. Most of the input parameters for the model were obtained through experimental measurements [196] except for the tortuosity and the thermal conductivity of the char which were obtained by optimization because they were almost impossible to be directly measured. A summary of some models is shown in Table 6.

Table 6. Examples of comprehensive pyrolysis models for charring materials

\begin{tabular}{|l|l|l|l|l|}
\hline Author & Software/method & $\begin{array}{l}\text { Kinetic } \\
\text { Scheme/method }\end{array}$ & Material & $\begin{array}{l}\text { Comments on Sensitivity/ } \\
\text { Parameter estimation }\end{array}$ \\
\hline Shi et al.[71] & FiresCone & Multi-step & PC & $\begin{array}{l}\text {-The grid spacing }<0.1 \mathrm{~mm} \\
\text { did not have effect on the } \\
\text { output parameters on the } \\
\text { solid phase i.e. } \\
\text { temperature of the surface } \\
\text { and MLR. }\end{array}$ \\
\hline $\begin{array}{l}\text { Stoliarov et al. } \\
{[15]}\end{array}$ & ThermaKin & $\begin{array}{l}\text { One global, first } \\
\text { order(PC) } \\
\text { Multi-step } \\
\text { (PVC) }\end{array}$ & PC, PVC & $\begin{array}{l}\text {-A large number of the } \\
\text { thermophysical properties } \\
\text { used as inputs in the model } \\
\text { were measured. } \\
\text {-Model sensitivity } \\
\text { uncertainties was conducted. }\end{array}$ \\
\hline $\begin{array}{l}\text { Salvador et al. } \\
{[156]}\end{array}$ & Finite Difference & $\begin{array}{l}\text { Multi-step } \\
\text { (cardboard) } \\
\text { One global } \\
\text { step(PE) }\end{array}$ & PE & $\begin{array}{l}\text {-Sensitivity was conducted } \\
\text { on emissivity, heat transfer } \\
\text { coefficient, view factor, } \\
\text { ambient temperature and } \\
\text { cone temperature. Cone } \\
\text { temperature was the most } \\
\text { influencing parameter. }\end{array}$ \\
\hline
\end{tabular}

$\mathrm{PC}$ - polycarbonate, $\mathrm{PVC}$ - poly(vinyl chloride), $\mathrm{PE}$ - polyethylene.

Nakabe et al. [197] developed a model for the study on ignition and transition to flame spread on a thermally-thin cellulosic sheet. The material was considered to be exposed to an external radiative heat flux under a quiescent microgravity atmosphere. The model took into account pyrolysis in the solid phase by considering 3 global decomposition reactions and a one-step global oxidation reaction for the gas phase. They observed that for a 30\% oxygen concentration, there was autoignition but no transition to flame spread until 50\%. More recent research works on the flame spread of charring materials include that of medium density fiberboard (MDF) [74] and corrugated cardboard [166] using FireFoam.

\section{Intumescent coatings}

Intumescent materials expand or swell to form a carbonaceous char of low conductivity when exposed to fire. Their expansion is therefore an important parameter that should be considered when modeling their fire behavior [198]. One of the earliest models to numerically represent the physical and chemical phenomena of an intumescent coating when exposed to an external flux was presented by Anderson et al. [199] in 1984. In this model, expansion was explicitly taken into 
account by assuming it to be dependent on the mass loss. In 1985, Anderson et al. [200] conducted complementary work but this time they implemented a frontal model. Over the past decades, several pyrolysis models of intumescent materials have been developed in literature varying from simple models $[199,201]$ to complex models involving multi-step reaction mechanisms [107, 149, 202, 203]. Griffin [107] reviewed and discussed the limitations of the intumescent models including those of Anderson. The main limitations included 1) the one dimensionality of the models given that the intumescent materials do not expand symmetrically during bench scale tests, 2) the unavailability of a complete set of temperature-dependent thermophysical properties, 3) the use of expansion factors to represent the swelling because of the not-so-well understood processes etc. These limitations often result in discrepancies between model predictions and experimental results. In the same paper, the author presented a model considering oxidation and a different approach for expansion. Expansion was taken into account by considering that it happens during the period of gas evolution and when the material has an acceptable viscosity for gas accumulation. A sensitivity analysis was then conducted to understand the thermal performance of the coating. The results are shown in Figure 22. The influence of the number of bubbles $\left(n_{b u b}\right)$ on the temperature of the substrate is also shown (line 5 and line 6). It is highlighted that a change in $\left(n_{b u b}\right)$ can induce a difference of $\left(>100^{\circ} \mathrm{C}\right)$ consequently showing the role of heat transfer by radiation. Line 4 shows the result when expansion is taken differently as in the present model. Line 2 and 3 shows the effect of combustion on the model.

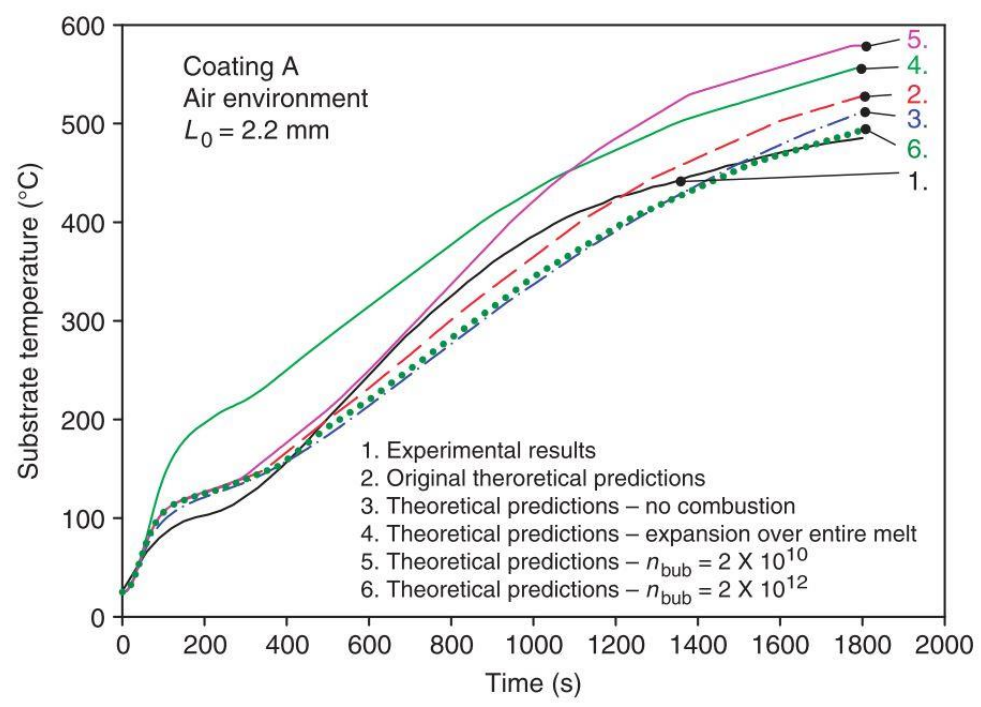

Figure 22. Sensitivity of the predicted substrate temperatures [107].

Staggs [202] developed a model that used a different kinetic scheme as compared to that used by other researchers such as Di Blasi and Branca [149], Di Blasi [203], and Griffin [107]. In this work a competitive one was used instead of parallel and only the kinetics involved in expansion was taken into account to describe the intumescent phenomena. Observations from the study emphasized the need to understand the phenomena that drives expansion and more work is required in the general modeling of this process. 
Different approaches to implement the swelling of a coating exist in literature. Zhang et al. [204, 205] took into account the swelling of the intumescent coating by considering the gas released from the chemical reaction of the blowing agent. The expansion was assumed to happen within a temperature range i.e. the temperature when the coating starts to melt and the temperature when the material has charred and no expansion was observed. Cirpici et al. [206] developed an analytical model for the swelling of materials that intumesce based on the bubble theory proposed by Amon and Denson [207]. The model was validated against experimental results under different fire conditions. Nyazika et al. [77] experimentally determined the swelling of a silicone-based intumescent coating using an infrared camera then implemented the swelling profile in the numerical model using the Arbitrary Lagrangian-Eulerian (ALE) Method. Furthermore, Okyay et al. [208] recently proposed a new approach by applying the theory of fractals and random nature events to conceptualize the expansion of different intumescent coatings. Other researchers have assumed that the fire behavior of an intumescent system can be assumed to be equivalent to a material going through phase change [209, 210].

On the other hand, Thermakin takes into account the intumescent phenomena by "scaling the contribution of gases to the overall volume by a factor related to the local composition" [211]. Li et al. [29] studied intumescent polymers namely poly(acrylonitrile butadiene styrene) (ABS), poly(ethylene terephthalate) (PET), poly(methyl methacrylate)-poly(vinyl chloride) alloy (Kydex) and polyetherimide (PEI). The experiments were conducted using a cone calorimeter in controlled gasification conditions and ThermaKin was used for the pyrolysis models. They observed that both Kydex and PEI highly intumesced. Between the two highly intumescent polymers, PEI exhibited a higher swelling rate. Their study incorporated swelling into the pyrolysis models and also took into account changes in the radiative exposure of the material samples associated with this swelling. Generally, the comparison between experimental and predicted results were good for all materials except for Kydex and PEI due to its their high swelling rates thereby inducing significant errors associated boundary conditions (Figure 23). Since the model was 1D, they suggested that a model with higher dimension would improve the results as well as some solid mechanics. 

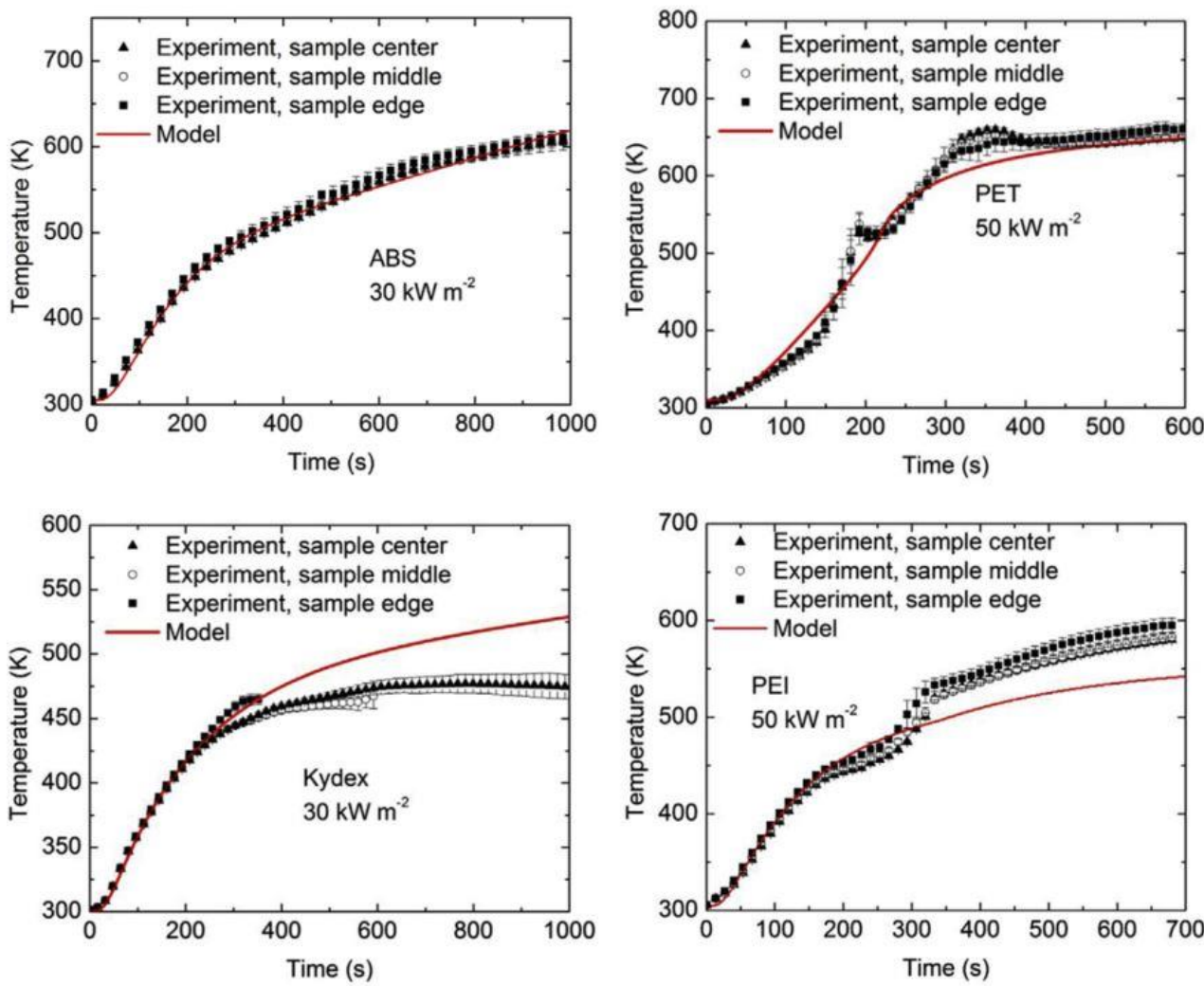

Figure 23. Comparison between the experimental and predicted temperature profiles at the bottom surface for radiant heat fluxes of $30 \mathrm{kWm}^{-2}$ and $50 \mathrm{kWm}^{-2}$ [29].

A summary of some models is shown in Table 7. It can be clearly noticed that there is no convention on the expansion mechanism considered in the models. It should be noted, even though some models do not implement a specific kinetic scheme, they do include coupling of conservation equations with an expansion sub-model which takes into account the chemical reactions.

Table 7. Summary of comprehensive pyrolysis models for intumescent materials.

\begin{tabular}{|l|l|l|l|}
\hline Author & $\begin{array}{l}\text { Kinetic } \\
\text { Scheme }\end{array}$ & Material & $\begin{array}{l}\text { Comments on the expansion } \\
\text { mechanism/sensitivity/parameter } \\
\text { estimation }\end{array}$ \\
\hline $\begin{array}{l}\text { Anderson and } \\
\text { Wauters [199] }\end{array}$ & - & Coating & $\begin{array}{l}\text {-Expansion assumed to be a function of mass } \\
\text { loss. } \\
- \text { TGA and DSC data were used to determine } \\
\text { the kinetics and thermodynamics of the } \\
\text { decomposition process using Fourier series. }\end{array}$ \\
\hline Shih et al. [209] & - & Coating & $\begin{array}{l}\text {-Analogous to a phase change process. } \\
\text { Di Blasi and } \\
\text { Branca [149] }\end{array}$ \\
\hline
\end{tabular}




\begin{tabular}{|c|c|c|c|}
\hline & & & $\begin{array}{l}\text { and Arrhenius parameters on the temperature } \\
\text { of the substrate. }\end{array}$ \\
\hline Griffin [107] & $\begin{array}{l}\text { Multi-step, } \\
\text { parallel } \\
\text { reactions }\end{array}$ & Coating & $\begin{array}{l}\text {-Gas forming during melting and stopping at } \\
\text { char formation + bubbles. } \\
\text { - The influence of the number of bubbles } \\
\left(n_{\text {bub }}\right) \text { on the temperature of the substrate } \\
\text { showed the role of heat transfer by radiation. } \\
\text { - Arrhenius parameters obtained using } \\
\text { Levenberg-Marqaudt algorithm. }\end{array}$ \\
\hline Staggs et al.[202] & $\begin{array}{l}\text { Multi- } \\
\text { step/competitive } \\
\text { reactions }\end{array}$ & Coating & $\begin{array}{l}\text {-The degradation step producing gas was } \\
\text { taken as the one driving expansion. }\end{array}$ \\
\hline Di Blasi [203] & $\begin{array}{l}\text { Independent } \\
\text { global reactions }\end{array}$ & Coating & $\begin{array}{l}\text {-Bubble dynamics and material swelling } \\
\text { sensitivity }\end{array}$ \\
\hline Gillet [212] & $\begin{array}{l}\text { COMSOL / one } \\
\text { global step, first } \\
\text { order }\end{array}$ & Coating & $\begin{array}{l}\text {-Expansion considered using expansion } \\
\text { factor } \\
\text {-Conducted sensitivity analysis (screening } \\
\text { and sensitivity coefficients) }\end{array}$ \\
\hline $\begin{array}{l}\text { Nyazika et al. } \\
\text { [77] }\end{array}$ & $\begin{array}{l}\text { COMSOL / one } \\
\text { step nth order }\end{array}$ & Coating & $\begin{array}{l}\text {-Expansion was determined experimentally } \\
\text { using an infrared camera then implemented } \\
\text { in COMSOL using ALE. } \\
\text {-Thermal properties were experimentally } \\
\text { determined for the virgin coating. }\end{array}$ \\
\hline Li et al.[29] & $\begin{array}{l}\text { Thermakin/ } \\
\text { semi-global }\end{array}$ & $\begin{array}{l}\text { ABS, PET, } \\
\text { Kydex, PEI }\end{array}$ & $\begin{array}{l}\text {-Swelling was taken into account in the } \\
\text { ThermaKin framework. } \\
\text {-Their model was based on fitting the model } \\
\text { to experimental results using the } \\
\text { methodology described in the optimization } \\
\text { section were the MLR was not used as fitting } \\
\text { targets but instead were for model validation. }\end{array}$ \\
\hline Butler et al. [213] & - & $\begin{array}{l}\text { Intumescent } \\
\text { material }\end{array}$ & $\begin{array}{l}\text {-The intumescent material was treated as a } \\
\text { highly viscous fluid. } \\
\text {-Swelling was considered using a growth rate } \\
\text { model based on bubbles at microscopic level. } \\
\text { The growth of the bubbles was dependent on } \\
\text { the gas released by the chemical } \\
\text { decomposition of the blowing agent as well as } \\
\text { the properties of the viscous fluid. } \\
\text {-The complete model coupled different } \\
\text { submodels including hydrodynamics, bubble } \\
\text { growth, and heat transfer }\end{array}$ \\
\hline Zhang et al. [204] & $\begin{array}{l}\text { Independent } \\
\text { global reactions }\end{array}$ & Coating & $\begin{array}{l}\text {-Gas released by the chemical reaction of the } \\
\text { blowing agent drives the expansion } \\
\text { mechanism }\end{array}$ \\
\hline
\end{tabular}




\section{CONCLUSIONS}

This paper reviewed the pyrolysis modeling methodologies used to simulate the fire behavior of combustible solids with emphasis on sensitivity analysis and the optimization techniques. The capability of pyrolysis models to predict the fire behavior of materials with reasonable accuracy has been demonstrated.

Both thermal and comprehensive models have been developed. Thermal models have shown to be computationally faster than comprehensive ones because they use a small number of parameters therefore their parameterization requires a smaller number of calibration experiments. However, generalized comprehensive pyrolysis models are more representative of the pyrolysis phenomena have been validated with reasonable accuracy for non-charring, charring and intumescent materials and sometimes taking into account phenomena of smoldering. For intumescent materials, expansion has been considered differently in the pyrolysis models depending on the modeler. The main problem is the not-so-well understood phenomena that drives expansion and some modelers have resorted to including fitting parameters which do not necessarily have a physical meaning. Indeed, a comprehensive understanding of the fire behavior of materials at experimental level is required first so as to improve the current models. Even though 1D model formulations have a low run cost, $2 \mathrm{D}$ or $3 \mathrm{D}$ models are more reliable and accurate.

Numerical techniques such as sensitivity analysis and optimization have become necessary. Several sensitivity methods have successfully been used and they have become a powerful tool in understanding the model responses to the input parameters. SA has proved to be useful in pyrolysis modeling by allowing the study of the response of a model based on its input parameters. It can guide the development and optimization of better pyrolysis models. Nevertheless, it is noteworthy that the SA results are model specific and depends on the experimental conditions: it should be analyzed depending on the modeled case. In addition, there is a lack of generality in the methodologies when conducting sensitivity studies which can make it difficult to determine the 'true' important parameters.

Optimization techniques have been successfully used to obtain model input parameters. Gradientbased algorithms are much more efficient for small problems involving a few number of parameters. When there are many parameters, experimental measurements can be used to reduce the number of parameters to be estimated. They have successfully been implemented but the major drawback like any other optimization techniques is in attaining the global optimum. Problems in attaining this optimum have been often attributed to errors that arise from the selected initial values. To counter these drawbacks, modern evolutionary algorithms have often been implemented. However, these evolutionary algorithms are based on heuristic and they are not optimized for problems involving a few number of parameters because they are time consuming [214]. Amongst the most used evolutionary algorithms (GA, SCE and SHC), the SCE method has proved to perform very well probably because it combines the strength of Nelder-Mead method (downhill simplex), controlled random search, genetic algorithm and complex shuffling [158, 172]. More advanced optimization techniques are starting to gain attention to overcome some 
obstacles, for example, coupling the Kissinger's method with GA where the Kissinger's method is first used to search for the possible initial parameters and then these parameters are fed into the GA accelerating the process. Combining these optimization techniques helps in reducing their drawbacks thereby increasing their efficiency. Moreover, to improve the optimization results the modeler can also fit a combined set of bench-scale data for example TGA data and cone calorimeter data. Systematic approaches involving several experimental data and decoupling the individual processes in pyrolysis have also been developed. It is noteworthy that the selected optimization technique and final model validation are highly important.

As the comprehensive understanding of the fire behavior of materials at experimental level continues to improve together with the modeling techniques, further understanding of the complex pyrolysis phenomena should be achieved.

\section{Acknowledgements}

This work has received funding from the European Research Council (ERC) under the European Union's H2020 - the Framework programme for Research and Innovation (2014-2020) / ERC Grant Agreement n670747 - ERC 2014 AdG/FireBar-Concept.

\section{References}

1. Sinha, S., Jhalani, A., Ravi, M., and Ray, A. (2000) Modelling of Pyrolysis in Wood - A Review, SESI Journal 10:1-17.

2. Kim, M., E. and Dembsey, N.A., Engineering Guide for Estimating Material Pyrolysis Properties for Fire Modeling, 2012, Worcester Polytechnic Institute.

3. Valencia, B.L. (2009) Experimental and numerical investigation of the thermal decomposition of materials at three scales: applicatiion to polyether polyurethane foam used in upholstered furniture), $\mathrm{PhD}$, Ecole Nationale Supérieure de Mécanique et d'Aérotechnique

4. Guillaume, E., Camillo, A., and Rogaume, T. (2013) Application and Limitations of a Method Based on Pyrolysis Models to Simulate Railway Rolling Stock Fire Scenarios, Fire Technology 50:317-348, http://dx.doi.org/10.1007/s10694-013-0379-9.

5. Price, D., M. , Hourston, D., J., and Dumont, F. ( 2000) Thermogravimetry of Polymers, Encyclopedia of Analytical Chemistry:8094-8105.

6. Staggs, J.E.J. (2007) Population balance models for the thermal degradation of PMMA, Polymer 48:3868-3876, http://dx.doi.org/10.1016/j.polymer.2007.04.075.

7. Kim, E., Lautenberger, C., and Dembsey, N., Property estimation for pyrolysis modeling applied to polyester FRP, in 11th International Conference and Exhibition2009: London.

8. Azhakesan, A.M., Shields, T.J., and Silcock, G.W.H. "Developments on the Fire Propagation Test," Fire Safety Science - Proceedings of the fourth international symposium.

9. Chaos, M., Khan, M.M., Krishnamoorthy, N., de Ris, J.L., and Dorofeev, S.B. (2011) Evaluation of optimization schemes and determination of solid fuel properties for CFD fire models using bench-scale pyrolysis tests, Proceedings of the Combustion Institute 33:2599-2606, http://dx.doi.org/10.1016/j.proci.2010.07.018. 
10. Girods, P., Bal, H., Biteau, H., Rein, G., and Torero, J. (2011) Comparison of Pyrolysis Behavior Results between the Cone Calorimeter and the Fire Propagation Apparatus Heat Sources, Fire Safety Science 10:889-901, http://dx.doi.org/10.3801/iafss.fss.10-889.

11. Quintiere, J.G. (1981) A simplified theory for generalizing results from a radiant panel rate of flame spread apparatus, Fire and Materials 5.

12. Guillaume, E., Didieux, F., Thiry, A., and Bellivier, A. (2014) Real-scale fire tests of one bedroom apartments with regard to tenability assessment, Fire Safety Journal 70:81-97, http://dx.doi.org/10.1016/j.firesaf.2014.08.014.

13. Stoliarov, S. and Lyon, R. (2008) Thermo-Kinetic Model of Burning for Pyrolyzing Materials, Fire Safety Science 9:1141-1152, http://dx.doi.org/10.3801/iafss.fss.9-1141.

14. Lautenberger, C. and Fernandez-Pello, C. (2009) Generalized pyrolysis model for combustible solids, Fire Safety Journal 44:819-839, http://dx.doi.org/10.1016/j.firesaf.2009.03.011.

15. Stoliarov, S.I., Crowley, S., Walters, R.N., and Lyon, R.E. (2010) Prediction of the burning rates of charring polymers, Combustion and Flame 157:2024-2034, http://dx.doi.org/10.1016/j.combustflame.2010.03.011.

16. Stoliarov, S.I., Leventon, I.T., and Lyon, R.E. (2014) Two-dimensional model of burning for pyrolyzable solids, Fire and Materials 38:391-408, http://dx.doi.org/10.1002/fam.2187.

17. Di Blasi C. (1993) Modelling and simulation of combustion processes of charring and noncharring solid fuels, Progress in Energy and Combustion Science 19:71-104.

18. Di Blasi, C., Galgano, A., and Branca, C. (2013) Modeling the thermal degradation of poly(methyl methacrylate)/carbon nanotube nanocomposites, Polymer Degradation and Stability 98:266-275, http://dx.doi.org/10.1016/j.polymdegradstab.2012.10.001.

19. Di Blasi, C. (2000) The state of the art of transport models for charrirng solid degradation, Polymer International 49:1133-1146.

20. Snegirev, A.Y., Talalov, V.A., Stepanov, V.V., and Harris, J.N. (2013) A new model to predict pyrolysis, ignition and burning of flammable materials in fire tests, Fire Safety Journal 59:132-150, http://dx.doi.org/10.1016/j.firesaf.2013.03.012.

21. Staggs, J. (2000) Simple mathematical models of char-forming polymers, Polymer International 49:1147 \pm 1152 .

22. Moghtaderi, B. "Pyrolysis of char forming solid fuels - A critical review of the matematical modelling techniques " 5th AOSFST. 2001. Newcastle, Australia.

23. Moghtaderi, B. (2006) The state-of-the-art in pyrolysis modelling of lignocellulosic solid fuels, Fire and Materials 30:1-34, http://dx.doi.org/10.1002/fam.891.

24. Lautenberger, C. and Fernandez-Pello, A.C., Pyrolysis modeling, thermal decomposition, and transport processes in combustible solids, in Transport Phenomena in Fires, M.F.a.B. Sunden, Editor. 2008, WIT Press.

25. Vermina Lundström, F., van Hees, P., and Guillaume, É. (2017) A review on prediction models for full-scale fire behaviour of building products, Fire and Materials 41:225-244, http://dx.doi.org/10.1002/fam.2380.

26. Kashiwagi, T. "Polymer combustion and flammability-role of the condensed phase," Proceedings of the Combustion Institute. 1994.

27. Lyon, R.E. and Janssens, M.L. Polymer Flammability. DOT/FAA/AR-05/14, 2005.

28. Lautenberger, C. (2014) Gpyro3D: A Three Dimensional Generalized Pyrolysis Model, Fire Safety Science 11:193-207, http://dx.doi.org/10.3801/iafss.fss.11-193. 
29. Li, J., Gong, J., and Stoliarov, S.I. (2015) Development of pyrolysis models for charring polymers, Polymer Degradation and Stability 115:138-152, http://dx.doi.org/10.1016/j.polymdegradstab.2015.03.003.

30. Shi, L. and Chew, M.Y.L. (2013) A review of fire processes modeling of combustible materials under external heat flux, Fuel 106:30-50, http://dx.doi.org/10.1016/j.fuel.2012.12.057.

31. Ohlemiller, T.J. (1985) Modeling of smoldering combustion propagation, Progress in Energy and Combustion Science 11:277-310.

32. Mouritz, A.P., et al. (2009) Review of fire structural modelling of polymer composites, Composites Part A: Applied Science and Manufacturing 40:1800-1814, http://dx.doi.org/10.1016/j.compositesa.2009.09.001.

33. Rein, G. (2009) Smouldering Combustion Phenomena in Science and Technology, International Review of Chemical Engineering 1:3-18.

34. Rein, G., Smouldering Combustion, in SFPE Handbook of Fire Protection Engineering. 2016. p. 581-603.

35. Chaos, M. (2013) Application of sensitivity analyses to condensed-phase pyrolysis modeling, Fire Safety Journal 61:254-264, http://dx.doi.org/10.1016/j.firesaf.2013.09.016.

36. Ramroth, W.T., Krysl, P., and Asaro, R.J. (2006) Sensitivity and uncertainty analyses for FE thermal model of FRP panel exposed to fire, Composites Part A: Applied Science and Manufacturing 37:1082-1091, http://dx.doi.org/10.1016/j.compositesa.2005.01.031.

37. Stoliarov, S.I., Safronava, N., and Lyon, R.E. (2009) The effect of variation in polymer properties on the rate of burning, Fire and Materials 33:257-271, http://dx.doi.org/10.1002/fam.1003.

38. Girardin, B., Fontaine, G., Duquesne, S., Forsth, M., and Bourbigot, S. (2015) Characterization of Thermo-Physical Properties of EVA/ATH: Application to Gasification Experiments and Pyrolysis Modeling, Materials (Basel) 8:7837-7863, http://dx.doi.org/10.3390/ma8115428.

39. Gardelle, B., Duquesne, S., Vandereecken, P., and Bourbigot, S. (2013) Characterization of the carbonization process of expandable graphite/silicone formulations in a simulated fire, Polymer Degradation and Stability 98:1052-1063, http://dx.doi.org/10.1016/j.polymdegradstab.2013.02.001.

40. Kim, E. and Dembsey, N. (2014) Parameter Estimation for Comprehensive Pyrolysis Modeling: Guidance and Critical Observations, Fire Technology 51:443-477, http://dx.doi.org/10.1007/s10694-014-0399-0.

41. Staggs, J.E.J. (2010) Thermal conductivity estimates of intumescent chars by direct numerical simulation, Fire Safety Journal 45:228-237, http://dx.doi.org/10.1016/j.firesaf.2010.03.004.

42. Linteris, G.T., Lyon, R.E., and Stoliarov, S.I. (2013) Prediction of the gasification rate of thermoplastic polymers in fire-like environments, Fire Safety Journal 60:14-24, http://dx.doi.org/10.1016/j.firesaf.2013.03.018.

43. Meunders, A., Baker, G., B., Arnold, L., Schröder, B., Spearpoint, M., and Pau, D., Parameter Optimization and Sensitivity Analysis for FDS modelling, in 10th International Conference on Performance-Based Codes and Fire Safety 2014: Brisbane, Australia. 
44. Lautenberger, C., Rein, G., and Fernandez-Pello, C. (2006) The application of a genetic algorithm to estimate material properties for fire modeling from bench-scale fire test data, Fire Safety Journal 41:204-214, http://dx.doi.org/10.1016/j.firesaf.2005.12.004.

45. Moghtaderi, B., Novozhilov, V., Fletcher, D., and Kent, J.H. (1997) An Integral Model for the Transient Pyrolysis of solid materials, Fire and Materials 21:7-16.

46. Theuns, E., Merci, B., Vierendeels, J., and Vandevelde, P. (2005) Critical evaluation of an integral model for the pyrolysis of charring materials, Fire Safety Journal 40:121-140, http://dx.doi.org/10.1016/j.firesaf.2004.09.003.

47. Theuns, E., Merci, B., Vierendeels, J., and Vandevelde, P. (2005) Extension and evaluation of the integral model for transient pyrolysis of charring materials, Fire and Materials 29:195-212, http://dx.doi.org/10.1002/fam.878.

48. Chen, Y., Delichatsios, M.A., and Motvalli, V. (1993) Material Pyrolysis Properties, Part I: An Integral Model for One-Dimensional Transient Pyrolysis of Charring and NonCharring Materials, Combustion Science and Technology 88:309-328, http://dx.doi.org/10.1080/00102209308947242.

49. Weng, W.G. and Fan, W.C. (2007) A pyrolysis model of charring materials considering the effect of ambient oxygen concentration, Fire and Materials 31:463-475, http://dx.doi.org/10.1002/fam.954.

50. Rhodes, B.T. and Quintiere, J.G. (1996) Burning rate and flame heat flux for PMMA in a cone calorimeter, Fire Safety Journal 26:221-240.

51. Hopkins, D. and Quintiere, J.G. (1996) Material fire properties and predictions for thermoplastics, Fire Safety Journal 26:221-240.

52. Moghtaderi, B., Novozhilov, V., Fletcher, D.F., and Kent, J.H. "An integral model for the pyrolysis of non-charring material," International Association for Fire Safety Science. 2006.

53. Theuns, E., Vierendeels, J., and Vandevelde, P. (2004) Validation of the integral model for the pyrolysis of charring materials with a moving grid, Journal of Computational and Applied Mathematics 168:471-479, http://dx.doi.org/10.1016/j.cam.2003.12.013.

54. Quintiere, J.G., A Semi-Quantitative Model for the Burning Rate of Solid Materials, 1992, National Institute of Standards and Technology.

55. Quintiere, J.G. and Iqbal, N. (1994) An approximate Integral Model for the Burning Rate of a Thermoplastic Material, Fire and Materials 18:89-98.

56. Spearpoint, M.J. and Quintiere, J.G. (2000) Predicting the Burning of Wood Using an Integral Model, Combustion and Flame 123:308-324.

57. Steckler, K., D., Kashiwagi, T., Baum, H., and Kanemaru, K. "Analytical model for Transient gasification of Non-charring Thermoplastics materials," Fire Safety Science-Proceedings of the 3rd International Symposium. IAFSS. 1991. Boston, USA.

58. Ghorbani, Z., Webster, R., Lázaro, M., and Trouvé, A. (2013) Limitations in the predictive capability of pyrolysis models based on a calibrated semi-empirical approach, Fire Safety Journal 61:274-288.

59. Bamford, C., Crank, J., and Malan, D. (1946) The combustion of wood. Part I, Mathematical Proceedings of the Cambridge Philosophical Society 42:162-182, http://dx.doi.org/10.1017/.

60. Roberts, A.F. and Clough, G. (1963) Thermal decomposition of wood in an inert atmosphere, Symposium (International) on Combustion 9:158-166. 
61. Tinney, E.R., The combustion of wooden dowels in heated air, in 10th International Symposium on Combustion1965: Pittsburgh.

62. Matsumoto, T., Fujiwara, T., and Kondo, J. (1969) Nonsteady thermal decomposition of plastics, Symposium (International) on Combustion.

63. Wilson, R.G., Thermophysical properties of six charring ablators from $140^{\circ}$ to $700^{\circ} \mathrm{K}$ and two chars from $800^{\circ}$ to $3000^{\circ} \mathrm{K}, 1965$, NASA: Washington D. C.

64. Kung, H.C. (1972) A mathematical model of wood pyrolysis Combustion and Flame 18:185-195.

65. Kansa, E.J., Perlee, H.E., and Chaiken, R.F. (1977) Mathematical Model of Wood Pyrolysis Including internal forced convection, Combustion and Flame 29:311-324.

66. Henderson, J.B., Wiebelt, J.A., and Tant, M.R. (1985) A Model for the Thermal Response of Polymer Composite materials with Experimental verification, Journal of Composite Materials 19:579-595.

67. Henderson, J.B. and Wiecek, T.E. (1987) A Mathematical Model to Predict the Thermal Response of Decomposing, Expanding Polymer Composites, Journal of Composite Materials 21:373-393, http://dx.doi.org/10.1177/002199838702100406.

68. Vovelle, C., Delfau, J.-L., Reuillon, M., Bransier, J., and Laraqui, N. (1987) Experimental and Numerical Study of the Thermal Degradation of PMMA, Combustion Science and Technology 53:187-201, http://dx.doi.org/10.1080/00102208708947026.

69. Lautenberger, C. (2007) A Generalized Pyrolysis Model for Combustible Solids), PhD, University of California

70. Snegirev, A., Talalov, V., Stepanov, V., and Harris, J. (2012) A new model to predict multistage pyrolysis of flammable materials in standard fire tests, Journal of Physics: Conference Series 395:012012, http://dx.doi.org/10.1088/1742-6596/395/1/012012.

71. Shi, L., Chew, M., Novozhilov, V., and Joseph, P. (2015) Modeling the Pyrolysis and Combustion Behaviors of Non-Charring and Intumescent-Protected Polymers Using "FiresCone", Polymers 7:1979-1997, http://dx.doi.org/10.3390/polym7101495.

72. McGrattan, K., Hostikka, S., Floyd, J., Baum, H., Rehm, R., Mell, W., and McDermott, R. Fire Dynamics Simulator (Version 5)Technical Reference Guide. National Institute ofStandards and Technology Special Publication, 2007. 1.

73. ; Available from: https://github.com/fireFoam-dev.

74. Zeinali, D., et al. "Computational Analysis of Pyrolysis and Flame Spread for MDF Panels Placed in a Corner Configuration," Eighth International Seminar on Fire and Explosion Hazards (ISFEH8). DOI: 10.20285/c.sklfs.8thISFEH.039.

75. Statler, D.L. and Gupta, R.K., A Finite Element Analysis on the Modeling of Heat Release Rate, in COMSOL Conference2008: Boston, MA, USA.

76. Girardin, B., Fontaine, G., Duquesne, S., Försth, M., and Bourbigot, S. (2017) Measurement of kinetics and thermodynamics of the thermal degradation for flame retarded materials: Application to EVA/ATH/NC, Journal of Analytical and Applied Pyrolysis 124:130-148, http://dx.doi.org/10.1016/j.jaap.2016.12.034.

77. Nyazika, T., Jimenez, M., Samyn, F., and Bourbigot, S. (2018) Modeling heat transfers across a silicone-based intumescent coating, Journal of Physics: Conference Series 1107:032012, http://dx.doi.org/10.1088/1742-6596/1107/3/032012.

78. Kempel, F., Schartel, B., Linteris, G.T., Stoliarov, S.I., Lyon, R.E., Walters, R.N., and Hofmann, A. (2012) Prediction of the mass loss rate of polymer materials: Impact of 
residue formation, Combustion and Flame 159:2974-2984, http://dx.doi.org/10.1016/j.combustflame.2012.03.012.

79. Linteris, G.T. (2011) Numerical simulations of polymer pyrolysis rate: Effect of property variations, Fire and Materials 35:463-480, http://dx.doi.org/10.1002/fam.1066.

80. Witkowski, A., et al. (2015) Development of an anaerobic pyrolysis model for fire retardant cable sheathing materials, Polymer Degradation and Stability 113:208-217, http://dx.doi.org/10.1016/j.polymdegradstab.2015.01.006.

81. Stoliarov, S.I. and Walters, R.N. (2008) Determination of the heats of gasification of polymers using differential scanning calorimetry, Polymer Degradation and Stability 93:422-427, http://dx.doi.org/10.1016/j.polymdegradstab.2007.11.022.

82. Lautenberger, C. and Fernandez-Pello, A. (2011) Optimization Algorithms for Material Pyrolysis Property Estimation, Fire Safety Science 10:751-764, http://dx.doi.org/10.3801/iafss.fss.10-751.

83. Gustafsson, S.E. (1991) Transient plane source techniques for thermal conductivity and thermal diffusivity measurements of solid materials, Review of Scientific Instruments 62:797-804, http://dx.doi.org/10.1063/1.1142087.

84. Bohac, V., Gustavsson, M.K., Kubicar, L., and Gustafsson, S.E. (2000) Parameter estimations for measurements of thermal transport properties with the hot disk thermal constants analyzer, Review of Scientific Instruments 71:2452-2455, http://dx.doi.org/10.1063/1.1150635.

85. Suleiman, B.M., Gustafsson, S.E., and Börjesson, L. (1996) A practical cryogenic resistive sensor for thermal conductivity measurements, Sensors and Actuators A 57:15-19.

86. Parker, W.J., Jenkins, R.J., Butler, C.P., and Abbott, G.L. (1961) Flash Method of Determining Thermal Diffusivity, Heat Capacity, and Thermal Conductivity, Journal of Applied Physics 32:1679-1684, http://dx.doi.org/10.1063/1.1728417.

87. Cowan, R.D. (1963) Pulse Method of Measuring Thermal Diffusivity at High Temperatures, Journal of Applied Physics 34:926-927, http://dx.doi.org/10.1063/1.1729564.

88. Cape, J.A. and Lehman, G.W. (1963) Temperature and Finite Pulse-Time Effects in the Flash Method for Measuring Thermal Diffusivity, Journal of Applied Physics 34:19091913, http://dx.doi.org/10.1063/1.1729711.

89. Mehling, H., Hautzinger, G., Nilsson, O., Fricke, J., Hofmann, R., and Hahn, O. (1998) Thermal difusivity of semitransparent materials determined by the laser -flash method applying a new analytical model, International Journal of Thermophysics 19:941-949.

90. Li, J. and Stoliarov, S.I. (2013) Measurement of kinetics and thermodynamics of the thermal degradation for non-charring polymers, Combustion and Flame 160:1287-1297, http://dx.doi.org/10.1016/j.combustflame.2013.02.012.

91. Li, J. and Stoliarov, S.I. (2014) Measurement of kinetics and thermodynamics of the thermal degradation for charring polymers, Polymer Degradation and Stability 106:2-15, http://dx.doi.org/10.1016/j.polymdegradstab.2013.09.022.

92. Stoliarov, S.I., Crowley, S., Lyon, R.E., and Linteris, G.T. (2009) Prediction of the burning rates of non-charring polymers, Combustion and Flame 156:1068-1083, http://dx.doi.org/10.1016/j.combustflame.2008.11.010.

93. Lobo, H. and Cohen, C. (1990) Measurement of Thermal Conductivity of Polymer Melts by the Line-source Method, Polymer Engineering \& Science 30:65-70. 
94. Tsilingiris, P.T. (2003) Comparative evaluation of the infrared transmission of polymer films, Energy Conversion and Management 44:2839-2856, http://dx.doi.org/10.1016/s0196-8904(03)00066-9.

95. Hallman, J.R. and Welker, J.R. (1974) Polymer Surface Reflectance-Absorptance Characteristics, Polymer Engineering \& Science 14:717-723.

96. Muller, M. (2012) Systematic approach of the synergism in flame retarded intumescent polyurethanes), $\mathrm{PhD}$, University of Lille 1

97. Tranchard, P., Samyn, F., Duquesne, S., Estebe, B., and Bourbigot, S. (2017) Modelling Behaviour of a Carbon Epoxy Composite Exposed to Fire: Part I-Characterisation of Thermophysical Properties, Materials (Basel) 10, http://dx.doi.org/10.3390/ma10050494.

98. De Ris, J.L. and Khan, M.M. (2000) A Sample Holder for Determining Material Properties, Fire and Materials 24:219-226.

99. Calabrese, L., Bozzoli, F., Bochicchio, G., Tessadri, B., Vocale, P., and Rainieri, S. (2015) Parameter estimation approach to the thermal characterization of intumescent fire retardant paints, Journal of Physics: Conference Series 655:012048, http://dx.doi.org/10.1088/1742-6596/655/1/012048.

100. Kim, E. (2014) Parameter Estimation Methods for Comprehensive Pyrolysis Modeling), $\mathrm{PhD}$, Worcester Polytechnic Institute

101. Stoliarov, S.I. and Li, J. (2015) Parameterization and Validation of Pyrolysis Models for Polymeric Materials, Fire Technology 52:79-91, http://dx.doi.org/10.1007/s10694-0150490-1.

102. Bruns, M.C. (2015) Inferring and Propagating Kinetic Parameter Uncertainty for Condensed Phase Burning Models, Fire Technology 52:93-120, http://dx.doi.org/10.1007/s10694-015-0457-2.

103. Levenberg, K. (1944) A method for the solution of certain non-linear problems in least squares, Quarterly of Applied Mathematics 2:164-168.

104. Marquardt, D.W. (1963) An algorithm for least-squares estimation of non linear parameters, Journal of the Society for Industrial and Applied Mathematics 11:431-441.

105. Ferriol, M., Gentilhomme, A., Cochez, M., Oget, N., and Mieloszynski. Thermal degradation of PMMA : Modelling of DTG and TG curves, Polymer Degradation and Stability 79:271-181.

106. Mamleev, V. and Bourbigot, S. (2005) Modulated thermogravimetry in analysis of decomposition kinetics, Chemical Engineering Science 60:747-766, http://dx.doi.org/10.1016/j.ces.2004.08.044.

107. Griffin, G.J. (2009) The Modeling of Heat Transfer across Intumescent Polymer Coatings, Journal of Fire Sciences 28:249-277, http://dx.doi.org/10.1177/0734904109346396.

108. Reverte, C., Dirion, J.-L., and Cabassud, M. (2007) Kinetic model identification and parameters estimation from TGA experiments, Journal of Analytical and Applied Pyrolysis 79:297-305.

109. Loulou, T., Salvador, S., and Dirion, J.L. (2003) Determination of Reaction Parameters for Cardboard Thermal Degradation Using Experimental Data, Chemical Engineering Research and Design 81:1265-1270, http://dx.doi.org/10.1205/026387603770866489.

110. Calabrese, L., Bozzoli, F., Bochicchio, G., Tessadri, B., Rainieri, S., and Pagliarini, G. (2014) Thermal characterization of intumescent fire retardant paints, Journal of Physics: Conference Series 547:012005, http://dx.doi.org/10.1088/1742-6596/547/1/012005. 
111. Bozzoli, F., Mocerino, A., Rainieri, S., and Vocale, P. (2018) Inverse heat transfer modeling applied to the estimation of the apparent thermal conductivity of an intumescent fire retardant paint, Experimental Thermal and Fluid Science 90:143-152, http://dx.doi.org/10.1016/j.expthermflusci.2017.09.006.

112. Scott, E.P. and Beck, J.V. (1992) Estimation of Thermal Properties in Carbon-Epoxy Composite Materials during Curing, Journal of Composite Materials 26.

113. Pau, D., Fleischmann, C., Spearpoint, M., and Li, K. (2014) Sensitivity of Heat of Reaction for Polyurethane Foams, Fire Safety Science 11:179-192, http://dx.doi.org/10.3801/iafss.fss.11-179.

114. Marquis, D.M., Batiot, B., Guillaume, E., and Rogaume, T. (2016) Influence of reaction mechanism accuracy on the chemical reactivity prediction of complex charring material in fire condition, Journal of Analytical and Applied Pyrolysis 118:231-248, http://dx.doi.org/10.1016/j.jaap.2016.02.007.

115. Richter, F. and Rein, G. (2017) Pyrolysis kinetics and multi-objective inverse modelling of cellulose at the microscale, Fire Safety Journal 91:191-199, http://dx.doi.org/10.1016/j.firesaf.2017.03.082.

116. Bal, N. (2012) Uncertainty and complexity in pyrolysis modelling), University of Edinburgh

117. Bal, N. and Rein, G. (2013) Relevant model complexity for non-charring polymer pyrolysis, Fire Safety Journal 61:36-44, http://dx.doi.org/10.1016/j.firesaf.2013.08.015.

118. Bal, N. and Rein, G. (2015) On the effect of inverse modelling and compensation effects in computational pyrolysis for fire scenarios, Fire Safety Journal 72:68-76, http://dx.doi.org/10.1016/j.firesaf.2015.02.012.

119. Rein, G., Carlos Fernandez-Pello, A., and Urban, D.L. (2007) Computational model of forward and opposed smoldering combustion in microgravity, Proceedings of the Combustion Institute 31:2677-2684, http://dx.doi.org/10.1016/i.proci.2006.08.047.

120. Ohlemiller, T.J. Modeling of Smoldering Combustion Propagation. NBSIR 84-2895, 1984.

121. Vyazovkin, S. and Wight, C., A. (1998) Isothermal and non-isothermal kinetics of thermally stimulated reaction of solids, International Reviews in Physical Chemistry 17:407-433.

122. E698-11, A., Standard Test Method for Kinetic Parameters for Thermally Unstable Materials by Differential Scanning Calorimetry Using the Kissinger Method, A. International, Editor 2012: West Conshohocken, PA,.

123. Vyazovkin, S., et al. (2014) ICTAC Kinetics Committee recommendations for collecting experimental thermal analysis data for kinetic computations, Thermochimica Acta 590:123, http://dx.doi.org/10.1016/j.tca.2014.05.036.

124. Jain, A.A., Mehra, A., and Ranade, V.V. (2016) Processing of TGA data: Analysis of isoconversional and model fitting methods, Fuel 165:490-498, http://dx.doi.org/10.1016/j.fuel.2015.10.042.

125. Opfermann, J.R., Kaisersberger, E., and Flammersheim, H.J. (2002) Model-free analysis of thermoanalytical data-advantages and limitations, Thermochim Acta 391:119-27.

126. Khawam, A. and Flanagan, D.R. (2006) Basics and applications of solid-state kinetics: a pharmaceutical perspective, J Pharm Sci 95:472-98, http://dx.doi.org/10.1002/jps.20559.

127. Brown, M.E., et al. (2000) Computational aspects of kinetic analysis - Part A The ICTAC kinetics project-data, methods and results, Thermochimica Acta 355:125-143. 
128. Roduit, B. (2000) Computational aspects of kinetic analysis. Part E - The ICTAC Kinetics Project - numerical techniques and kinetics of solid state processes, Thermochimica Acta 355:171-180.

129. Ozawa, T. (1965) A New Method of Analyzing Thermogravimetric Data, Bull. Chem. Soc. Jpn. 38:1881-1886.

130. Coats, A.W. and Redfern, J.P. (1964) Kinetic Parameters from Thermogravimetric Data, Nature 201:68-69.

131. Vyazovkin, S. and Wight, C., A. (1997) Kinetics of solids, Annu Rev Phys Chem. 48:12549.

132. Vyazovkin, S., Burnham, A.K., Criado, J.M., Pérez-Maqueda, L.A., Popescu, C., and Sbirrazzuoli, N. (2011) ICTAC Kinetics Committee recommendations for performing kinetic computations on thermal analysis data, Thermochimica Acta 520:1-19, http://dx.doi.org/10.1016/j.tca.2011.03.034.

133. Mani, T., Murugan, P., and Mahinpey, N. (2009) Determination of Distributed Activation Energy Model Kinetic Parameters Using Simulated Annealing Optimization Method for Nonisothermal Pyrolysis of Lignin, Ind. Eng. Chem. Res. 48:1464-1467.

134. Rein, G., Lautenberger, C., Fernandezpello, A., Torero, J., and Urban, D. (2006) Application of genetic algorithms and thermogravimetry to determine the kinetics of polyurethane foam in smoldering combustion, Combustion and Flame 146:95-108, http://dx.doi.org/10.1016/j.combustflame.2006.04.013.

135. Li, K.-Y., Huang, X., Fleischmann, C., Rein, G., and Ji, J. (2014) Pyrolysis of MediumDensity Fiberboard: Optimized Search for Kinetics Scheme and Parameters via a Genetic Algorithm Driven by Kissinger's Method, Energy \& Fuels 28:6130-6139, http://dx.doi.org/10.1021/ef501380c.

136. Song, C., Parameter estimation of the pyrolysis model for fir based on particle swarm algorithm, in Second International Conference on Mechanic Automation and Control Engineering2011.

137. Park, W.-H. and Yoon, K.-B. (2013) Optimization of pyrolysis properties using TGA and cone calorimeter test, Journal of Thermal Science 22:168-173, http://dx.doi.org/10.1007/s11630-013-0608-z.

138. Park, W.-H., Yoon, K.-B., Chang, H.-C., and Kim, T.-K. (2012) Estimation of pyrolysisrelated properties using repulsive particle swarm optimization, Journal of Mechanical Science and Technology 26:2129-2132, http://dx.doi.org/10.1007/s12206-012-0529-x.

139. Khawam, A. and Flanagan, D.R. (2006) Solid-state kinetic models: basics and mathematical fundamentals, $J$ Phys Chem $B$ 110:17315-28, http://dx.doi.org/10.1021/jp062746a.

140. Burnham, A.K. and L., B.R. (1999) Global Kinetic Analysis of Complex Materials, Energy and Fuels 13.

141. Tranchard, P., Duquesne, S., Samyn, F., Estèbe, B., and Bourbigot, S. (2017) Kinetic analysis of the thermal decomposition of a carbon fibre-reinforced epoxy resin laminate, Journal of Analytical and Applied Pyrolysis 126:14-21, http://dx.doi.org/10.1016/j.jaap.2017.07.002.

142. Bourbigot, S., Gilman, J.W., and Wilkie, C.A. (2004) Kinetic analysis of the thermal degradation of polystyrene-montmorillonite nanocomposite, Polymer Degradation and Stability 84:483-492, http://dx.doi.org/10.1016/j.polymdegradstab.2004.01.006. 
143. Rogaume, T. (2018) Thermal decomposition of solid fuels. Objectives, challenges and modelling, Journal of Physics: Conference Series 1107:022001, http://dx.doi.org/10.1088/1742-6596/1107/2/022001.

144. Opfermann, J. (2000) Kinetic Analysis Using Multivariate Non-linear Regression. I. Basic concepts, Journal of Thermal Analysis and Calorimetry 60 641-658.

145. Anderson, H.L., Kemmler, A., and Strey, R. (1996) Comparison of different non-linear evaluation methods in thermal analysis, Thermochimica Acta 271:23-29.

146. Bruns, M.C., Koo, J.H., and Ezekoye, O.A. (2009) Population-based models of thermoplastic degradation: Using optimization to determine model parameters, Polymer Degradation and Stability 94:1013-1022, http://dx.doi.org/10.1016/j.polymdegradstab.2009.02.007.

147. Ceamanos, J., Mastral, J.F., Millera, A., and Aldea, M.E. (2002) Kinetics of pyrolysis of high density polyethylene. Comparison of isothermal and dynamic experiments, Journal of Analytical and Applied Pyrolysis 65:93-110.

148. Koga, N. ( 1994) A review of the mutual dependence of Arrhenius parameters evaluated by the thermoanalytical study of solid reactions_the kinetic compensation effect, Thermochimica Acta 244 1-20

149. Di Blasi, C. and Branca, C. (2001) Mathematical Model for the Nonsteady Decomposition of Intumescent Coatings, AIChE J. 47:2359-2370.

150. Rozycki, C. (1984) Comparison of methods of determining Arrhenius evaluation of parameters by Least Squares Method Journal of Thermal Analysis and Calorimetry 29 959963.

151. Lyon, R.E. (2000) Heat Release Kinetics, Fire and Materials 24:179-186.

152. Stoliarov, S.I. and Lyon, R.E., Thermo-Kinetic Model of Burning, 2008, U.S. Department of Transportation, Federal Aviation Administration.

153. Li, J., Gong, J., and Stoliarov, S.I. (2014) Gasification experiments for pyrolysis model parameterization and validation, International Journal of Heat and Mass Transfer 77:738744, http://dx.doi.org/10.1016/j.ijheatmasstransfer.2014.06.003.

154. Oztekin, E.S., Crowley, S.B., Lyon, R.E., Stoliarov, S.I., Patel, P., and Hull, T.R. (2012) Sources of variability in fire test data: A case study on poly(aryl ether ether ketone) (PEEK), Combustion and Flame 159:1720-1731, http://dx.doi.org/10.1016/j.combustflame.2011.11.009.

155. McKinnon, M.B., Stoliarov, S.I., and Witkowski, A. (2013) Development of a pyrolysis model for corrugated cardboard, Combustion and Flame 160:2595-2607, http://dx.doi.org/10.1016/j.combustflame.2013.06.001.

156. Salvador, S., Quintard, M., and David, C. (2008) Combustion of a substitution fuel made of cardboard and polyethylene: influence of the mix characteristics-modeling, Fire and Materials 32:417-444, http://dx.doi.org/10.1002/fam.978.

157. Webster, R. (2009) Pyrolysis model parameter optimization using a customized stochastic hill-climber algorithm and bench scale fire test data), MS Thesis, University of Maryland

158. Duan, Q.Y., Gupta, V.K., and Sorooshian, S. (1993) Shuffled Complex Evolution Approach for Effective and Efficient Global Minimization, Journal of Optimization Theory and Application 76:501-521.

159. Houck, C., Joines, J.A., and Kay, M.G., A Genetic Algorithm for Function Optimization A Matlab Implementation, 1995. 
160. Jimenez, M., Duquesne, S., and Bourbigot, S. (2006) Characterization of the performance of an intumescent fire protective coating, Surface and Coatings Technology 201:979-987, http://dx.doi.org/10.1016/j.surfcoat.2006.01.026.

161. Matala, A., Hostikka, S., and Mangs, J. (2008) Estimation of pyrolysis model parameters for solid materials using thermogravimetric data, Fire Safety Science 9:1213-1223, http://dx.doi.org/10.3801/iafss.fss.9-1213.

162. Lefebvre, J., Duquesne, S., Mamleev, V., Bras, M.L., and Delobel, R. (2003) Study of the kinetics of pyrolysis of a rigid polyurethane foam: use of the invariant kinetics parameters method, Polymers for Advanced Technologies 14:796-801, http://dx.doi.org/10.1002/pat.397.

163. Lautenberger, C. and Fernandez-Pello, A. "Optimization Algorithms for Material Pyrolysis Property Estimation," Fire Safety Science - Proceedings of the Tenth International symposium. 2011. DOI: 10.3801/iafss.fss.10-751.

164. Chen, Y., Motevalli, V., and Delichatsios, M.A. (1995) Material Pyrolysis Properties, Part II: Methodology for the Derivation of Pyrolysis Properties for Charring Materials, Combustion Science and Technology 104:401-425, http://dx.doi.org/10.1080/00102209508907730.

165. Ding, Y., Wang, C., and Lu, S. (2015) Modeling the pyrolysis of wet wood using FireFOAM, Energy Conversion and Management 98:500-506, http://dx.doi.org/10.1016/j.enconman.2015.03.106.

166. Chaos, M., Khan, M., M „, Krishnamoorthy, N., Chatterjee, P., Wang, Y., and Dorofeev, S.B. "Experiments and modeling of single- and triple-wall corrugated cardboard: Effective material properties and fire behavior," Fire and Materials. 2011. San Francisco, California USA: Interscience Communications.

167. Ghorbani, Z., Webster, R., Lázaro, M., and Trouvé, A., Critical evaluation of parameter estimation techniques for pyrolysis of charring materials, in 8th U. S. National Combustion Meeting2013: University of Utah.

168. Capote, J., Alvear, D., Abreu, O., Lazaro, M., and Puente, E. (2011) Pyrolysis Characterization of a Lineal Low Density Polyethylene, Fire Safety Science 10:877-888, http://dx.doi.org/10.3801/iafss.fss.10-877.

169. Marquis, D.M., Guillaume, E., Camillo, A., Rogaume, T., and Richard, F. (2013) Existence and uniqueness of solutions of a differential equation system modeling the thermal decomposition of polymer materials, Combustion and Flame 160:818-829, http://dx.doi.org/10.1016/j.combustflame.2012.12.008.

170. Marquis, D.M. and Guillaume, É. (2011) Modelling Reaction-to-fire of Polymer-based Composite Laminate, http://dx.doi.org/10.5772/21688.

171. Lauer, P., Trettin, C., and Wittbecker, F.W. Performance of optimization algorithms for deriving material data from bench scale tests.

172. Iraa, J., Hasalováa, L., and Jahodaa, M. "The use of optimization techniques for estimation of pyrolysis model input," Application of Structural Fire Engineering. 2013. Prague, Czech Republic

173. Saha, B., Reddy, P.K., and Ghoshal, A.K. (2008) Hybrid genetic algorithm to find the best model and the globally optimized overall kinetics parameters for thermal decomposition of plastics, Chemical Engineering Journal 138:20-29, http://dx.doi.org/10.1016/j.cej.2007.05.024. 
174. Najafi, H. and Woodbury, K.A. (2015) Online heat flux estimation using artificial neural network as a digital filter approach, International Journal of Heat and Mass Transfer 91:808-817, http://dx.doi.org/10.1016/j.ijheatmasstransfer.2015.08.010.

175. Ding, Y., McKinnon, M.B., Stoliarov, S.I., Fontaine, G., and Bourbigot, S. (2016) Determination of kinetics and thermodynamics of thermal decomposition for polymers containing reactive flame retardants: Application to poly(lactic acid) blended with melamine and ammonium polyphosphate, Polymer Degradation and Stability 129:347362, http://dx.doi.org/10.1016/j.polymdegradstab.2016.05.014.

176. Rabitz, H. (1981) Chemical sensitivity analysis theory with applications to molecular dynamics and kinetics, Computers \& Chemirlry 5:167-180.

177. Rabitz, H., Kramer, M., and Dacol, D. (1983) Sensitivity analysis in chemical kinetics, Ann. Rev. Phys. Chern. 34:419-61.

178. Hamby, D.M. (1994) A review of techniques for parameter sensitivity analysis of environmental models, Environmental Monitoring and Assessment 32:135-154.

179. Batiot, B., Rogaume, T., Collin, A., Richard, F., and Luche, J. (2016) Sensitivity and uncertainty analysis of Arrhenius parameters in order to describe the kinetic of solid thermal degradation during fire phenomena, Fire Safety Journal 82:76-90, http://dx.doi.org/10.1016/j.firesaf.2016.03.007.

180. Saltelli, A., Tarantola, S., Campolongo, F., and Ratto, M., Sensitivity Analysis - A Guide to assessing scientific models. 2004: John Wiley \& Sons.

181. Galgano, A., Di Blasi, C., Ritondale, S., and Todisco, A. (2014) Numerical simulation of the glowing combustion of moist wood by means of a front-based model, Fire and Materials 38:639-658, http://dx.doi.org/10.1002/fam.2203.

182. Stoliarov, S., Crowley, S., and Lyon, R., Prediction of the burning rates of noncharring polymers, 2009, U.S. Department of Transportation, Federal Aviation Administration.

183. Linteris, G., Zammarano, M., Wilthan, B., and Hanssen, L. (2012) Absorption and reflection of infrared radiation by polymers in fire-like environments, Fire and Materials 36:537-553, http://dx.doi.org/10.1002/fam.1113.

184. Dong, Z., Xie, L., Yang, Y., Bridgwater, A.V., and Cai, J. (2017) Local Sensitivity Analysis of Kinetic Models for Cellulose Pyrolysis, Waste and Biomass Valorization 10:975-984, http://dx.doi.org/10.1007/s12649-017-0097-5.

185. Zeng, W.R., Li, S.F., and Chow, W.K. (2016) Review on Chemical Reactions of Burning Poly(methyl methacrylate) PMMA, Journal of Fire Sciences 20:401-433, http://dx.doi.org/10.1177/0734904102020005482.

186. Di Blasi, C., Crescitelli, S., Russo, G., and Cinque, G. (1991) Numerical model of ignition processes of polymeric materials including gas-phase absorption of radiation, Combustion and Flame 89:333-344.

187. Esfahani, J.A. and Kashani, A. (2005) One-dimensional numerical model for degradation and combustion of polymethyl methacrylate, Heat and Mass Transfer 42:569-576, http://dx.doi.org/10.1007/s00231-005-0647-4.

188. Zong, R., Kang, R., Hu, Y., and Zhi, Y. (2017) Modeling the pyrolysis study of noncharring polymers under reduced pressure environments, Heat and Mass Transfer 54:1135-1144, http://dx.doi.org/10.1007/s00231-017-2185-2.

189. Zhang, J., Shields, T.J., and Silcock, G.W.H. (1997) Effect of melting behaviour on upward flame spread of thermoplastics, Fire and Materials 21:1-6. 
190. Leventon, I.T., Li, J., and Stoliarov, S.I. (2015) A flame spread simulation based on a comprehensive solid pyrolysis model coupled with a detailed empirical flame structure representation, Combustion and Flame 162:3884-3895, http://dx.doi.org/10.1016/j.combustflame.2015.07.025.

191. Oñate, E., Rossi, R., Idelsohn, S.R., and Butler, K.M. (2009) Melting and spread of polymers in fire with the particle finite element method, International Journal for Numerical Methods in Engineering:n/a-n/a, http://dx.doi.org/10.1002/nme.2731.

192. Li, K., Hostikka, S., Dai, P., Li, Y., Zhang, H., and Ji, J. (2017) Charring shrinkage and cracking of fir during pyrolysis in an inert atmosphere and at different ambient pressures, Proceedings of the Combustion Institute 36:3185-3194, http://dx.doi.org/10.1016/j.proci.2016.07.001.

193. Li, K.Y., Cheng, X., and Zhang, H. (2014) A simplified model on vertical density profile and shrinkage ratio of virgin and charred medium density fibreboard, Fire and Materials 38:659-672, http://dx.doi.org/10.1002/fam.2207.

194. Shen, D.K., Gu, S., and Luo, K.H. (2009) Analysis of Wood Structural Changes under Thermal Radiation, Energy \& Fuels 23:1081-1088.

195. Li, K., Mousavi, M., and Hostikka, S. (2017) Char cracking of medium density fibreboard due to thermal shock effect induced pyrolysis shrinkage, Fire Safety Journal 91:165-173, http://dx.doi.org/10.1016/j.firesaf.2017.04.027.

196. Salvador, S., Quintard, M., and David, C. (2004) Combustion of a substitution fuel made of cardboard and polyethylene: influence of the mix characteristics - experimental approach, Fuel 83:451-462, http://dx.doi.org/10.1016/j.fuel.2003.10.004.

197. Nakabe, K., McGrattan, K.B., Kashiwagi, T., Baum, H., Yamashita, T., and Kushida, G. (1994) Ignition and Transition to Flame Spread Over a Thermally thin cellulosic sheet in a microgravity environment, Combustion and Flame 98:361-374.

198. Jimenez, M., Duquesne, S., and Bourbigot, S. (2006) Multiscale Experimental Approach for developing High-Performance Intumescent Coatings, Ind. Eng. Chem. Res. 45:45004508, http://dx.doi.org/doi:10.1021/ie060040x.

199. Anderson, C.E. and Wauters, D.K. (1984) A thermodynamic heat transfer model for intumescent systems, International Journal of Engineering Science 22:881-889, http://dx.doi.org/10.1016/0020-7225(84)90036-3.

200. Anderson, C.E.J., Dziuk, J.J., Mallow, W.A., and Buckmaster, J. (1985) Intumescent Reaction Mechanisms, Journal of Fire Sciences 3.

201. Gillet, M., Autrique, L., and Perez, L. (2007) Mathematical model for intumescent coatings growth: application to fire retardant systems evaluation, Journal of Physics D: Applied Physics 40:883-899, http://dx.doi.org/10.1088/0022-3727/40/3/030.

202. Staggs, J.E.J., Crewe, R.J., and Butler, R. (2012) A theoretical and experimental investigation of intumescent behaviour in protective coatings for structural steel, Chemical Engineering Science 71:239-251, http://dx.doi.org/10.1016/j.ces.2011.12.010.

203. Di Blasi, C. (2004) Modeling the effects of high radiative heat fluxes on intumescent material decomposition, Journal of Analytical and Applied Pyrolysis 71:721-737, http://dx.doi.org/10.1016/j.jaap.2003.10.003.

204. Zhang, Y., Wang, Y.C., Bailey, C.G., and Taylor, A.P. (2012) Global modelling of fire protection performance of an intumescent coating under different furnace fire conditions, Journal of Fire Sciences 31:51-72, http://dx.doi.org/10.1177/0734904112453566. 
205. Zhang, Y., Wang, Y.C., Bailey, C.G., and Taylor, A.P. (2012) Global modelling of fire protection performance of intumescent coating under different cone calorimeter heating conditions, Fire Safety Journal 50:51-62, http://dx.doi.org/10.1016/j.firesaf.2012.02.004.

206. Cirpici, B.K., Wang, Y.C., Rogers, B.D., and Bourbigot, S. (2016) A theoretical model for quantifying expansion of intumescent coating under different heating conditions, Polymer Engineering \& Science 56:798-809, http://dx.doi.org/10.1002/pen.24308.

207. Amon, M. and Denso, C.D. (1986) A study of the dynamics of foam growth: Analysis of the growth of closely spaced spherical bubbles, Polymer Engineering \& Science 26.

208. Okyay, G., Naik, A.D., Samyn, F., Jimenez, M., and Bourbigot, S. (2019) Fractal conceptualization of intumescent fire barriers, toward simulations of virtual morphologies, Sci Rep 9:1872, http://dx.doi.org/10.1038/s41598-019-38515-9.

209. Shih, Y.C., Cheung, F.B., and Koo, J.H. (2016) Theoretical Modeling of Intumescent FireRetardant Materials, Journal of Fire Sciences 16:46-71, http://dx.doi.org/10.1177/073490419801600107.

210. Bourbigot, S., Duquesne, S., and Leroy, J.-M. (1999) Modeling of Heat Transfer of a Polypropylene-Based Intumescent System during Combustion, Journal of Fire Sciences 17:42-56, http://dx.doi.org/10.1177/073490419901700103.

211. McKinnon, M.B. and Stoliarov, S.I. (2015) Pyrolysis Model Development for a Multilayer Floor Covering, Materials (Basel) 8:6117-6153, http://dx.doi.org/10.3390/ma8095295.

212. Gillet, M. (2009) Analyse de systèmes intumescents sous haut flux : modélisation et identification paramétrique), $\mathrm{PhD}$, Université d'Angers

213. Butler, K.M., Baum, H.R., and Kashiwagi, T. "Three dimensional Modeling of Intumescent behavior in Fires," Fire Safety ScienceProceedings of the fifth International Symposium. 1997. Melbourne, Australia.

214. Rein, G. (2005) Computational Model of Forward and Opposed Smoldering Combustion with Improved Chemical Kinetics), PhD, University of California 